\title{
Cyclic (Alkyl)- and (Aryl)-(amino)carbene Coinage Metal Complexes and their Applications
}

Rodolphe Jazzar*, Michele Soleilhavoup*, and Guy Bertrand*

UCSD-CNRS Joint Research Laboratory (UMI 3555), Department of Chemistry and Biochemistry, University of California, San Diego, La Jolla, California 92093-0358, United States

*E-mail: rjazzar@ucsd.edu

*E-mail: msoleilhavoup@ucsd.edu

*E-mail: gbertrand@ucsd.edu

\begin{abstract}
Cyclic (alkyl)- and (aryl)-(amino)carbenes (CAACs and CAArCs) are stronger $\sigma-$ donors and $\pi$-acceptors than imidazol-2-ylidenes and imidazolidin-2-ylidenes, the well-known Nheterocyclic carbenes (NHCs). Consequently, they form strong bonds with coinage metals, and stabilize both low and high oxidation states. This Focus Review shows that CAACs and CAArCs have allowed for the isolation of copper and gold complexes which were believed to be only transient intermediates. This has not only allowed for a better understanding of the mechanism of known processes but has also led to the development of novel coinage metal-catalyzed reactions. In addition to their role in homogeneous catalysis, CAAC and CAArC coinage metal complexes have recently found applications in medicinal chemistry, as well as in materials science. When possible, the performance of CAAC and CAArC ligands are compared with those of classical NHCs.
\end{abstract}


CONTENTS

1. Introduction

2. Coordination Chemistry of Cyclic (Alkyl)- and (Aryl)-(Amino)carbenes with Coinage Metals

2.1. Synthesis of (CAAC) $\mathrm{MCl}(\mathrm{M}=\mathrm{Cu}, \mathrm{Ag}, \mathrm{Au})$ Complexes

2.2. Synthesis of Various Gold(I) and Gold(III) Complexes from (CAAC)AuCl and (CAAC)AuOH

2.3. Synthesis of (CAAC)CuH Complexes

2.4. Synthesis of CAAC Coinage Metal Alkene, Alkyne, and Aryl $\pi$-Complexes

2.5. Synthesis of CAAC Coinage Metal PCO Complexes

2.6. Synthesis of CAAC Coinage Metal(0) Complexes

2.7. Synthesis of CAAC Coinage Metal Clusters

2.8. Synthesis of HemilabileCAAC-Gold(I) and (III) Complexes. Oxidative addition at Gold(I)

2.9. Coordination Chemistry of CAAC-6 and BiCAAC

2.10. Synthesis of Saturated Abnormal Carbene and Cyclic (Aryl)(amino)carbene Coinage Metal Complexes

3. Cyclic (Alkyl)(Amino)carbene Coinage Metal Complexes in Catalysis

3.1. Catalytic Cross-Coupling of Two Unsaturated Carbon Centers Leading to Allenes

3.2. Gold Catalyzed Hydroamination of Alkynes and Allenes, and Hydroammoniumation and Methylamination of Alkynes

3.3. (CAAC)-Mono- and -Bis-(copper)acetylide Complexes in Catalysis.

3.4. (CAAC) Coinage Metals for the Activation of Small Molecules

3.4.1. (CAAC) $\mathrm{CuBH}_{4}$ Complexes for the Catalytic Hydrolytic Dehydrogenation of $\mathrm{BH}_{3} \mathrm{NH}_{3}$ and for the Reduction of $\mathrm{CO}_{2}$ into Formate with $\mathrm{H}_{2}$.

3.4.2. Trinuclear (CAAC) Gold Clusters as Catalysts for the Carbonylation of Amines 3.5. Miscellaneous

3.5.1. (CAAC) Gold and Copper Catalysts for the Hydroarylation of Styrene with Anilines

3.5.2. (CAAC)Gold(I) Complexes in Gold/Palladium Dual Catalysis

3.5.3. (CAAC) Gold(III) Complexes in Migratory Insertion of Carbenes into $\mathrm{Au}(\mathrm{III})$ C Bonds.

3.6. Chiral CAAC Ligands in Enantioselective Catalysis

4. Biological Applications of Cyclic (Alkyl)- and (Aryl)-(Amino)carbene Coinage Metal Complexes

5. Optoelectronic Applications of Cyclic (Alkyl)(amino)carbene Coinage Metal Complexes

6. Conclusions and Outlook

Author Information

Corresponding Author

ORCID

Notes

Biographies

Acknowledgments

References 


\section{INTRODUCTION}

Since their discovery in 2005,,$^{1,2}$ five-membered cyclic (alkyl)(amino)carbenes (CAAC) 1 have been the subject of several reviews..$^{3,4,5,6,7,8}$ However none of them have comprehensively covered their coordination chemistry towards coinage metals. Even more importantly many significant discoveries in this field have been made in recent years and thus have not been discussed in the previous review articles. This Focus Review will not be limited to CAACs 1, but will also include six-membered cyclic (alkyl)(amino)carbenes (CAAC-6) $2,{ }^{9}$ bicyclic (alkyl)(amino)carbenes (BiCAAC) 3, ${ }^{10}$ the so-called saturated abnormal NHCs ( $s a \mathrm{NHC}$ ) 4, ${ }^{11}$ as well as cyclic (aryl)(amino)carbenes (CAArC) $\mathbf{5}^{12}$ and $\mathbf{6},{ }^{13}$ (Figure 1). Because of the importance of classical NHCs in coinage metal chemistry, ${ }^{14,15,16,17,18,19}$ we will compare the results obtained with 1-6 with those of imidazol-2-ylidenes $\mathbf{7}^{20}$ and imidazolidin-2-ylidenes $\mathbf{8} .^{21}$

To understand the advantages and disadvantages of carbenes 1-6 compared to classical NHCs 7 and 8, a comparison of their electronic properties is necessary. This will be only briefly summarized since detailed analyses have already been reported in the previous reviews mentioned above. Although the calculated energy of the HOMO and LUMO of carbenes vary slightly depending on the level of theory, the same trend has been observed. Figure 1 summarizes the results obtained at the B3LYP/def2-TZVPP level of theory with ultrafine grid. With the exception of the so-called $s a \mathrm{NHC}$ 4, all the cyclic (alkyl)(amino)carbenes 1-3 are both more $\sigma$-donating and $\pi$-accepting than NHCs $\mathbf{7}$ and $\mathbf{8},{ }^{22}$ because of the presence of the electropositive carbon and of only one $\pi$-donor amino group. Cyclic (aryl)(amino)carbenes 5-6 are still strong electron donors, but they are by far more $\pi$-accepting than all the other carbenes considered in this review, although less than the diamidocarbenes reported by Hudnall and Bielawski (LUMO: $-2 \mathrm{eV}$ ). ${ }^{23} \mathrm{It}$ is important to note that although carbenes 1-3 as well as NHCs $\mathbf{7}$ and $\mathbf{8}$ can be isolated and are stable in solution and in the solid state, carbenes 4-6 have not yet been isolated. 


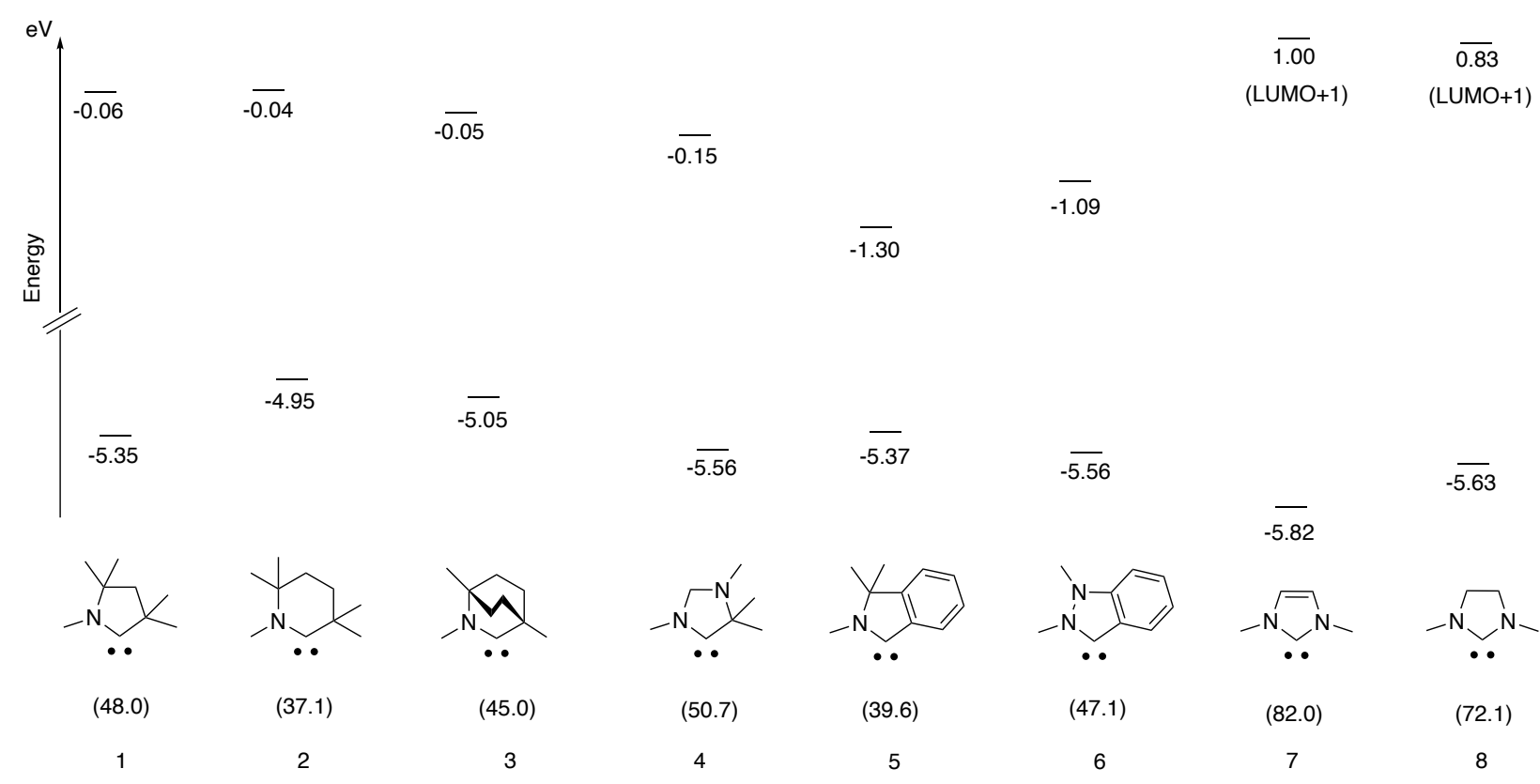

Figure 1. Calculated energy of the HOMO and LUMO of carbenes 1-6, considered in this Focus Review, and of NHCs $\mathbf{7}$ and $\mathbf{8}$ for comparison (B3LYP/def2-TZVPP level of theory with ultrafine grid).

\section{COORDINATION CHEMISTRY OF CYCLIC (ALKYL)- AND (ARYL)- (AMINO)CARBENES WITH COINAGE METALS}

\subsection{Synthesis of (CAAC)MCl $(\mathrm{M}=\mathrm{Cu}, \mathrm{Ag}, \mathrm{Au})$ Complexes}

The steric bulk and flexibility of the substituents on the $\alpha$-carbon of CAACs have a dramatic effect on their complexation to gold ${ }^{24}$ and $\operatorname{silver}^{25}$ (Scheme 1). When bulky and rigid substituents, such as menthyl or adamantyl, are present, the corresponding $\mathrm{LAuCl}$ complexes $\mathbf{9 a}$ and $\mathbf{9 b}$, as well as $\mathrm{LAgCl} \mathbf{1 0 b}$ can readily be isolated. When the smaller and flexible cyclohexyl, cyclohexylene, ethyl or methyl groups are used, the mono-carbene gold and silver complexes can be observed and utilized as such, but are difficult to isolate; instead, the cationic bis(carbene) complexes such as 11c-e and $\mathbf{1 2 f}$ are obtained. Since cationic bis(carbene) complexes $\mathbf{1 1}$ and $\mathbf{1 2}$ are certainly more inert than the mono-carbenes counterparts 9 and 10, these findings provide a good indication of the range of substituents, which might allow CAAC gold and silver complexes to find catalytic applications. In contrast, mono-carbene copper complexes are readily isolable even with small CAACs such as $\mathbf{1 f}$ as shown by $\mathbf{1 3 f} .^{26,27}$ Note that all these gold, silver and copper complexes can 
be prepared by simple addition at room temperature of the free carbene 1 to $\mathrm{Au}\left(\mathrm{SMe}_{2}\right) \mathrm{Cl}, \mathrm{AgCl}$ and $\mathrm{CuCl}$, respectively. Alternatively, following the seminal discovery by Lin et al. ${ }^{28}$ on the ability of $\mathrm{Ag}(\mathrm{I})-\mathrm{NHC}$ complexes to transfer Ag-bound NHC ligands to another metal, both the silver $\mathbf{1 0}^{25}$ and even the copper complexes $\mathbf{1 3}^{29}$ can undergo a transmetallation to give the desired CAACcoinage metal complexes.

\section{Scheme 1. Synthesis of (CAAC)MCl complexes $(\mathrm{M}=\mathrm{Au}, \mathrm{Ag}, \mathrm{Cu})$}

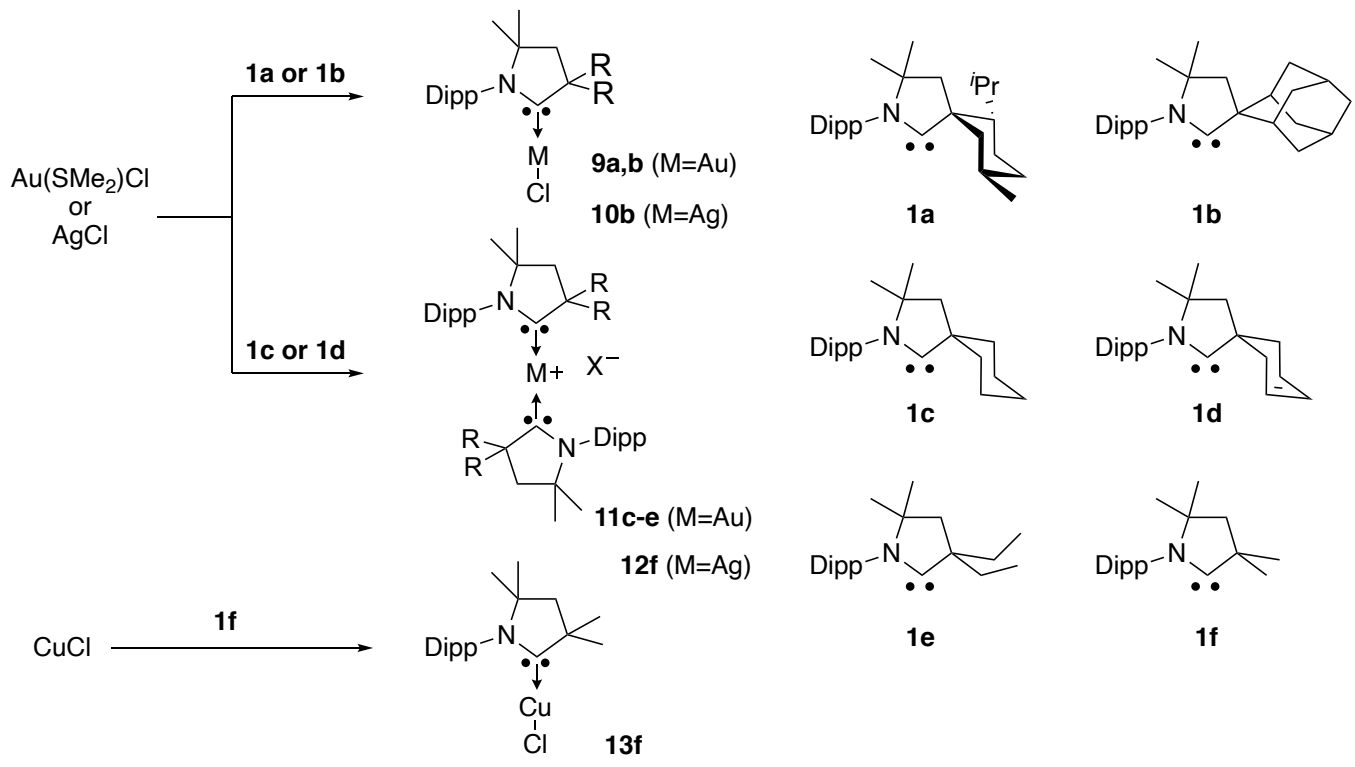

Cyclic (alkyl)(amino)carbene gold complexes have also been prepared via an elegant cyclizationrearrangement cascade (Scheme 2). ${ }^{30}$ This protocol allows for the preparation of a variety of chiral CAAC-gold complexes in a highly stereoselective manner.

Scheme 2. Synthesis of CAACAuCI complexes via a cyclization-rearrangement cascade.

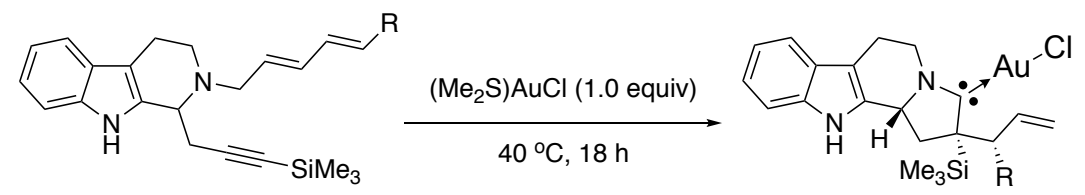


2.2. Synthesis of Various Gold(I) and Gold(III) Complexes from (CAAC)AuCl and (CAAC)AuOH

Romanov and Bochmann prepared a variety of gold(I) and gold(III) complexes, ${ }^{31}$ using (CAAC)AuCl and (CAAC)AuOH complexes, the latter being more basic than (NHC)AuOH ${ }^{32}$ (Scheme 3). Indeed, by studying the reactivity of (CAAC)gold-hydroxide complexes towards a variety of fluoroarenes, they concluded that they can activate $\mathrm{C}-\mathrm{H}$ bonds with $\mathrm{pKa}$ values lower than about 31.5. Surprisingly, despite the more electron-donating properties of CAACs, compared to NHCs, their gold complexes proved to be more resistant to oxidation and more prone to halogen cleavage of the $\mathrm{Au}-\mathrm{C}$ bonds than (NHC)gold(I) complexes.

Scheme 3. Synthesis of various gold(I) and gold(III) complexes from (CAAC)AuCl and (CAAC)AuOH

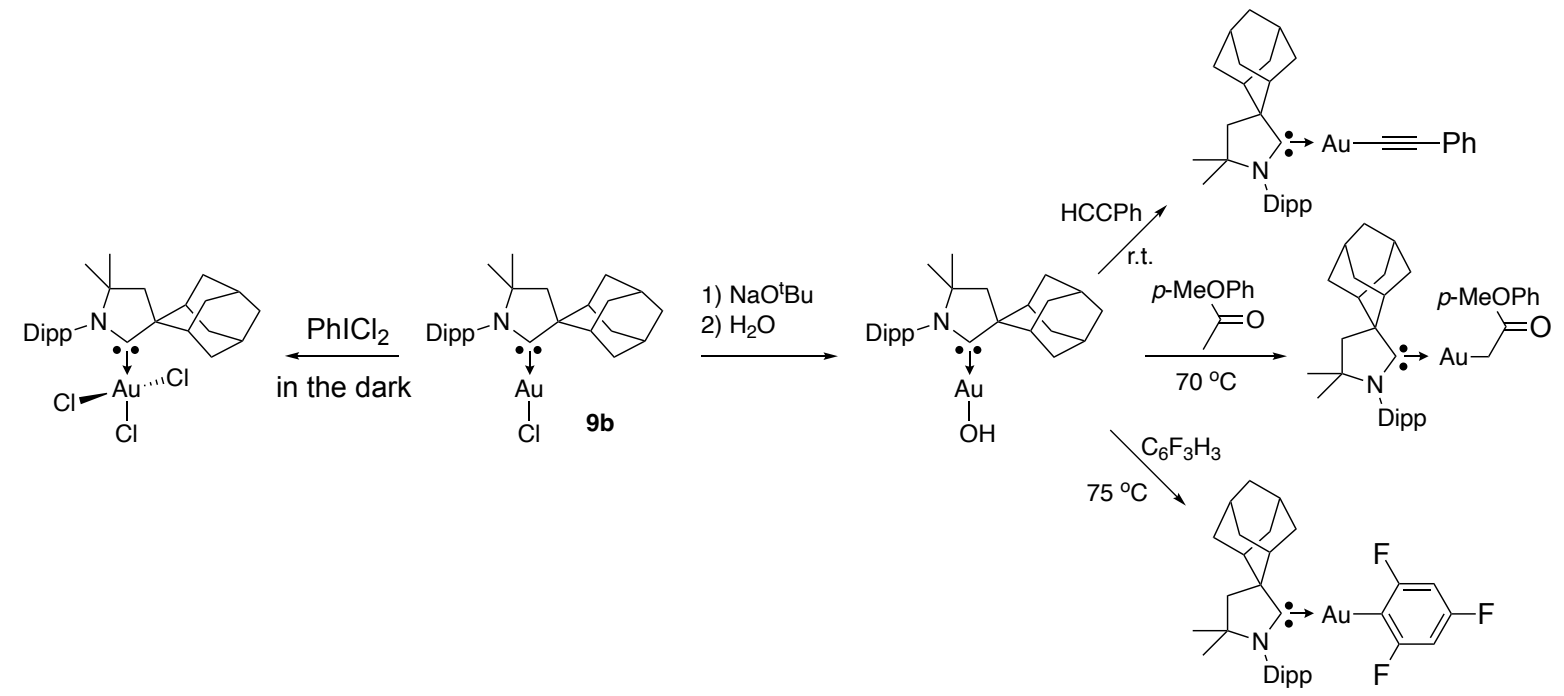

\subsection{Synthesis of (CAAC)CuH Complexes}

In contrast to monomeric gold hydrides, which can readily be isolated, ${ }^{33,34}$ copper hydrides have the propensity to aggregate ${ }^{35}$ as evidenced by the widely used Stryker reagent $\left[\left(\mathrm{Ph}_{3} \mathrm{P}\right) \mathrm{CuH}\right]_{6}{ }^{36}$ With the exception of the recently reported complex $14,{ }^{37}$ featuring the extremely bulky 1,3 bis[2,6-bis[di(4-tert-butylphenyl)-methyl]-4-methylphenyl]imidazol-2-ylidene (IPr**), ${ }^{38}$ dimeric (NHC)copper hydride complexes are unstable with a few exceptions ${ }^{39,40,41}$ (Scheme 4). In contrast, the dimeric (CAAC)copper hydride $\mathbf{1 5}$ was isolated and can be stored in solution for weeks at 
room temperature..$^{42}$ Interestingly, addition of an L ligand to $\mathbf{1 5}$ led to $\mathbf{1 6}$ in which the hydride has shifted to the carbene carbon. This unprecedented rearrangement suggests that the presence of a second $\mathrm{L}$ ligand, in addition to the extremely strong $\sigma$-donating CAAC, makes the copper very electron-rich, and confirmed the low-lying LUMO of CAACs.

Scheme 4. The crystalline copper hydride dimer supported by bulky NHCs (14) and CAACs (15), and the unprecedented rearrangement of the latter by addition of a $L$ ligand
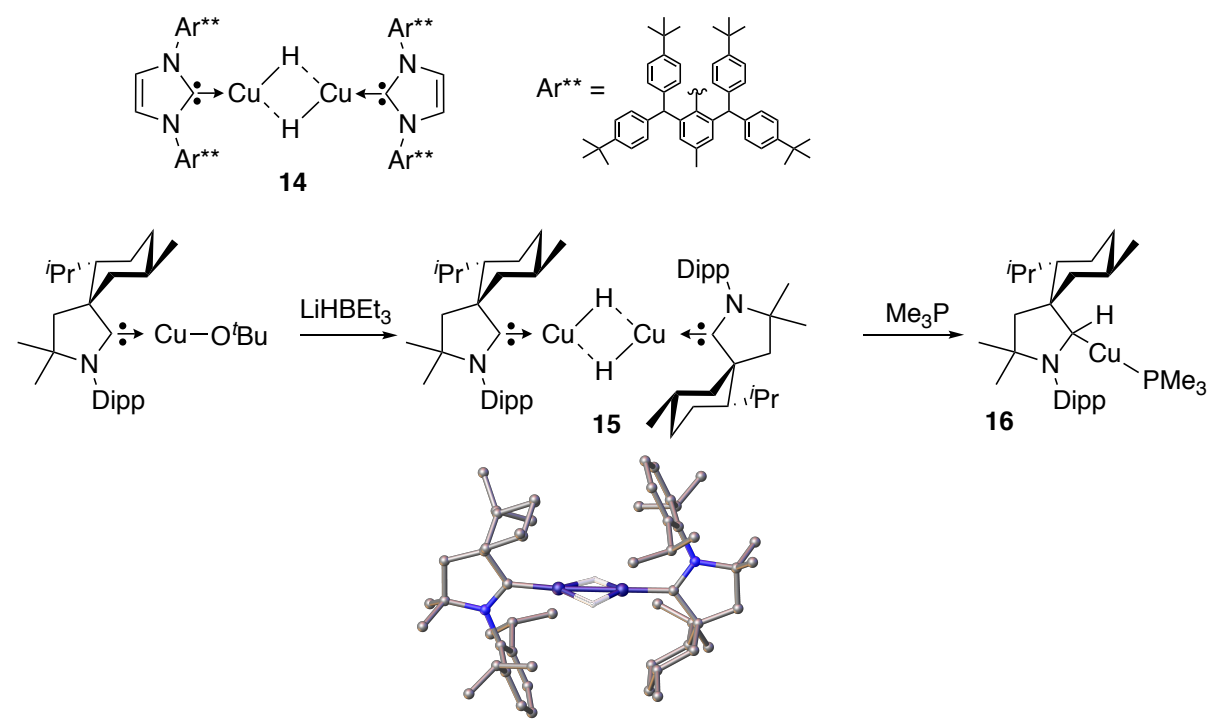

\subsection{Synthesis of CAAC-Coinage Metal Alkene, Alkynes, and Aryl $\pi$-Complexes}

$\alpha$ - and $\beta$-Hydride abstractions from alkyl complexes, affording metal-carbene and metal-alkene complexes, respectively, are well known reactions. However, it was only in 2013 that such processes were reported for gold. ${ }^{43}$ When the tert-butyl gold complex 17 was treated with triphenylcarbenium tetrafluoroborate, an instantaneous reaction occurred, affording the gold(I)alkene complex 18, demonstrating the possibility of $\beta$-hydride abstraction (Scheme 5). To probe the $\alpha$-hydride abstraction, the gold(I)-neopentyl complex 19 was reacted with $\mathrm{Ph}_{3} \mathrm{C}^{+} \mathrm{BF}_{4}{ }^{-}$, and the two diastereomeric gold(I)-(2-methylbut-2-ene) complexes 21 were isolated, although the reaction was drastically slower than in the case of $\mathbf{1 7}$. All attempts to characterize the putative carbene intermediate 20 failed, which is not surprising since, with rare exceptions, ${ }^{44,45,46,47,48,49,50}$ non- 
heteroatom substituted carbene gold complexes are very unstable. However, when triphenylcarbenium tetrafluoroborate was reacted with the gold(I) dithianyl complex $\mathbf{2 2}$, the expected cationic bis(carbene) gold(I) complex $\mathbf{2 3}$ was obtained, demonstrating the $\alpha$-hydride abstraction process.

Scheme 5. $\alpha$ - and $\beta$-hydride abstractions from alkyl gold complexes 17 and 19, respectively, lead to alkene $\pi$-complexes, whereas $\alpha$-hydride abstraction from 22 affords the corresponding carbene complex 23
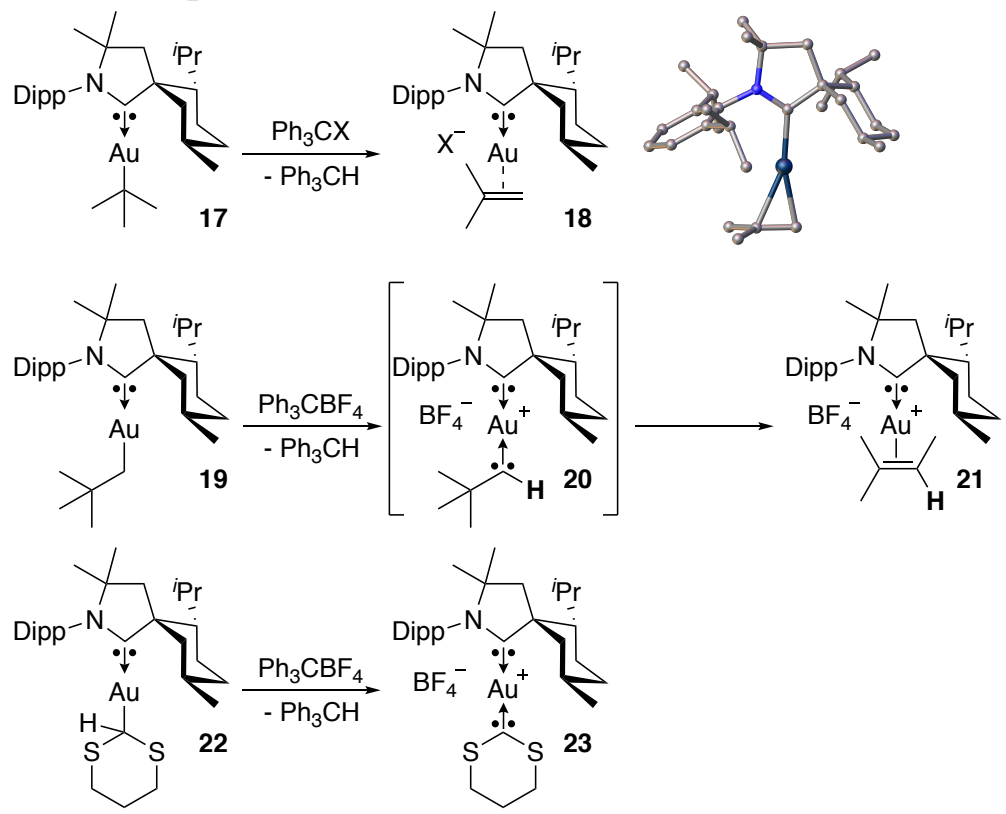

In addition to alkenes, as in $\mathbf{1 8}$ and $\mathbf{2 1}$, alkynes and even arenes can give $\pi$-complexes with (CAAC)coinage metals. The most striking example is arguably the cationic $\pi, \sigma$-bis(copper) acetylide 25 (Scheme 6) ${ }^{51}$ Indeed, in 2013, Fokin et al. reported that "monomeric copper-acetylide complexes (similar to 24) are not reactive towards organic azides unless an exogenous copper catalyst is added". ${ }^{52}$ They postulated that the catalytically active complex in the Cu-catalyzed azide-alkyne "click reaction ${ }^{53,54,55}$ was in fact a cationic $\pi, \sigma$-bis(copper) acetylide. They further stated that these dinuclear species were "non-isolable and highly reactive intermediates". However, in 2015, our group first prepared the mononuclear copper complex $\mathbf{2 4}$ by adding lithium phenyl acetylide with (CAAC)CuOAc. Note that with the exceptions of (NHC)copper acetylides, ${ }^{56}$ these complexes are usually polymeric. Then, addition of (CAAC)CuOTf to $\mathbf{2 4}$ gave the desired 
cationic dinuclear complex $\mathbf{2 5}$, which proved to be air-stable and thermally robust. In solution, a very fast exchange between the two $(\mathrm{CAAC}) \mathrm{Cu}$ units occurred, but in the solid state an X-ray diffraction study shows two different types of coordination, $\pi$ and $\sigma$. The isolation of complex 25 has allowed for a detailed mechanistic study of the Cu-catalyzed azide-alkyne "click reaction" (See Section 3.3.).

Scheme 6. Synthesis of the monocopper acetylide 24 and supposedly unstable dinuclear complex 25, which is the catalytically active complex in the Cu-catalyzed azide-alkyne cycloaddition "click reaction"

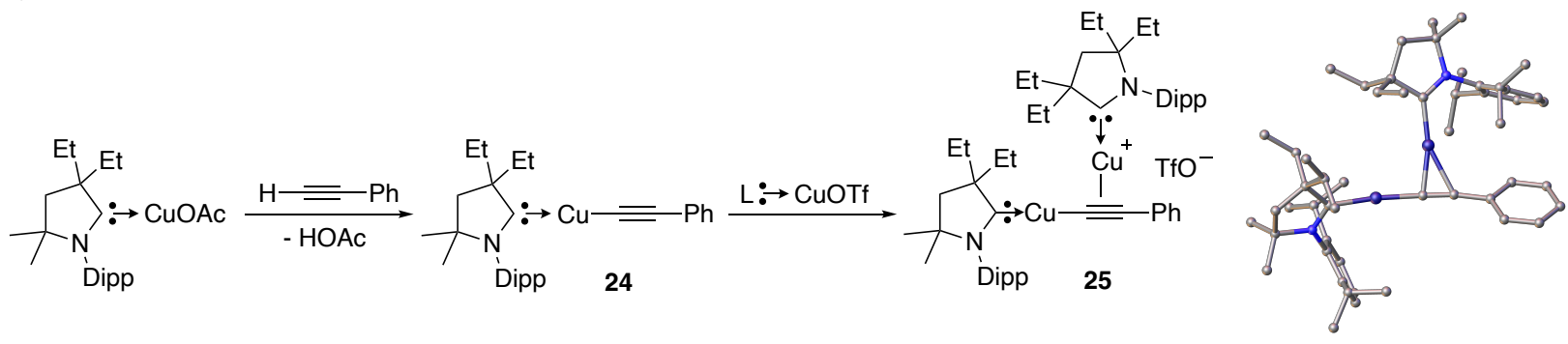

The most common catalytic systems in gold catalysis involve LAuCl complexes, which through in situ salt metathesis generate the active species, supposedly a cationic monoligated $\mathrm{LAu}^{+}$ complex. Because of their strong $\sigma$-donating properties, CAACs are certainly good candidates to stabilize such compounds. However, treatment of a toluene suspension of $\mathbf{9 b}$ with [(Toluene) $\left.\mathrm{SiEt}_{3}\right]^{+}\left[\mathrm{B}\left(\mathrm{C}_{6} \mathrm{~F}_{5}\right)_{4}\right]^{-}$cleanly led to complex $\mathbf{2 6}$ (Scheme 7). ${ }^{57}$ Though not a truly "naked" cation, the $\eta^{2}$-binding mode hardly perturbs the aromatic ring, allowing this complex to behave as the proposed active cation for mechanistic studies. Note that a few similar complexes bearing bulky phosphine ligands have also been isolated. ${ }^{58}$

Scheme 7. Synthesis of the crystalline $\left[(\mathrm{CAAC}) A u\left(\eta^{2} \text {-toluene }\right)\right]^{+}\left[B\left(\mathrm{C}_{6} \mathrm{~F}_{5}\right)_{4}\right]^{-}$complex 26
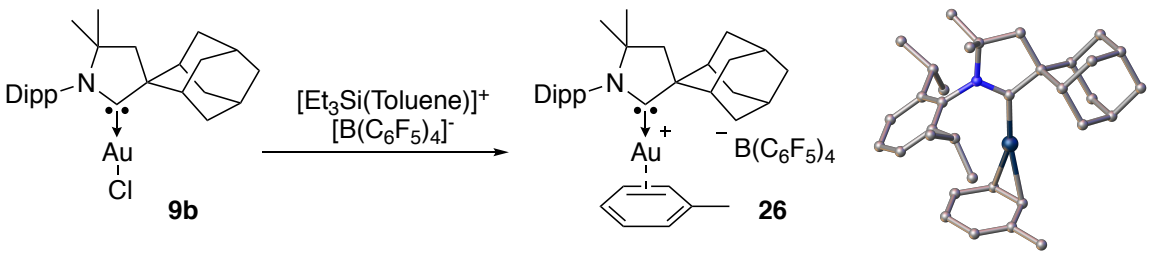


\subsection{Synthesis of CAAC-Coinage Metal PCO Complexes}

The ability of CAACs to efficiently stabilize metals in low oxidation states has been used to study the complexation of phosphaethynolate salts $\mathrm{M}^{+}(\mathrm{PCO})^{-}$, which are strong reducing agents. ${ }^{59}$ It has been found that $\mathrm{NaPCO}$ reacts with $(\mathrm{CAAC}) \mathrm{AuCl}$ and $(\mathrm{CAAC}) \mathrm{CuO}^{t} \mathrm{Bu}$ cleanly affording 27 and 29, respectively (Scheme 8). ${ }^{60}$ Despite the similarities of the solid state structures, a computational study shows that the coordination modes of PCO with gold and copper are $\eta^{1}$ and $\eta^{2}$, respectively, which leads to a difference in reactivity. The gold complex 27 is stable in the solid state but rearranges over the course of a week in solution at room temperature into the trinuclear complex 28. The copper complex 29 decomposes in a few hours and is very reactive. A simple addition of free CAAC 1 f to 29 gives rise the cationic bis(CAAC)Cu complex 30, in which the PCO fragment is the anionic counterpart.

Scheme 8. The coordination modes of PCO with gold and copper are $\eta^{1}$ and $\eta^{2}$, respectively, which induces different reactivity

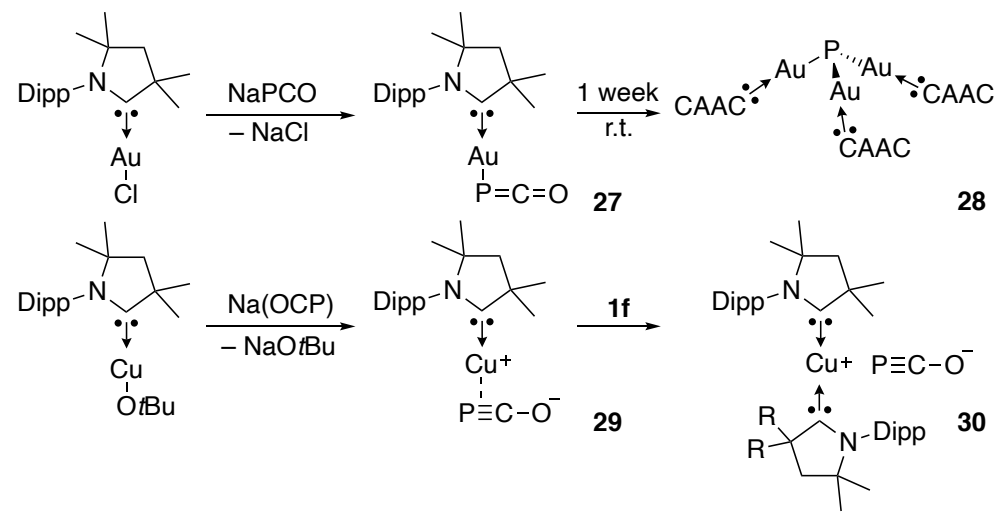

\subsection{Synthesis of CAAC-Coinage Metal(0) Complexes}

The applications above highlighted the advantages of the strong electron-donating properties of CAACs. However, their strong $\pi$-accepting properties ${ }^{61,62}$ can also be exploited to stabilize electron-rich centers and paramagnetic species. ${ }^{63,64}$ Indeed, it has been shown that the cationic bis(CAAC) gold 11c and copper $13 f$ complexes can be reduced by a potassium mirror and $\mathrm{KC}_{8}$, respectively, to offer the bis(CAAC)Au ${ }^{65}$ and $\mathrm{Cu}^{66}$ complexes 31 and $\mathbf{3 2}$ with the metal in the 
formal oxidation state zero (Scheme 9) ${ }^{67}$ In both cases, X-ray diffraction studies revealed a linear geometry with both five-membered ring CAACs being co-planar. The bonding situation for both complexes is very similar. Calculations, using the NBO method, showed that the spin density is localized on the carbene carbons $(\mathbf{3 1}: 60 \%$; 32: 68\%) and the nitrogen atoms $(31: 20 \%$; 32: 18\%) while only $17 \%$ and $10 \%$ resides at gold and copper. The shape of the SOMO indicates that the unpaired electron is delocalized over the $\mathrm{p}(\pi) \mathrm{AOs}$ of the carbene and the $\mathrm{p}(\pi) \mathrm{AO}$ of $\mathrm{Au}$; consequently, the electronic configuration of gold is $\mathrm{d}^{10} \mathrm{~s}^{0} \mathrm{p}^{1}$. Similarly, in complex $\mathbf{3 2}$ the copper center has a $\mathrm{d}^{10}$ electronic configuration, the unpaired electron being delocalized over two carbene carbon atoms. ${ }^{68}$

Scheme 9. Synthesis of mononuclear gold(0) and copper(0) complexes 31 and 32; solid state structure and SOMO of 31; synthesis and solid state structure of the dinuclear gold(0) complex 33

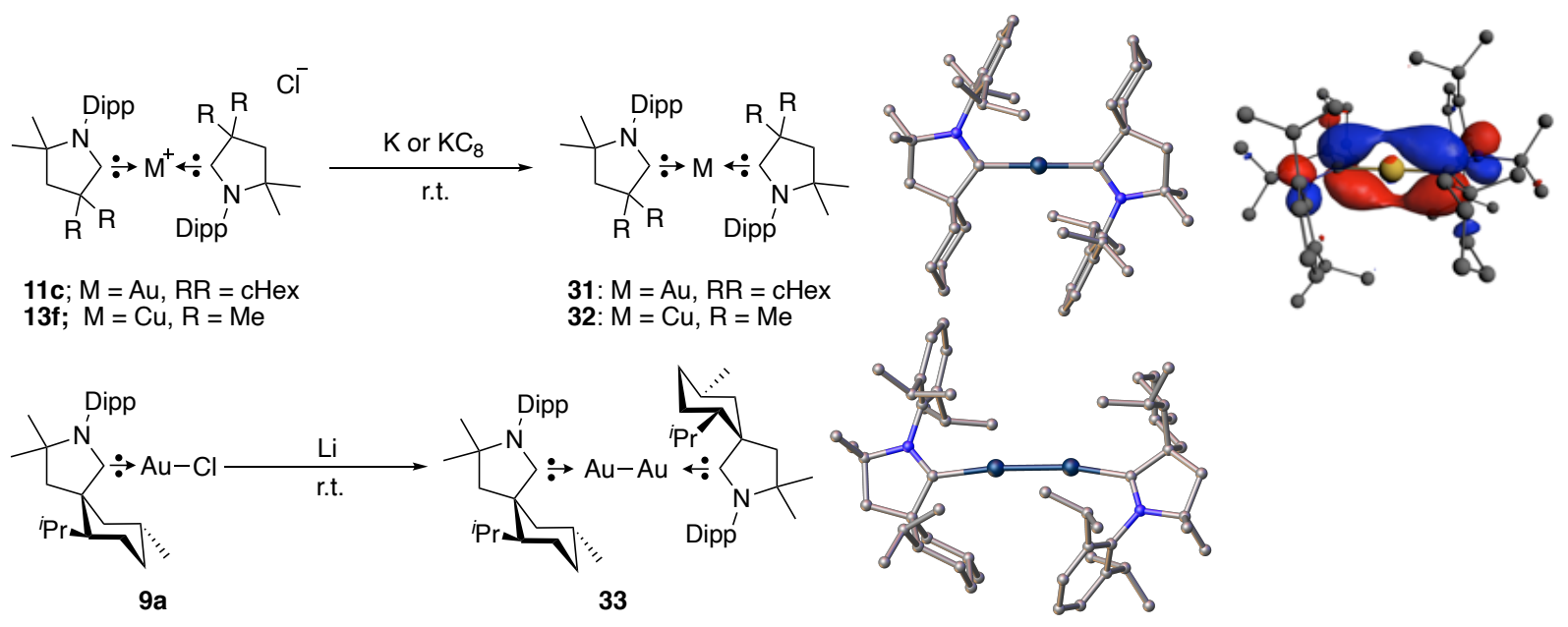

On the other hand, the reduction of the gold complex 9a, in which the small cyclohexyl-CAAC of $11 \mathrm{c}$ has been replaced by the bulky menthyl-CAAC, gave rise to the dinuclear complex 33 (Scheme 9). As predicted by Schwerdtfeger and Boyd ${ }^{69}$ for the model compound $\left(\mathrm{H}_{3} \mathrm{P}\right) \mathrm{Au}-\mathrm{Au}\left(\mathrm{PH}_{3}\right)$, the $\mathrm{C} 1$ $\mathrm{Au} 1-\mathrm{Au} 2-\mathrm{C} 2$ skeleton is almost linear and the $\mathrm{Au}-\mathrm{Au}$ bond short [2.552 $\AA$ ]. Note that naked $\mathrm{Au}_{2}$ has a calculated Au-Au bond length of $2.546 \AA$, which is very close to that observed in $\mathbf{3 3}$. Interestingly, calculations found that in contrast to the mononuclear complex 31, the $\mathrm{Au}_{2}$ fragment in 33 binds the ligands through its electronic ${ }^{2} \mathrm{~S}\left(\mathrm{~d}^{10} \mathrm{~s}^{1} \mathrm{p}^{0}, J=1 / 2\right)$ ground state. It is important to 
note that before this work, apart from elemental gold, the zero oxidation state had only been found in mixed gold(0)/gold(I) complexes, ${ }^{70}$ as exemplified by $\left[\left(\mathrm{Ph}_{3} \mathrm{PAu}\right)_{6}\right]^{2+} 2\left(\mathrm{BF}_{4}^{-}\right)^{71}$ and $\left[\left(t \mathrm{Bu}_{3} \mathrm{PAu}\right)_{4}\right]^{2+} 2\left(\mathrm{BF}_{4}^{-}\right) \cdot{ }^{72}$ A nice demonstration of the efficiency of CAACs to stabilize gold $(0)$ complexes comes from the work of Sadighi et al. ${ }^{73}$ who have shown that, in contrast to $\mathbf{3 3}$, (NHC)Au-Au(NHC) complexes were unstable and led to colloidal gold.

CAACs also allowed for the isolation of neutral, paramagnetic, formally gold(0) (allenylidene)(carbene) and bis(allenylidene) complexes (Scheme 10). ${ }^{74}$ Note that although a large number of allenylidene transition metal complexes are known, ${ }^{75}$ this is rare with gold, and all involve gold(I ${ }^{76}$ and gold(III). ${ }^{77}$ The (allenylidene)(carbene)Au(I) complex 34 was obtained in a few steps, and subsequent reduction with one equivalent of $\mathrm{KC}_{8}$ in $\mathrm{THF}$ at room temperature, afforded the neutral gold complex $\mathbf{3 5}$ as yellow crystals. The Mulliken spin density analysis showed that $93.9 \%$ of the spin density resides on the CCC fragment, with only 3.8 and $1.8 \%$ located on the CAAC ligand and the Au atom, respectively. Consequently, 35 has very weak gold( 0 ) character, and can be viewed as a gold(I) complex with a paramagnetic anionic ligand.

Scheme 10. Preparation of (allenylidene)(carbene) and bis(allenylidene) gold complexes 35 and 38, respectively

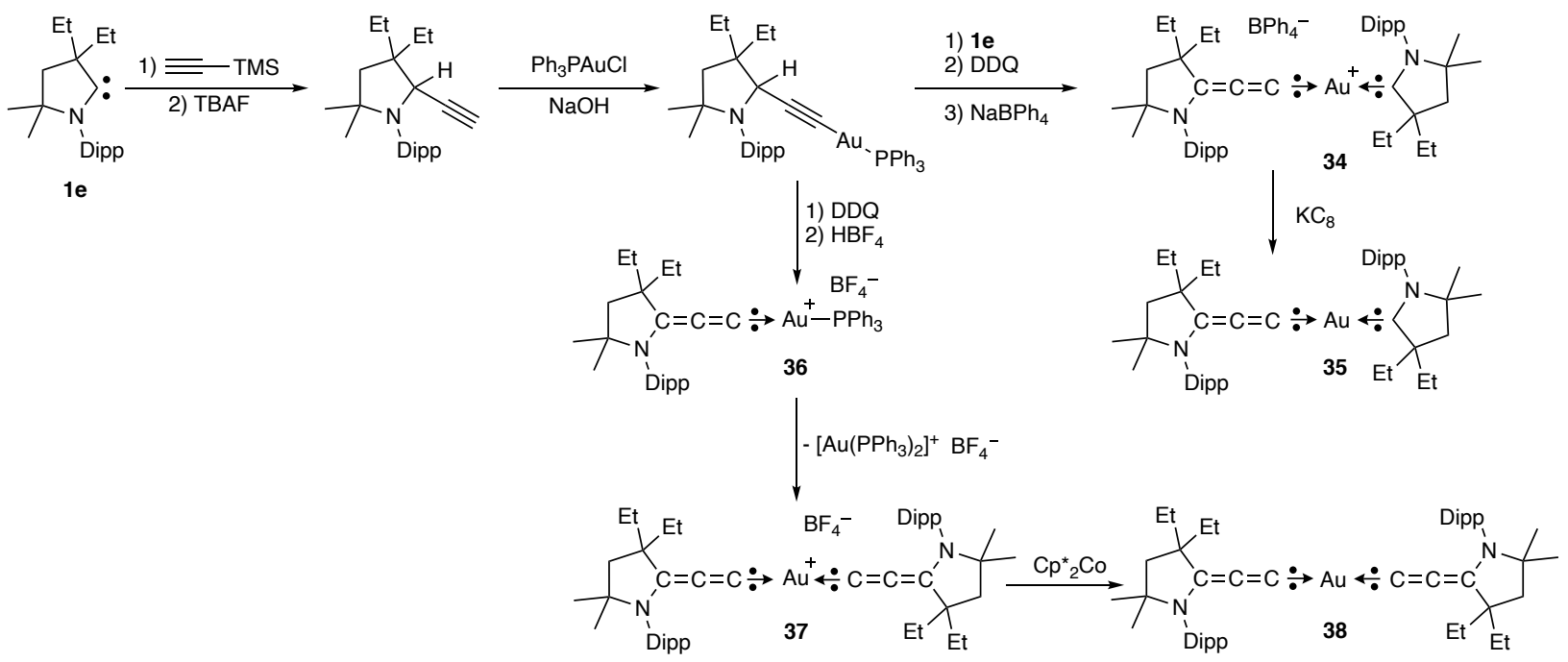

The cationic bis(allenylidene) gold(I) complex 37 can be prepared step by step using the same strategy as for $\mathbf{3 4}$, but also by dismutation of complex 36 (Scheme 10). The cyclic voltammogram 
of 37 showed two well-defined one-electron reversible reductions at -1.69 and $-2.04 \mathrm{~V}$ versus $\mathrm{Fc}^{+} / \mathrm{Fc}$. The first reduction potential is shifted to an even more positive value than that of the (allenylidene)(CAAC)gold(I) complex $34(-1.73 \mathrm{~V})$ demonstrating that the allenylidene behaves as a stronger $\pi$-acceptor than CAACs. However, chemical reduction of $\mathbf{3 7}$ resulted in a dark green solution, which was EPR active, but all attempts to grow single crystals of $\mathbf{3 8}$ led to decomposition. Notably, only bis(allenylidene) complexes of $\mathrm{Ag},{ }^{78} \mathrm{Pd},{ }^{78,79} \mathrm{Pt},{ }^{79}$ and $\mathrm{Ru}^{80}$ have been isolated so far.

\subsection{Synthesis of CAAC-Coinage Metal Clusters}

A variety of gold clusters, ${ }^{81,82}$ including nanoparticles are available, and have found numerous applications. ${ }^{83,84,85}$ All of these species are positively charged, and the isolation of $\mathbf{3 1}, \mathbf{3 3}$ and $\mathbf{3 5}$ indicate that CAACs might also be able stabilize neutral clusters of different sizes, mimicking gold surfaces. Therefore, the preparation of the smallest possible clusters, namely tris(gold) clusters, was attempted ${ }^{86}$ Note that before this work, there was only one example of such a small cluster, namely the NHC supported cluster 39 reported by Sadighi et al. ${ }^{87}$ (Scheme 11). Small phosphinesupported gold clusters are usually prepared by reduction of $\mu_{3}$-oxo complexes $\left[\left(\mathrm{R}_{3} \mathrm{PAu}\right)_{3} \mathrm{O}\right]^{+} \mathrm{X}^{-}$ 42. ${ }^{88,89}$ Although, it has been reported that the analogous NHC-supported $\mu_{3}$-oxo species cannot be prepared, ${ }^{87}$ the reaction of $(\mathrm{CAAC}) \mathrm{AuCl}$ complex $9 \mathbf{c}$ with $\mathrm{Ag}_{2} \mathrm{O}$, in presence of $\mathrm{NaBF}_{4}$, cleanly gave rise to the desired cluster 40c. Subsequent reduction with carbon monoxide ${ }^{90}$ afforded the cationic tris(gold) cluster 41c. Interestingly, similar CAAC-supported clusters such as 41e and mixed (CAAC)(phosphine)-supported cluster $\mathbf{4 3}$ can be obtained by ligand exchange, using the readily available phosphine-supported $\mu_{3}$-oxo complex $\mathbf{4 2}$ as a precursor. Unfortunately, all attempts to obtain the corresponding neutral trinuclear $\mathrm{Au}(0)$ clusters failed. 
Scheme 11. The only known trinuclear Au cluster 39; preparation of CAAC-Au clusters 41e and 43

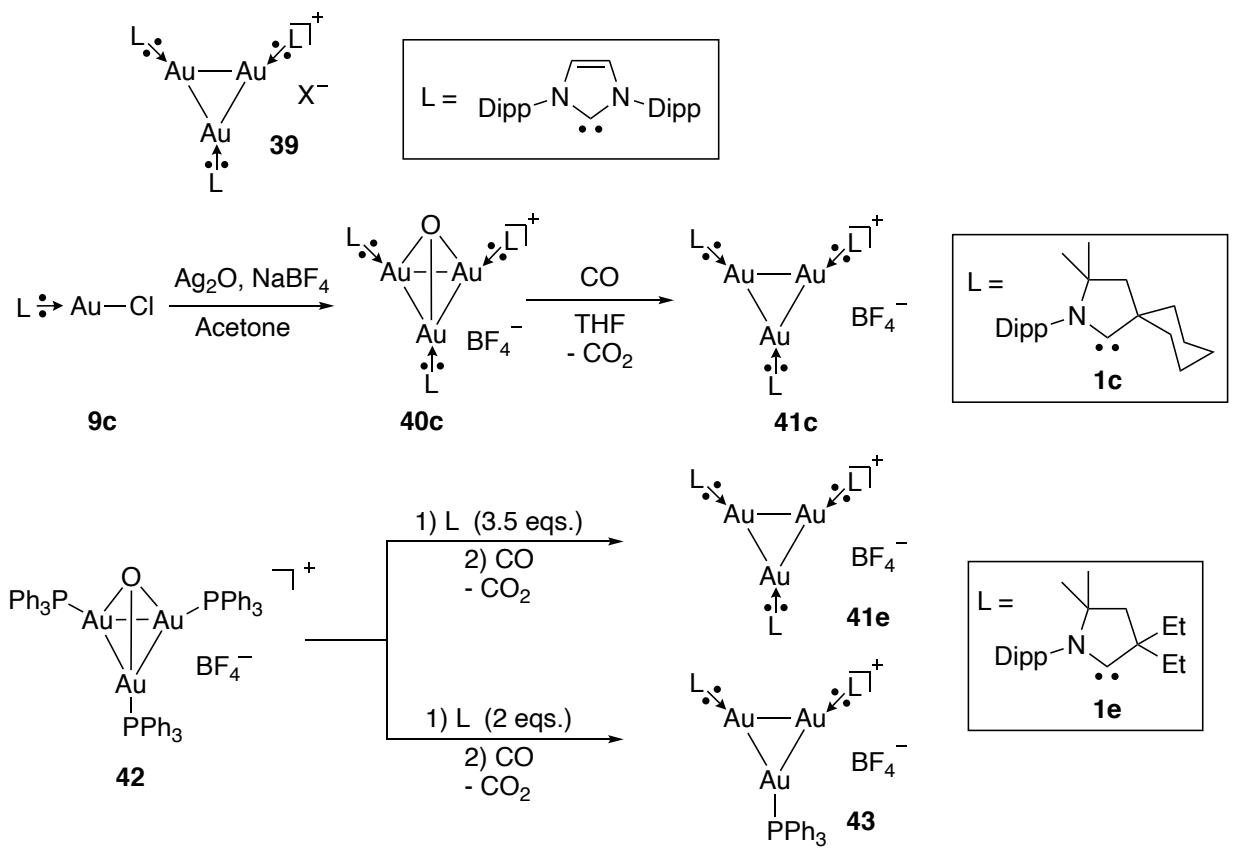

To be comprehensive, there are also two reports describing CAAC supported copper clusters (Scheme 12). Fassler et al. ${ }^{91}$ has explored the coordination of $\mathrm{Ge}_{9}$ Zintl clusters to (CAAC)Cu(I) fragments. All the resulting clusters feature $\left(\eta^{1}-\mathrm{CAAC}\right) \mathrm{Cu}\left(\eta^{3}-\mathrm{Ge}_{9}\right)$ units, and their structures have been compared with analogous clusters supported by NHCs. ${ }^{92}$ Corrigan et al. ${ }^{93}$ prepared a series of phosphorescent homo- and hetero-metallic copper(I)-chalcogenide clusters by the reaction of a copper(I) trimethylsilylchalcogenolate $(\mathrm{CAAC}) \mathrm{CuESiMe}_{3}(\mathrm{E}=\mathrm{S}, \mathrm{Se})$ with $\left.(\mathrm{CAAC}) \mathrm{CuOAc}\right)$. 
Scheme 12. Preparation of CAAC copper(I) clusters with main group elements.
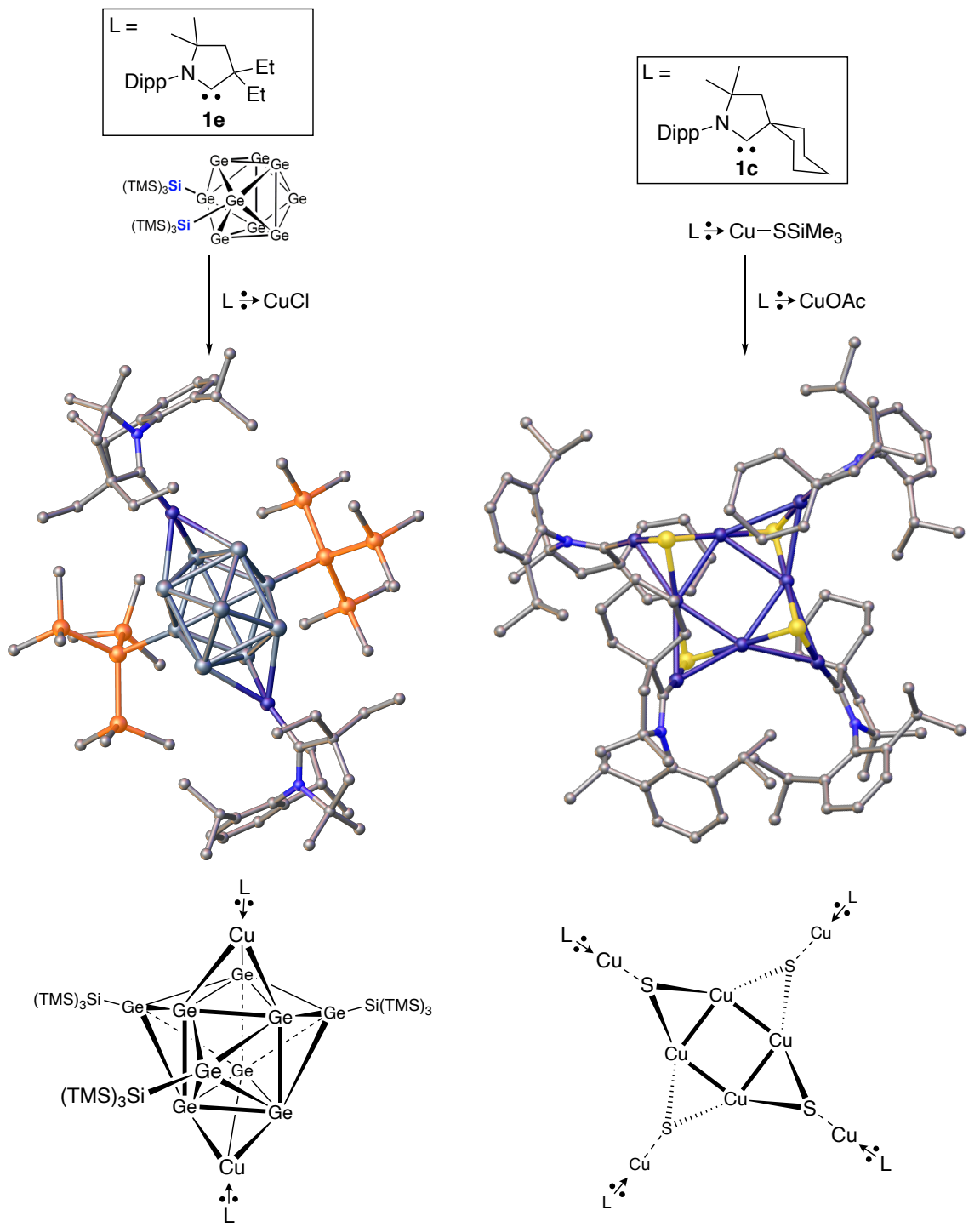

2.8. Synthesis of HemilabileCAAC-Gold(I) and (III) Complexes. Oxidative addition at Gold(I)

The hemilabile CAAC 1g has been used as a ligand to access gold(I) complexes, but more interestingly gold(III) complexes (Scheme 13). ${ }^{94}$ Indeed, it is recognized that oxidative addition at gold(I) is kinetically and thermodynamically difficult, ${ }^{95,96}$ but Bourissou et al. ${ }^{97,98}$ and Toste et al. ${ }^{99}$ have shown that peculiar cationic gold(I) complexes react with biphenylene to give the corresponding gold(III). ${ }^{100}$ The imine nitrogen of $\mathbf{1 g}$ does not coordinate the gold(I) center of $\mathbf{4 4}$ 
$(\mathrm{Au}-\mathrm{N}>3.39 \AA)$. However, upon addition of biphenylene at room temperature, in the presence of $\mathrm{KB}\left(\mathrm{C}_{6} \mathrm{~F}_{5}\right)_{4}$, the gold(III) complex $\mathbf{4 5}$ was obtained, in which the imine ligand coordinates the gold center $(\mathrm{Au}-\mathrm{N}=2.25 \AA)$. Since a stoichiometric mixture of monodentate (CAAC)AuCl complex and $\mathrm{KB}\left(\mathrm{C}_{6} \mathrm{~F}_{5}\right)_{4}$, does not react with biphenylene even upon heating to $80{ }^{\circ} \mathrm{C}$, it can be concluded that the pendant imine moiety stabilizes the gold(III) center. This result suggests that hemilabile bidentate CAACs should be suitable ligands for catalysis involving high oxidation states and might outcompete the corresponding NHCs. ${ }^{101}$

Scheme 13. The imine nitrogen of $1 \mathrm{~g}$ favors the oxidative addition of biphenylene by stabilizing the resulting gold(III) center

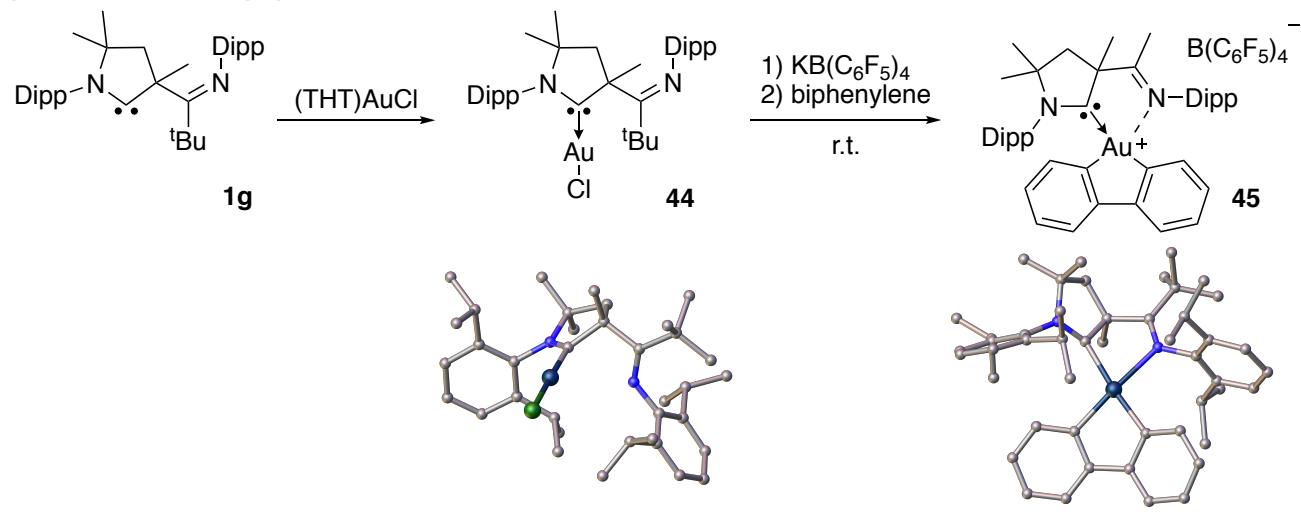

\subsection{Coordination Chemistry of CAAC-6 and BiCAACs}

Six-membered ring CAAC gold(I) complexes have been used to compare the steric properties of CAAC-6 with those of five-membered ring CAACs. ${ }^{9}$ From the X-ray data of $\mathbf{9 b}$ and $\mathbf{4 6} \mathbf{b}$, it was found that the corresponding CAAC-6 2b has a percent buried volume (\%Vbur $)^{102,103,104}$ of 51.2\% compared to $47.8 \%$ for CAAC $1 \mathbf{b}$ (Figure 2). This is mainly due to the wider carbene bond angle (2b: $\left.117.9^{\circ} ; \mathbf{1 b}: 106.4^{\circ}\right)$. 

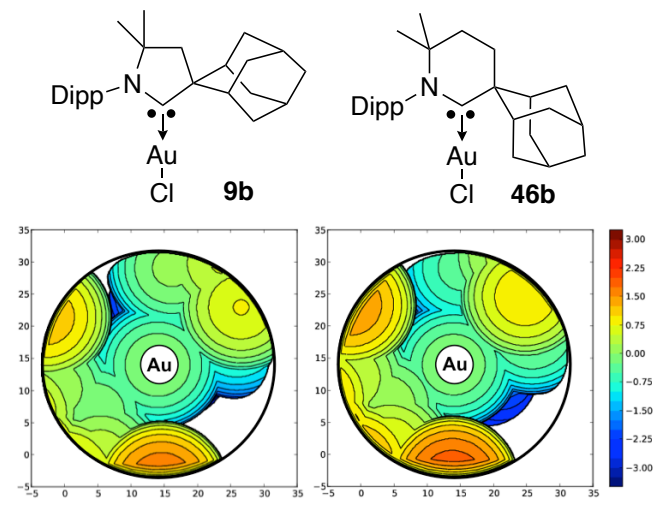

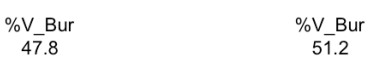

Figure 2. Probing sterics of CAAC-5 versus CAAC-6. Modified with permission from ref 9. Copyright 2018 American Chemical Society.

BiCAAC 3, due to its higher HOMO and lower LUMO, forms even stronger gold-carbon bonds than CAAC 1e. ${ }^{10}$ Indeed, when one equivalent of BiCAAC 3 was added to the (CAAC)AuPh complex 47, an equilibrium featuring a 65/35 ratio of (BiCAAC)AuPh 48 and (CAAC)AuPh 47, along with free CAAC 1e and BiCAAC 3, was observed after $40 \mathrm{~h}$ at $60^{\circ} \mathrm{C}$ (Scheme 14).

Scheme 14. Ligand exchange reactions at gold showing that BiCAAC 3 forms even stronger gold-carbon bonds than CAAC 1e
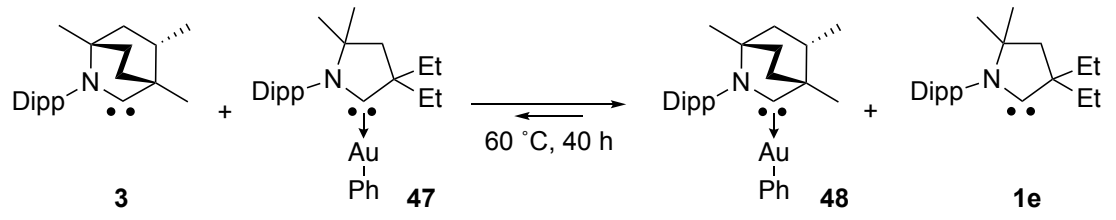

\subsection{Synthesis of Saturated Abnormal Carbene and Cyclic (Aryl)(amino)carbene Coinage Metal Complexes}

The so-called saturated abnormal carbenes 4 reported by Hashmi et al. ${ }^{11,105}$ have not yet been isolated, nor is its cationic precursor readily prepared. Therefore, saNHC-gold complexes $\mathbf{4 9}$ have to be synthesized in the coordination sphere of gold, through a [3+2] dipolar cycloaddition of isonitrile gold complexes to an azomethine ylide, generated from the commercially available Nbenzyl-N-methoxymethyl-N-(trimethylsilyl)methylamine (Scheme 15). 
Scheme 15. Synthesis of the saturated abnormal carbene-gold complex 49

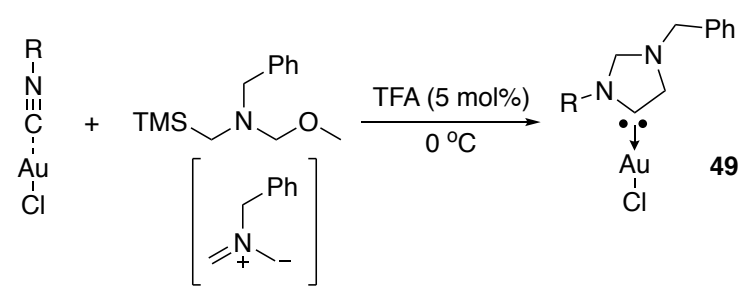

Cyclic (amino)(aryl)carbenes 5-6 have never been isolated either, but their cationic precursors are readily available. Gold complexes can be prepared by deprotonation of the corresponding aldiminium salts with $\mathrm{LiN}\left(\mathrm{SiMe}_{3}\right)_{2}$ at $-78{ }^{\circ} \mathrm{C}$ in the presence of $\left(\mathrm{Me}_{2} \mathrm{~S}\right) \mathrm{AuCl}$ as shown for $\mathbf{5 0 a},{ }^{12}$ whereas the copper analogue is obtained by treatment of the salt precursor with CuOAc. ${ }^{106}$ Alternatively, a transmetallation route can be used as exemplified by the preparation of $\mathbf{5 1},{ }^{13,107,108,109}$ or even by reaction with the Nolan NHC gold(I) hydroxide $[\mathrm{IPrAuOH}\}^{32,110}$ as described by Breher et $a l^{111}$ for the dinuclear complex 52 (Scheme 16). Note that complexes based on ditopic NHCs, analogous to $\mathbf{5 2}$ have been discussed as building blocks for electronically coupled systems. ${ }^{112,113}$

\section{Scheme 16. Synthesis of cyclic (amino)(aryl)carbene gold and copper complexes}
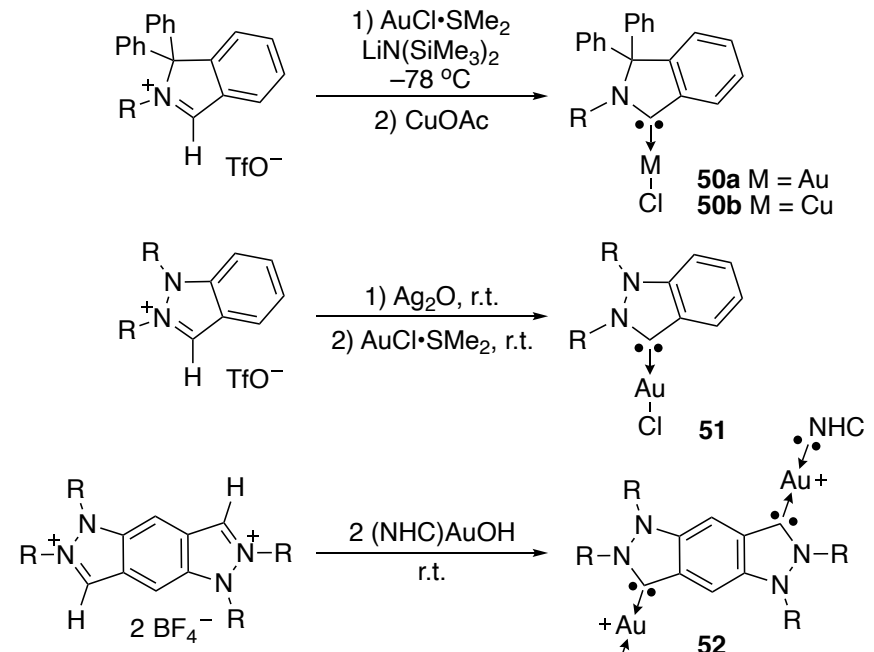

$2(\mathrm{NHC}) \mathrm{AuOH}$

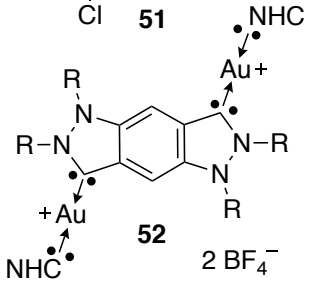




\section{CYCLIC (ALKYL)(AMINO)CARBENE COINAGE METAL COMPLEXES IN CATALYSIS}

In the past two decades, efficient and selective gold and copper catalysts have been developed to promote a variety of chemical transformations, as evidenced by the number of reviews summarizing various aspects of this growing field. ${ }^{114,115,116,117,118,119}$ Due to the peculiar electronic and steric properties of cyclic (alkyl)(amino)carbenes, their coinage metal complexes were found to be active in new catalytic reactions, which are discussed below.

\subsection{Catalytic Cross-Coupling of Two Unsaturated Carbon Centers Leading to Allenes}

The first breakthrough in catalysis with (CAAC)gold complexes was the serendipitous discovery that the gold cation $\mathbf{2 6}$, either isolated or prepared in situ by mixing (CAAC)AuCl $\mathbf{9 b}$ with one equivalent of $\mathrm{KB}\left(\mathrm{C}_{6} \mathrm{~F}_{5}\right)_{4}$ in toluene, promotes the cross-coupling of enamines and terminal alkynes to yield allenes (Scheme 17). ${ }^{57}$ This observation was very surprising since this reaction usually affords propargyl amines as observed with other catalysts, ${ }^{120}$ including (CAAC)AuCl $\mathbf{9 b}$ or $\left(\mathrm{Ph}_{3} \mathrm{P}\right) \mathrm{AuCl} / \mathrm{KB}\left(\mathrm{C}_{6} \mathrm{~F}_{5}\right)_{4}$. Mono-, di-, and tri-substituted enamines and aryl-, alkyl-, and trimethylsilyl-substituted alkynes can be used, including sterically hindered substrates.

Scheme 17. In contrast with other catalysts, the (CAAC)gold cation 26 promotes the crosscoupling of enamines and terminal alkynes to yield allenes

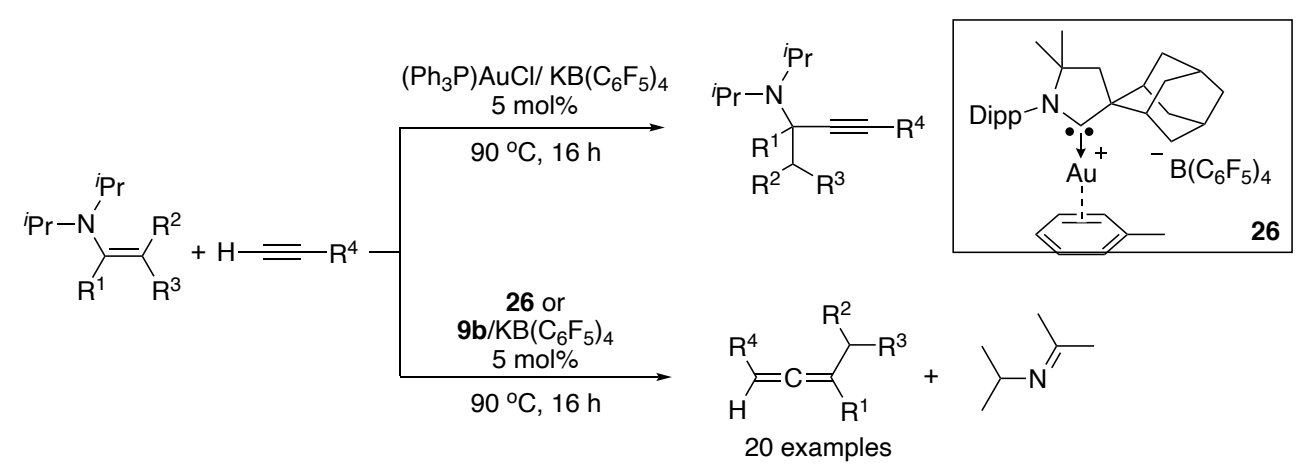

Gold complex 26 is also a very efficient catalyst for hydroamination of alkynes (see Section 3.2.).

Of particular interest, it promotes the addition of secondary amines, which allowed for the 
synthesis of tertiary enamines with alkyl substituents at nitrogen. ${ }^{121}$ Therefore, taking into account the results discussed above, a one-pot preparation of allenes was developed by coupling two alkynes, using a sacrificial secondary amine. This synthetic strategy was applied to the homo- and hetero-coupling of alkynes. For example, in the presence 1,2,3,4-tetrahydroisoquinoline as dihydrogen donor, the homocoupling of tert-butylacetylene gave rise to allene $\mathbf{5 3}$ in $89 \%$ yield (Scheme 18). This allene results from the anti-Markovnikov addition of the amine to the alkyne and the same regioselectivity was observed with trimethylsilylacetylene, probably because of the steric hindrance of both reactants. However, with $n$-butyl acetylene, the allene 54, resulting from the Markovnikov addition of the amine was formed, whereas with cyclohexylacetylene a 14/86 mixture of the two isomeric allenes $\mathbf{5 3}$ and $\mathbf{5 4}$ was obtained. For the cross-coupling reaction, a set of four different terminal alkynes was tested with 3-hexyne as an internal alkyne, and again 1,2,3,4tetrahydroisoquinoline as a sacrificial amine. After heating at $130^{\circ} \mathrm{C}$ for $16 \mathrm{~h}$, the expected allenes were obtained in good to excellent yields. 
Scheme 18. One-pot preparation of allenes by homo- and heterocoupling of two alkynes, using a sacrificial secondary amine

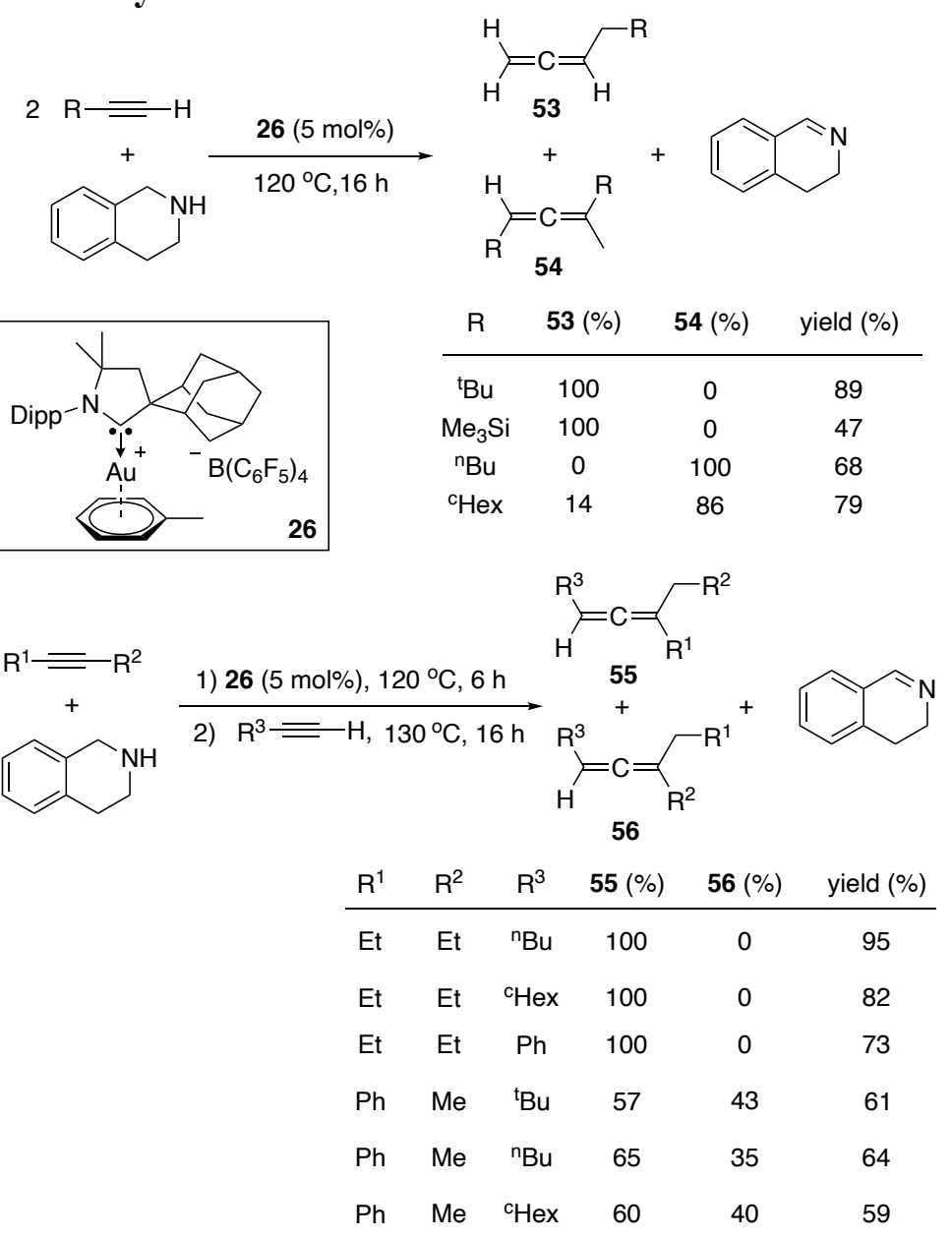

The coupling of two alkynes to form allenes is one of the very rare chemical transformations that combines two different reactions, yet relies on a single catalyst. Since gold complexes are known for their excellent functional group tolerance, this one-pot process should find applications in the synthesis of complex molecules.

\subsection{Gold Catalyzed Hydroamination of Alkynes and Allenes, and Hydroammoniumation and Methylamination of Alkynes}

Although various homogeneous catalysts, ${ }^{122,123}$ including gold ${ }^{124}$ and copper $^{125}$, have been used to effect the so-called hydroamination reaction, the cationic gold complexes $\mathbf{2 6}$ and $\mathbf{5 7}$ were the first homogeneous catalysts able to promote the catalytic hydroamination of alkynes and allenes with ammonia (Scheme 19). ${ }^{126}$ Before this discovery, there were only two publications dealing 
with the homogeneous catalytic functionalization of $\mathrm{NH}_{3}$. Indeed in 2006, Shen and Hartwig, ${ }^{127}$ and Surry and Buchwald ${ }^{128}$ reported the palladium-catalyzed coupling of aryl halides with ammonia in the presence of a stoichiometric amount of base. The difficulties in using $\mathrm{NH}_{3}$ as a reagent for transition metals ${ }^{129}, 130,131$ stems from the formation of inert Lewis acid-base complexes, the so-called Werner complexes.

Despite these challenges, in the presence of $5 \mathrm{~mol} \%$ of (CAAC) $\mathrm{AuNH}_{3} \mathbf{5 7}, \mathrm{NH}_{3}$ adds to terminal alkynes at $110^{\circ} \mathrm{C}$ leading to the Markovnikov imine, whereas for internal alkynes heating at 160 ${ }^{\circ} \mathrm{C}$ is necessary to obtain the expected tautomer of the corresponding enamines (Scheme 19). A very detailed computational study by Ujaque et al. ${ }^{132}$ concluded that the electronic properties of CAACs render the formation of the alkyne complex energetically achievable, despite the stability of the Werner complex, thus enabling for the hydroamination reaction to take place. Nitrogen heterocycles, such as pyrroles, could also be prepared in excellent yields in one step from diynes. These products result from the Markovnikov addition of $\mathrm{NH}_{3}$, followed by ring-closing hydroamination. The scope of the reaction is not limited to alkynes, complex $\mathbf{5 7}$ also promotes the $\mathrm{NH}_{3}$ hydroamination of allenes. For the parent allene and the 1,1-dialkyl substituted derivative, the $\mathrm{NH}_{2}$ group adds exclusively at the less-hindered terminus; however mono-, di-, and trisubstituted amines are formed. Tetrasubstituted allenes also undergo hydroamination with

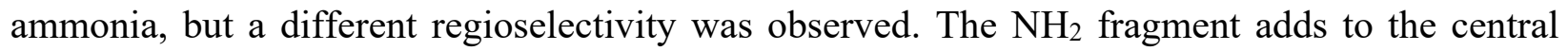
carbon, probably because of steric factors, and only the monohydroamination product was obtained. 
Scheme 19. (CAAC)AuNH ${ }_{3}$ complex 57 was the first complex able to promote the hydroamination of alkynes and allenes with ammonia
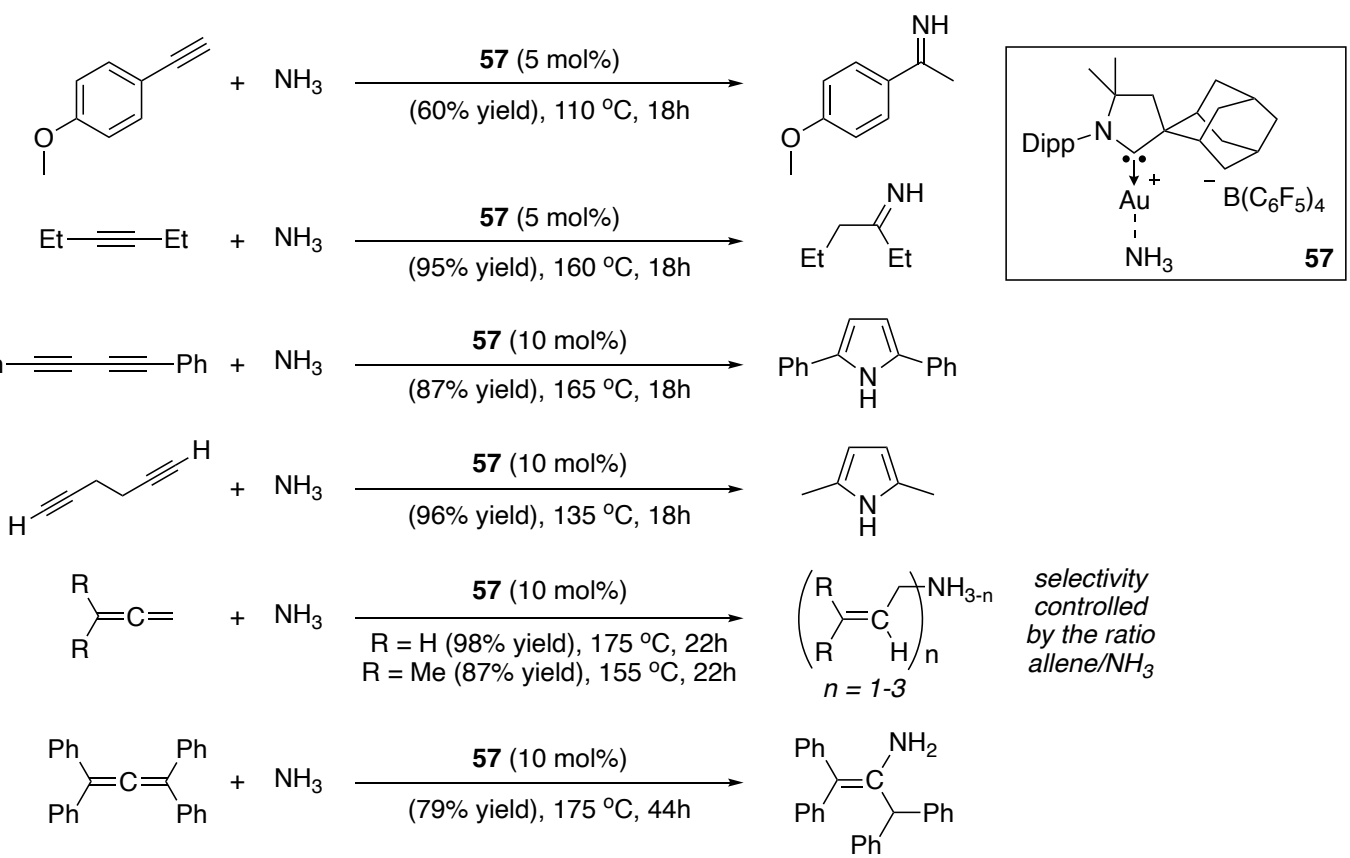

Like $\mathrm{NH}_{3}$, parent hydrazine is a difficult substrate for transition metal catalyzed reactions. Before our work, ${ }^{133}$ there was no report on hydroamination reaction with hydrazine, and only one example of transition-metal catalyzed functionalization of $\mathrm{H}_{2} \mathrm{NNH}_{2}$, namely the palladium catalyzed crosscoupling with aryl chlorides and tosylates. ${ }^{134}$ There are several difficulties associated with hydrazine. Akin to ammonia, $\mathrm{H}_{2} \mathrm{NNH}_{2}$ forms inert Werner complexes. In addition, hydrazine is known to be a strong reducing reagent that leads to inactive metal( 0 ) particles. As an illustration, the formation of gold particles has been reported in the reaction of gold chloride with hydrazine, ${ }^{135}$ and cationic trinuclear phosphine-gold complexes of the type $\left(\mathrm{R}_{3} \mathrm{PAu}\right)_{3}(\mathrm{O})^{+} \mathrm{X}$ - have been shown to promote the dehydrogenation of $\mathrm{H}_{2} \mathrm{NNH}_{2}$ to give $\mathrm{N}_{2}$ complexes. ${ }^{136}$ In contrast, a stoichiometric amount of (CAAC)AuCl $9 \mathbf{a}^{133}$ and $\mathrm{KB}\left(\mathrm{C}_{6} \mathrm{~F}_{5}\right)_{4}$ reacts cleanly with hydrazine to give the corresponding Werner complex $\mathbf{5 8}$, which is active for the hydrohydrazination of a variety of alkynes and bis(alkynes) at rather high temperatures $\left(90-100^{\circ} \mathrm{C}\right)($ Scheme 20). Interestingly, in the presence of $\mathrm{KB}\left(\mathrm{C}_{6} \mathrm{~F}_{5}\right)_{4},(\mathrm{saNHC}) \mathrm{AuCl}$ complexes $\mathbf{4 9}^{137}$ [or even (anti-Bredt-NHC)AuCl], ${ }^{138,139}$ in 
other words complexes featuring rather $\pi$-accepting carbenes, promote the same reaction at room temperature, although the scope of applications is much narrower. Indeed, with complex 49 the hydrohydrazination of alkyl substituted alkynes as well as internal alkynes does not occur. Lledos et al. ${ }^{140}$ performed a very sophisticated computational study and concluded that the mechanism of the hydrazination reaction involved the substitution of the hydrazine ligand by the alkyne, leading to a gold $\pi$-complex. After the nucleophilic attack of hydrazine on the activated carbon-carbon triple bond, nitrogen to carbon atom proton transfer occurs assisted by the nucleophile. Then carbon to nitrogen atom gold migration yields the enamine intermediate. Lastly, a second nucleophile-assisted nitrogen to carbon atom proton transfer leads to the more stable imine tautomer.

Scheme 20. (CAAC) and (saNHC) gold complexes 58 and 49 promote the hydrohydrazination of alkynes with parent hydrazine
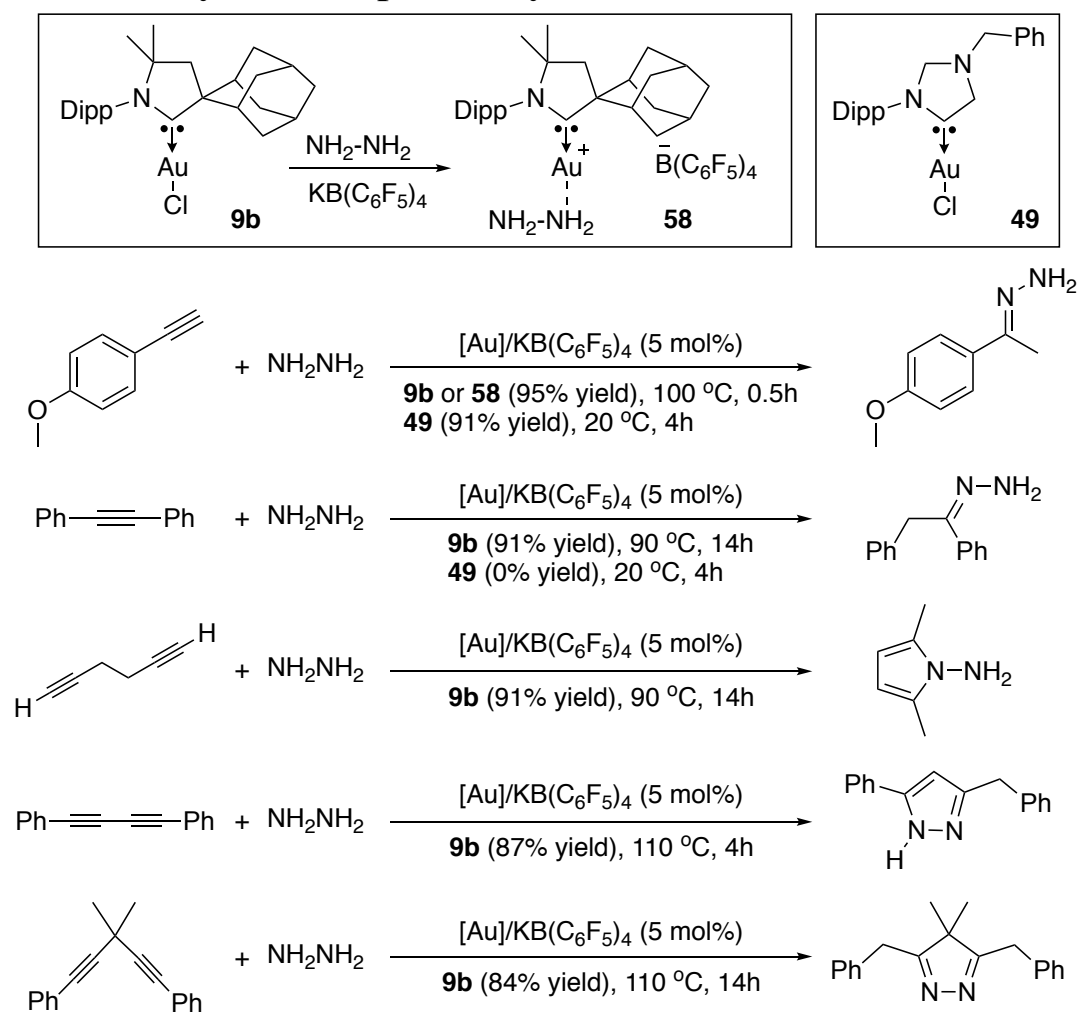

Secondary dialkylamines are also challenging substrates as they are very basic, and in addition early transition metals cannot be employed to promote hydroamination reactions, because of the 
involvement of an imido complex (LxM=NR) in the catalytic cycle. ${ }^{141}$ Consequently, there are very few examples of intermolecular hydroamination reaction with secondary amines. It was found that a stoichiometric amount of $\mathrm{KB}\left(\mathrm{C}_{6} \mathrm{~F}_{5}\right)_{4}$ and gold(I) complex $\mathbf{9} \mathbf{b}^{121}$ or $9 \mathbf{g}^{142}$ catalyzes the addition of many types of secondary amines to terminal as well as internal alkynes, including the first examples of intermolecular hydroamination of internal alkynes with secondary alkyl amines (Scheme 21). In the presence of $\mathrm{KB}\left(\mathrm{C}_{6} \mathrm{~F}_{5}\right)_{4}$, complex $9 \mathbf{b}$ also promotes the hydroamination of allenes with secondary amines, including dialkylamines. ${ }^{143}$ Interestingly, for all the amines considered, the amino fragment always adds to the less substituted terminus of the CCC skeleton, giving access to allyl amines, which are important building blocks.

\section{Scheme 21. CAAC-catalyzed intermolecular hydroamination of alkynes and allenes with secondary dialkylamines}

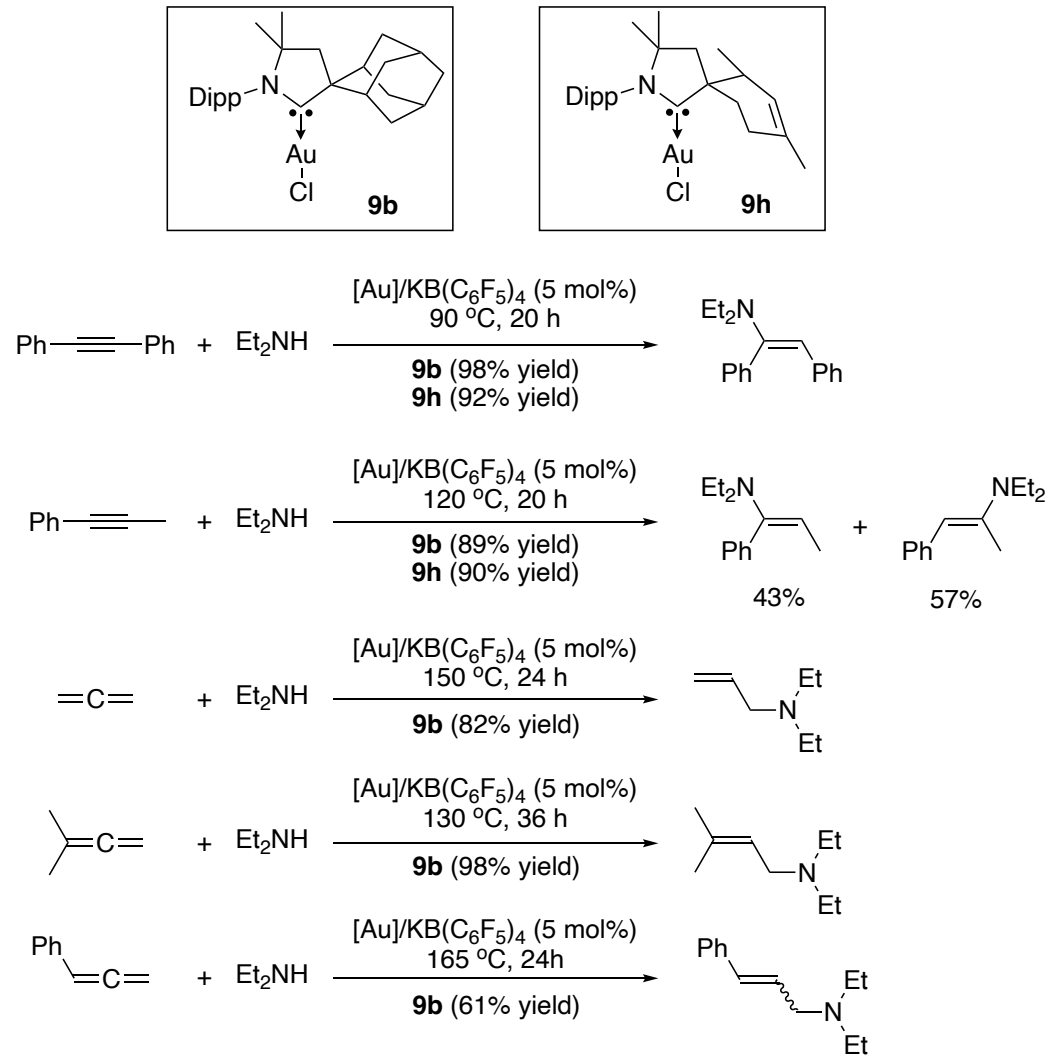

In Scheme 18, it was shown that the ability of (CAAC)Au+ complex 26 to promote the hydroamination of internal alkynes with secondary amines allowed for the one-pot preparation of allenes by coupling two alkynes, using a sacrificial secondary amine. Similarly, following the 
works by Yi et al. ${ }^{144}$ and Che et al., ${ }^{145}$ our group developed a one-pot three-component synthesis of 1,2-dihydroquinolines, involving a tandem hydroamination-hydroarylation protocol. ${ }^{142}$ Interestingly, for both the ruthenium-based and the ( $\mathrm{NHC}) \mathrm{AuCl} / \mathrm{AgSbF}_{6}$ catalysts of $\mathrm{Yi}$ and Che, respectively, only terminal alkynes could be used and since the second molecule of alkyne reacts quickly, the $\mathrm{C} 2$ and $\mathrm{C} 4$ substituents are the same (Scheme 22). With a stoichiometric mixture of $9 \mathrm{~g}$ and $\mathrm{KB}\left(\mathrm{C}_{6} \mathrm{~F}_{5}\right)_{4}(5 \mathrm{~mol} \%)$ the only serious limitation for the three-component cyclization is the use of a terminal alkyne for the second step. Consequently, the dihydroquinoline skeleton can be readily decorated with three different $\mathrm{R}^{1}, \mathrm{R}^{2}$ and $\mathrm{R}^{3}$ substituents.

\section{Scheme 22. Comparison of the scope of the previously reported one-pot three-component synthesis of 1,2-dihydroquinolines with that observed with $\mathrm{CAAC}$-gold $9 \mathrm{~g} / \mathrm{KB}\left(\mathrm{C}_{6} \mathrm{~F}_{5}\right)_{4}$}

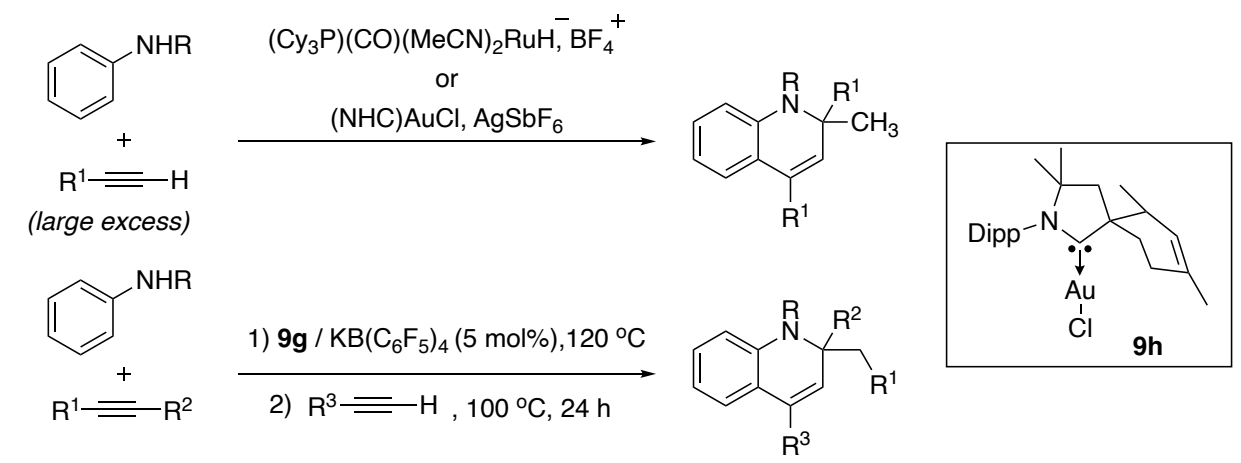

In the course of mechanistic studies of the gold-catalyzed hydroamination of alkynes, two novel reactions were discovered, namely the intramolecular hydroammoniumation and aminomethylation of carbon-carbon triple bonds (Scheme 23). ${ }^{146}$ Indeed, it was found that in the presence of $5 \mathrm{~mol} \%$ of a 1:1 mixture of complex $9 \mathbf{b}$ and AgOTf, the conjugate acid of 2-alkynylbenzenamines undergo cyclization affording $\mathbf{5 9}$ in excellent yield after a few hours at $60-70{ }^{\circ} \mathrm{C}$. Aryl and alkyl substituents are tolerated on the alkyne and on the amine, and not surprisingly the cyclization is facilitated when weakly basic amines are used. Examples of direct addition of a carbon-nitrogen bond to a carbon-carbon triple bond are very rare, and involve relatively weak C-N bonds, such as in allylamines or amides. ${ }^{147,148}$ However, 10 mol\% of a 1:1 mixture of complex 9b and $\mathrm{KB}\left(\mathrm{C}_{6} \mathrm{~F}_{5}\right)_{4}$ promotes the intramolecular aminomethylation of 2-alkynyl-N,N'-dimethyl- 
benzenamines giving rise to the corresponding indoles 60 in very good yields after $20 \mathrm{~h}$ at $160^{\circ} \mathrm{C}$. This cyclization tolerates aryl or alkyl substituents on the alkyne, but is limited to N,N'-dimethylbenzenamines.

Scheme 23. Intramolecular hydroammoniumation and aminomethylation of carbon-carbon triple bonds giving 59 and 60 , respectively

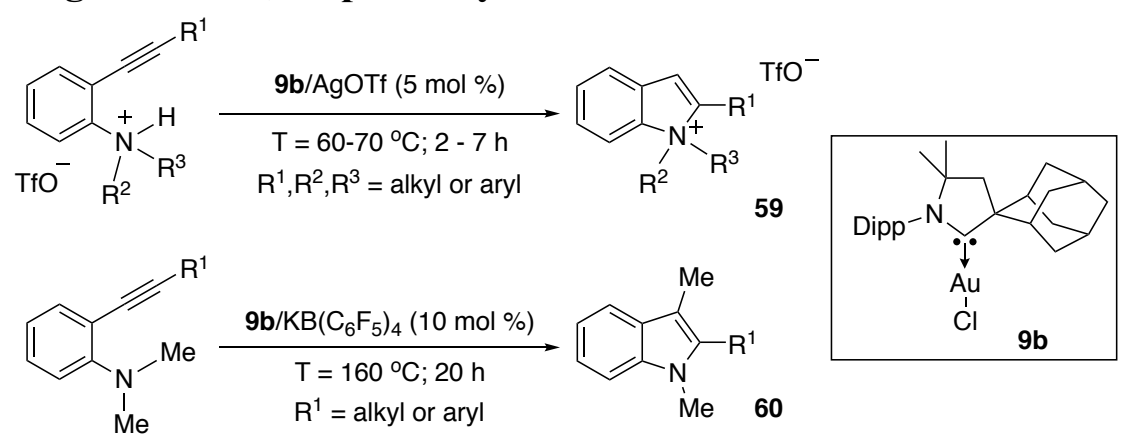

Importantly, many of the reactions described in this section required very drastic conditions, as exemplified by the $\mathrm{NH}_{3}$ hydroamination of tetrasubstituted allenes, which requires 44 hours at 175 ${ }^{\circ} \mathrm{C}$ (Scheme 19). This is a clear demonstration of the very unusual thermal stability of cationic (CAAC)gold(I) complexes, which is due to the peculiar electronic properties of CAACs.

\section{3. (CAAC)-Mono- and -Bis-(copper)acetylide Complexes in Catalysis.}

The isolation of the mono- and bis-(copper)acetylide complexes $\mathbf{2 4}$ and $\mathbf{2 5}{ }^{51}$ has not only allowed for a better understanding of the mechanism of the Cu-catalyzed azide-alkyne "click reaction", but has also led to the development of novel copper-catalyzed reactions.

For the $\mathrm{CuAAC}$, it has been possible to demonstrate several important features of the mechanism. Although both $\mathbf{2 4}$ and $\mathbf{2 5}$ are active in the catalytic cycle, the dinuclear complex $\mathbf{2 5}$ is involved in the kinetically favored pathway (Scheme 24). The resting state of the catalytic cycle is the bis(copper) triazole complex 61. Lastly, the alkyne serves as the proton source for the demetallation of $\mathbf{6 1}$, which regenerates $\mathbf{2 5}$, leaving out the mononuclear complex $\mathbf{2 4}$ from the catalytic cycle. 
Scheme 24. Both the mono-copper 24 and the bis-copper acetylide 25 are active in the CuAAC reaction, but the latter is more efficient. The alkyne is the proton source for the demetallation step, which regenerates 25 , thereby excluding 24 from the preferred catalytic cycle. Reproduced with permission from ref 51. Copyright 2015 AAAS.

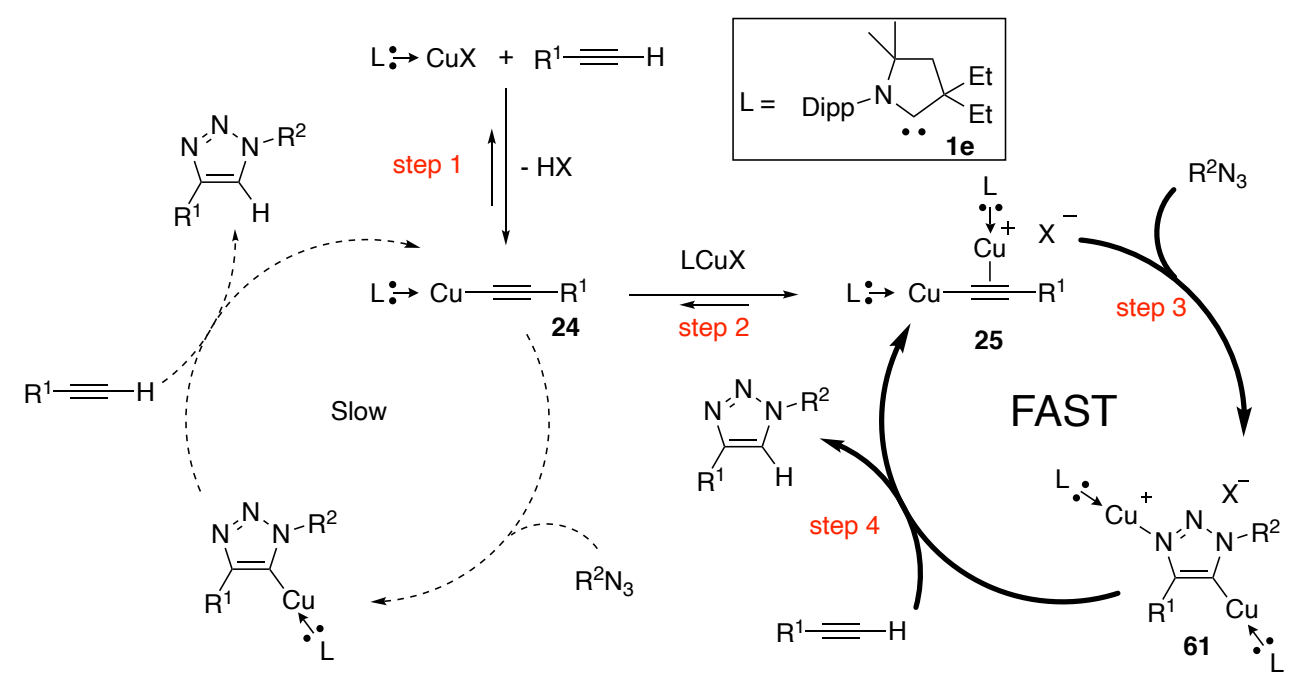

The CuAAC reactions promoted by CAAC-supported copper complexes are slow enough to be monitored, and to study the successive steps of the catalytic cycle. Of particular interest, the influence of the $\mathrm{X}$ ligand has been investigated by carrying out stoichiometric reactions. ${ }^{149}$ For the metalation step giving $\mathbf{2 4}$ (step 1), which involves a deprotonation of the alkyne, basic ligands are the most efficient (Scheme 25). Indeed, with $\mathrm{X}={ }^{t} \mathrm{BuO}$, the metalation is fast and irreversible, whereas with PhO, a dynamic equilibrium can only be observed by NMR. Lastly, with TfO, no spectroscopic evidence for the formation of $\mathbf{2 4}$ can be found, but the latter can be obtained by adding an external base like triethylamine. In contrast, the formation of the bis(copper)acetylide 25 (step 2) is favored by non-nucleophilic ligands with TfO being the best. For step 3, the bis(copper)triazole 61 was only observed when $\mathrm{X}=\mathrm{TfO}$; but when $\mathrm{X}=\mathrm{Cl}$, $\mathrm{AcO}$, or $\mathrm{PhO}$, a $\mathrm{C}$ monometallated triazole was obtained. For the last step of the catalytic cycle, namely the protodemetalation of triazole by the alkyne (step 4), all X ligands performed similarly ( $\mathrm{k}_{\text {obs }}$ between 0.5 $10^{-4} \mathrm{~s}^{-1}$ and $\left.2.210^{-4} \mathrm{~s}^{-1}\right)$, except for the acetate $\left(\mathrm{k}_{o b s}>37010^{-4} \mathrm{~s}^{-1}\right)$. This acceleration is characteristic of a base assisted proton transfer mechanism as observed in biological systems. ${ }^{150}$ 
From these results, it appears that the acetate is a good compromise, basic enough for the metalation step, not too nucleophilic to prevent the formation of the bis(copper)acetylide $\mathbf{2 5}$, and very efficient in promoting the proto-demetalation step. This rationalized why the acetate is often used in $\mathrm{CuAAC}$ reactions.

Scheme 25. Influence of the $\mathrm{X}$ ligand on the first two steps of the CuAAC reaction

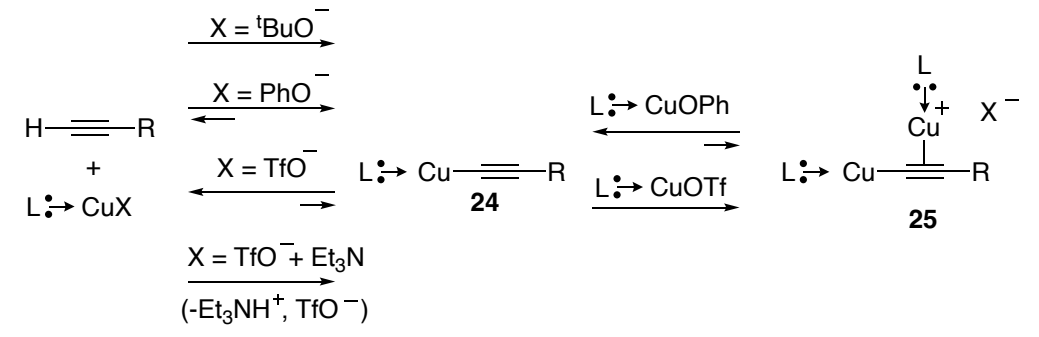

The knowledge of the influence of the $\mathrm{X}$ ligand ${ }^{151}$ on the formation of $\mathbf{2 4}$ versus $\mathbf{2 5}$ has allowed for the rational design of copper catalysts that selectively promote either the hydroboration ${ }^{152}$ or the dehydrogenative borylation ${ }^{153}$ of terminal alkynes with pinacolborane (Scheme 26). Indeed, in complexes 24, which can be prepared with $\mathrm{LCuOPh}$, the triple bond is available for hydroboration leading to alkenyl boronic esters $\mathbf{6 2}$. In contrast, in dinuclear complexes $\mathbf{2 5}$, which are readily obtained by reacting LCuOTf with terminal alkynes in the presence of triethylamine with ammonium triflate as the byproduct, the triple bond is protected. The polarized copper-carbon bond of $\mathbf{2 5}$ can undergo a $\sigma$-bond metathesis with pinacolborane giving rise to the alkynyl boronic ester 63, along with the copper hydride 64 (Scheme 27). The latter reacts with ammonium triflate to regenerate LCuOTf and triethylamine with the elimination of dihydrogen.

Scheme 26. Influence of the $X$ ligand on the fate of the reaction of pinacolborane with phenyl acetylene

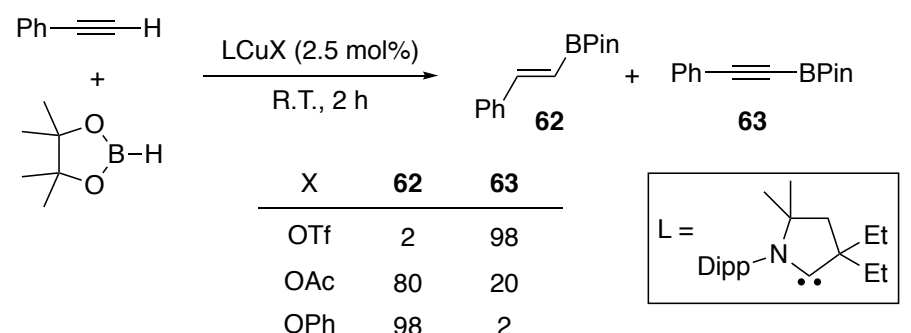


Scheme 27. Postulated catalytic cycle for the dehydrogenative borylation of terminal alkynes with pinacolborane. Modified with permission from ref 153. Copyright 2017 Royal Chemical Society.

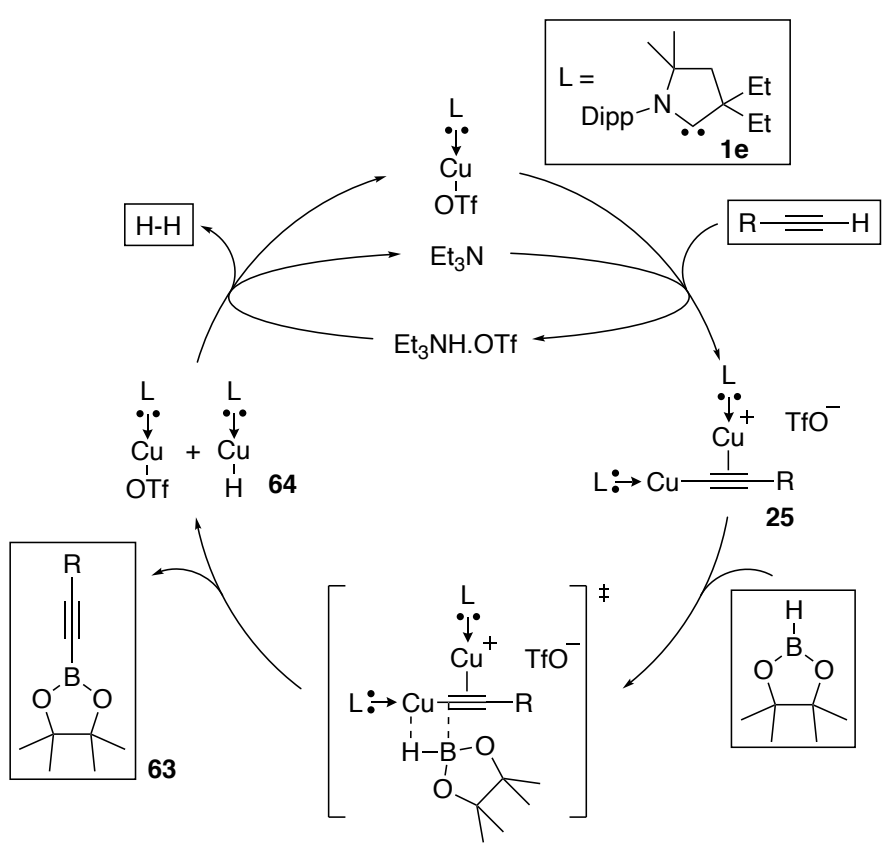

Both the dehydrogenative borylation and the hydroboration processes are readily applicable to a broad range of terminal alkynes bearing functionalities such as $\mathrm{OMe}, \mathrm{CN}, \mathrm{F}, \mathrm{Cl}$, TMS and $\mathrm{CO}_{2} \mathrm{Me}$. Importantly, the alkenyl (62) and alkynyl boronic esters (63) were isolated in good to excellent yields via simple filtration through a short plug of dry neutral alumina. This straightforward protocol allows for gram-scale synthesis of these boronic esters.

Note that the catalytic dehydrogenative borylation of $\mathrm{C}\left(\mathrm{sp}^{3}\right)-\mathrm{H}$ and $\mathrm{C}\left(\mathrm{sp}^{2}\right)-\mathrm{H}$ bonds discovered by Hartwig et al. ${ }^{154}$ and Smith et al. ${ }^{155}$ are well studied. ${ }^{156}$ In contrast, there are only a few reports by Ozerov et al. ${ }^{157,158,159}$ for C(sp)-H bonds, using iridium and palladium complexes supported by pincer ligands, and one by Tsuchimoto et al. ${ }^{160}$ with zinc triflate, which has a rather narrow scope.

\section{4. (CAAC)-Coinage Metals for the Activation of Small Molecules}

\subsection{1. (CAAC)-CuBH 4 Complexes for the Catalytic Hydrolytic Dehydrogenation of} $\mathrm{BH}_{3} \mathrm{NH}_{3}$ and for the Reduction of $\mathrm{CO}_{2}$ into Formate with $\mathrm{H}_{2}$.

Ammonia borane $\left(\mathrm{BH}_{3} \mathrm{NH}_{3}\right)$ and metal borohydrides $\mathrm{M}\left(\mathrm{BH}_{4}\right)_{\mathrm{n}}$ are excellent hydrogen storage materials. ${ }^{161}$ Developing catalysts based on cheap transition metals capable of releasing $\mathrm{H}_{2}$ at room 
temperature with a high rate of hydrogen generation is vital for the large-scale application of these inorganic compounds. ${ }^{162}$ It was first observed that the CAAC copper complex 13e reacts with $\mathrm{BH}_{3} \mathrm{NH}_{3}$ or $\mathrm{NaBH}_{4}$ to give $\mathbf{6 5}$ in which two hydrogen atoms of $\mathrm{BH}_{4}$ interact with the metal (Scheme 28). Interestingly, in contrast to other $\mathrm{LCuBH}_{4}$ complexes, as exemplified by $\left(\mathrm{Ph}_{3} \mathrm{P}\right) \mathrm{CuBH}_{4}$ which decomposes at $-20{ }^{\circ} \mathrm{C},{ }^{163} \mathbf{6 5}$ is perfectly stable at room temperature. Then, it was found that $(\mathrm{CAAC}) \mathrm{CuBH}_{4} 65$ and $(\mathrm{CAAC}) \mathrm{CuCl} 13 \mathrm{e}$ complexes are highly efficient catalyst for the hydrolytic dehydrogenation of $\mathrm{BH}_{3} \mathrm{NH}_{3} .{ }^{26}$ Indeed, when a $1 \mathrm{~mol} \%$ acetone/water solution of $13 \mathbf{e}$ was added to $\mathrm{BH}_{3} \mathrm{NH}_{3}, 2.6$ moles of $\mathrm{H}_{2}$ were released per mole of $\mathrm{BH}_{3} \mathrm{NH}_{3}$ over 5 minutes, which corresponds to a turnover frequency (TOF) of $3100 \mathrm{~mol}_{\text {of }} \mathrm{H}_{2}$ per mol of 13e per hour. More impressive, by using $1 \mathrm{~mol} \%$ of $\mathbf{6 5}$, the hydrolytic dehydrogenation reaction was finished within 2 minutes at room temperature, with 2.8 moles of $\mathrm{H}_{2}$ released per mole of $\mathrm{BH}_{3} \mathrm{NH}_{3}$, thus giving a TOF of 8400 . This TOF is more than 1000 times higher than that reported with $\mathrm{CuCl}_{2},{ }^{164}$ and compares well with those obtained in the hydrolytic dehydrogenation of ammonia borane promoted by noble metal catalysts. ${ }^{161}$ Importantly, $\mathbf{1 3 e}$ and $\mathbf{6 5}$ are very robust. The catalytic solution can be handled in air and recycled more than 15 times without significant loss of activity.

\section{Scheme 28. Preparation of (CAAC)CuBH 65 and hydrolytic dehydrogenation of $\mathrm{BH}_{3} \mathrm{NH}_{3}$}

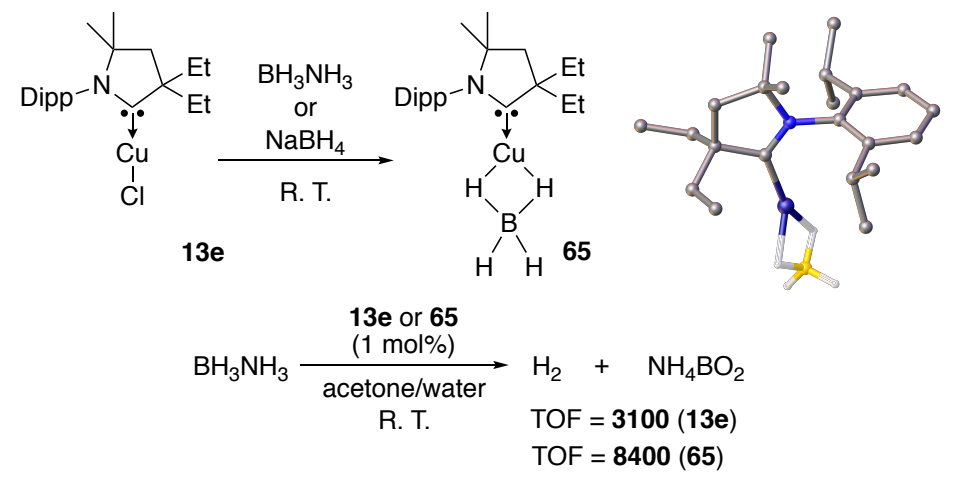

Following the pioneering work of Inoue et al. ${ }^{165}$ the reduction of $\mathrm{CO}_{2}$ into formic acid with $\mathrm{H}_{2}$ has successfully been performed with a variety of noble metal catalysts ${ }^{166}$ and TONs up 
to $3,500,000 \cdot{ }^{167}$ However, this is not the case with abundant and inexpensive first-row metals such as copper. Indeed, although copper hydrides efficiently insert $\mathrm{CO}_{2}$ as shown by the numerous copper-catalyzed carboxylation reactions, ${ }^{168,169}$ they have difficulty activating molecular hydrogen; consequently, TONs below 500 are usually obtained. ${ }^{170}$ On the other hand, frustrated Lewis pairs (FLPs) $)^{171,172}$ are well-known to activate $\mathrm{H}_{2}{ }^{173,174}$ but cannot reduce $\mathrm{CO}_{2}$ catalytically because of the formation of a strong B-O bond. ${ }^{175}$ It then became reasonable to believe that a copper hydride activating $\mathrm{CO}_{2}$, working in tandem with a Lewis pair as $\mathrm{H}_{2}$ activator, would provide an efficient synergy for the catalytic reduction of $\mathrm{CO}_{2}$ with $\mathrm{H}_{2}$. Indeed, it was found that using the copper borohydride complex 65 as a copper hydride surrogate and $\mathrm{B}\left(\mathrm{C}_{6} \mathrm{~F}_{5}\right)_{3} / \mathrm{DBU}$ as the frustrated Lewis pair, $\mathrm{CO}_{2}$ was cleanly reduced into the formate after 24 hours at $100{ }^{\circ} \mathrm{C}$ with TONs reaching 1880 (Scheme 29). ${ }^{176,177}$

\section{Scheme 29. Tandem copper hydride-Lewis pair catalyzed reduction of carbon dioxide into formate with dihydrogen.}

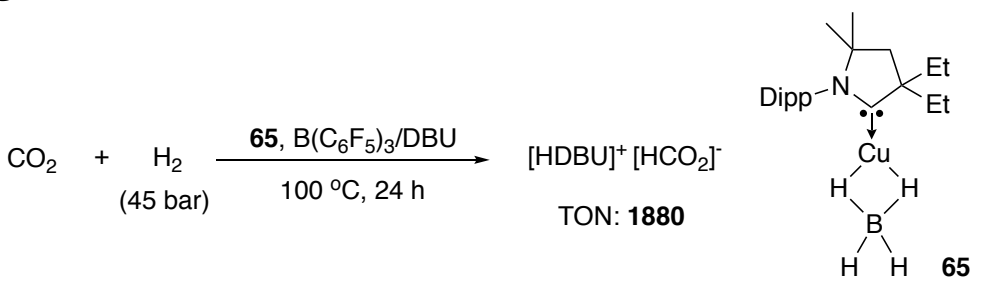

Interestingly, the elementary steps of the catalytic cycle were reproduced stoichiometrically (Scheme 30 ). The copper borohydride complex 65 reacted with $\mathrm{CO}_{2}(10$ bar) at $80^{\circ} \mathrm{C}$ giving the insertion product 66 upon elimination of $\mathrm{BH}_{3}$. Then it was confirmed that a known FLP, namely $\mathrm{B}\left(\mathrm{C}_{6} \mathrm{~F}_{5}\right)_{3}$ and 1,2,2,6,6-pentamethylpiperidine (PMP), cleaved molecular hydrogen to give $67 .{ }^{178}$ Lastly, it was shown that at room temperature a stoichiometric amount of $\mathbf{6 6}$ reacted within minutes with $\mathbf{6 7}$ to give the formate and the borane-stabilized monomeric (CAAC)CuHBCF adduct 68. 
Scheme 30. Stoichiometric reactions mimicking the elementary steps of the catalytic cycle of the tandem copper hydride-Lewis pair catalyzed reduction of carbon dioxide by $\mathrm{H}_{2}$

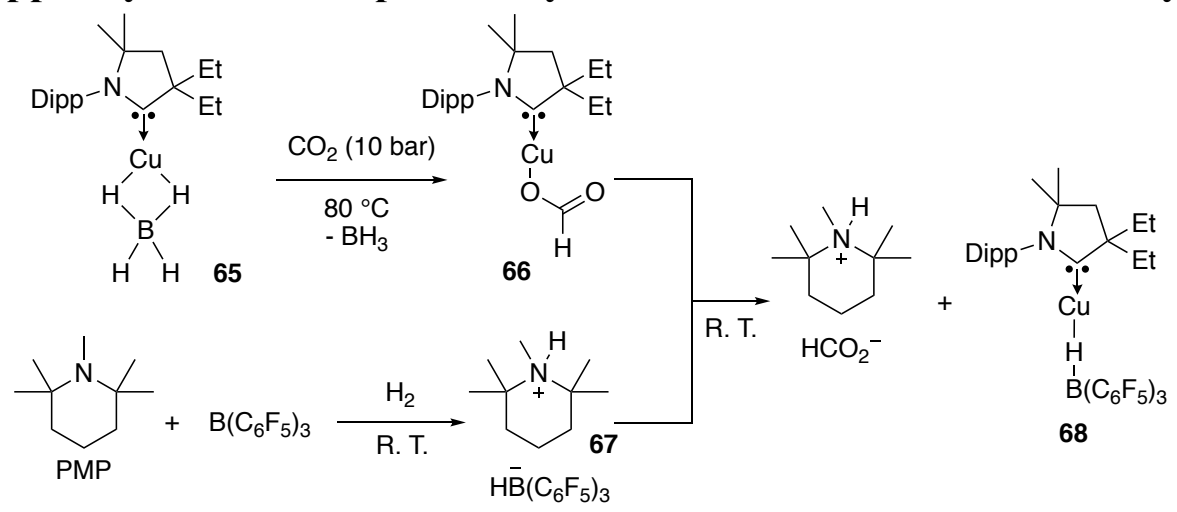

These results suggest that the synergy between a transition metal center and a Lewis pair could be extended to other reactions.

\subsubsection{Trinuclear (CAAC) Gold Clusters as Catalysts for the Carbonylation of Amines}

In 2012 Corma et al. ${ }^{179,180,181}$ reported that very small metallic gold clusters could display catalytic activities that are much higher than those obtained with gold nanoparticles and mononuclear homogeneous gold catalysts. This striking discovery led to the question of whether very small, well-defined clusters, capped with ligands, such as 40-43 (Scheme 11), could also behave as efficient catalysts. ${ }^{86}$ To tackle this question, the carbonylation of amines, which is the simplest and most environmentally friendly route for the preparation of urea derivatives, ${ }^{182}$ was chosen. It was found that $2.5 \mathrm{~mol} \%$ of trinuclear gold complex $41 \mathrm{e}$ catalyzed the carbonylation of cyclohexylamine under 30 psi of $\mathrm{CO}$ and 10 psi of $\mathrm{O}_{2}$. After 2 days at $90{ }^{\circ} \mathrm{C}$, the $\mathrm{N}, \mathrm{N}^{\prime}-$ dicyclohexylurea was formed in 69\% yield (Scheme 31). Similarly, benzyl amine and 2phenylethylamine were converted into the corresponding urea in $74 \%$ and $72 \%$ yields, respectively. In the case of the more sterically hindered substrates, such as 2-adamantylamine, the conversion was significantly decreased, while no reaction was observed with the less basic aniline. Importantly, no decomposition of 41e could be observed during these reactions, demonstrating its robustness. 
Scheme 31. Carbonylation of amines catalyzed by the trinuclear gold cluster $41 \mathrm{e}$

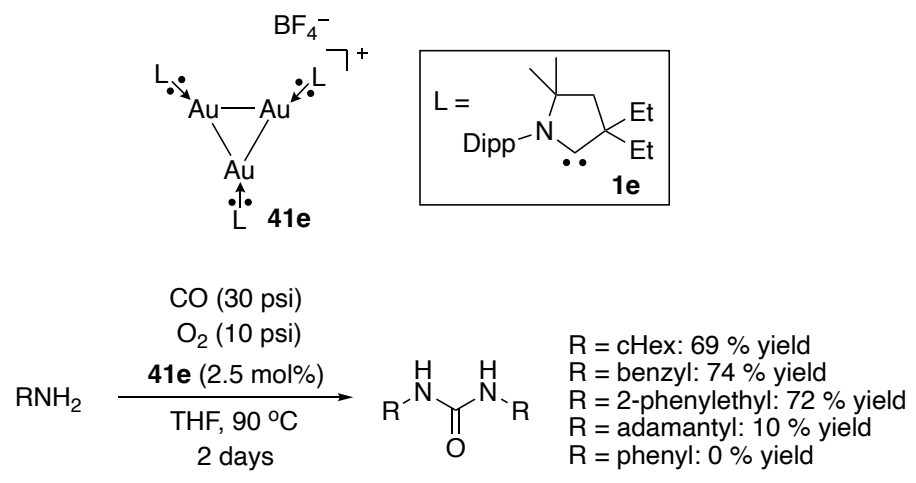

The well-defined nature of 41e allowed for a mechanistic study of the carbonylation reaction. It has been found that $\mathrm{CO}$ does not react with 41e or the amine in the absence of air. However, 41e reacts with cyclohexylamine in the presence of oxygen, leading after two days at 70 ${ }^{\circ} \mathrm{C}$ to the dinuclear complex $\mathbf{6 9}$, which was isolated (Scheme 32). Then, when CO was added to 69, the trinuclear cluster 41e was recovered along with cyclohexyl isocyanate and traces of urea. Note that upon addition of amine, which transforms 41e into 69, two gold centers are oxidized, while in the addition of $\mathrm{CO}$ to $\mathbf{6 9}$ giving back 41, two gold centers are reduced. This is a very rare example of a gold catalyzed process involving a definite change of oxidation state of the metal. ${ }^{183,184,185}$

Scheme 32. Stoichiometric reactions for a better understanding of the catalytic cycle of the carbonylation of amines

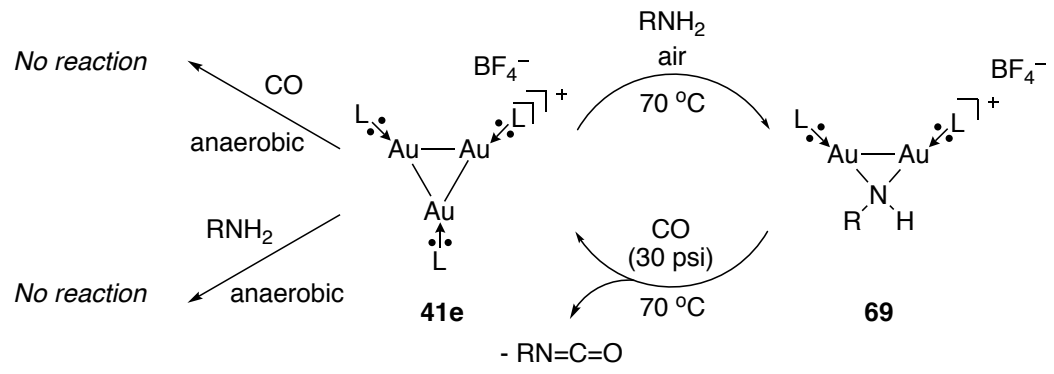




\subsection{Miscellaneous}

\subsection{1. (CAAC)-Gold and -Copper Catalysts for the Hydroarylation of Styrene with} Anilines

Friedel-Crafts reactions, such as the intermolecular hydroarylation of alkenes, ${ }^{186,187}$ usually require Lewis acid catalysts, and are therefore rarely efficient for basic substrates, such as amines. However, in the presence of $\mathrm{KB}\left(\mathrm{C}_{6} \mathrm{~F}_{5}\right)_{4}$, the (CAAC)AuCl complex 44, featuring the hemilabile CAAC 1g, promoted the hydroarylation of $\alpha$-methylstyrene with N,N-dimethyl aniline (Scheme 33). ${ }^{94}$ A $97 \%$ conversion was observed after only $12 \mathrm{~h}$ at $120^{\circ} \mathrm{C}$, which is slightly better than that with the CAAC supported gold complex 9e, and even the anti-Bredt gold complex 71, which requires $24 \mathrm{~h}$ at $135^{\circ} \mathrm{C} .{ }^{188}$ Even more striking, the analogous copper complex $\mathbf{7 0}$ also promotes the same hydroarylation reaction at $120^{\circ} \mathrm{C}$ with a $97 \%$ conversion after $12 \mathrm{~h}$. Importantly, under the same experimental conditions, the monodentate CAAC copper complex $\mathbf{1 3 e}$ gave only traces of the hydroarylation product. The superiority of complex $\mathbf{7 0}$ over $\mathbf{1 3 e}$ might be due to the presence of a basic moiety on the side chain of the CAAC ligand, which could assist a formal proton transfer. Although examples of intramolecular copper-catalyzed hydroarylation of alkenes have been reported, ${ }^{189} \mathbf{7 0}$ was the first copper complex able to promote the intermolecular version.

Scheme 33. Comparison of (carbene)-gold and -copper catalysts for the hydroarylation of $\alpha$ methylstyrene with anilines
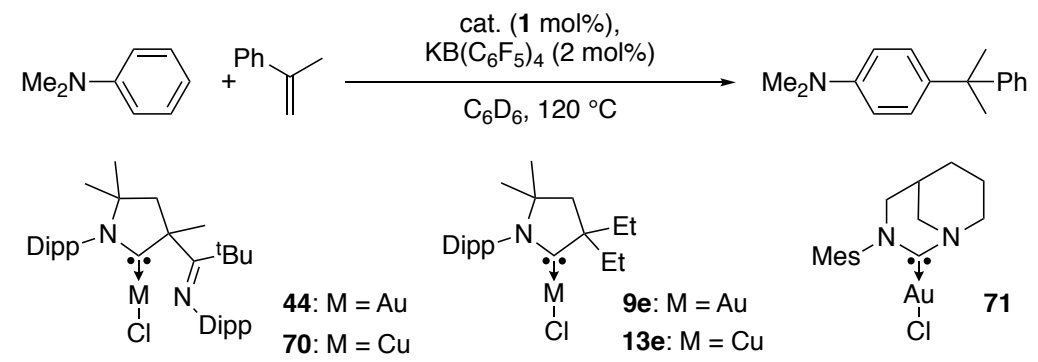

$$
\begin{aligned}
& \text { cat. }=44: 12 \text { h, } 97 \%(1 \mathrm{~h}, 45 \%) \\
& \text { cat. }=9 \text { e: } 12 \text { h, } 89 \%(1 \mathrm{~h}, 33 \%) \\
& \text { cat. }=71: 24 \text { h, } 97 \% \text { but at } 135^{\circ} \mathrm{C}
\end{aligned}
$$




\subsection{2. (CAAC)Gold(I) Complexes in Gold/Palladium Dual Catalysis}

Blum et al. developed elegant dual-catalytic systems combining the Lewis acidic activity of $\mathrm{Au}(\mathrm{I})$ with a Lewis basic transition metal catalyst. ${ }^{190,191}$ They reported that a stoichiometric mixture of (CAAC)AuCl 13b and $\mathrm{NaBAr}^{\mathrm{F}}$ (5 mol\%), with $\mathrm{Pd}_{2} \mathrm{dba}_{3}(2.5 \mathrm{~mol} \%)$ promotes at room temperature the rearrangement of vinyl aziridines into pyrrolizidine and indolizidine frameworks (Scheme 34). ${ }^{192}$ The scope of the reaction is reasonably broad as long as bulky R substituents are used to increase the Thorpe-Ingold effect. Methyl substitution at the internal position of the tethered alkene was tolerated, as well as increasing the olefin tether length.

Scheme 34. Gold/palladium promoted rearrangement of vinyl aziridines into pyrrolizidines
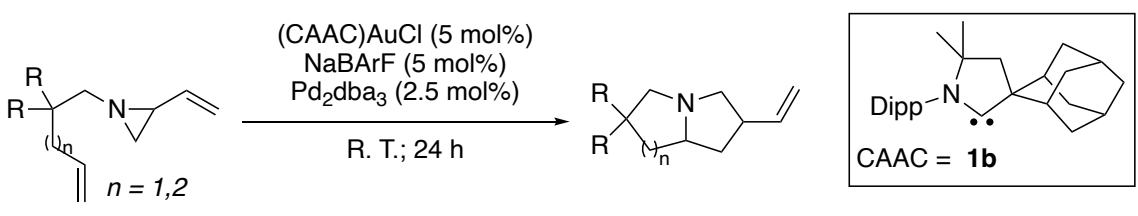

Following a very detailed mechanistic study, the authors concluded that the reaction did not proceed through carbophilic $\mathrm{Au}(\mathrm{I})$ catalysis. Instead, the $\mathrm{Au}(\mathrm{I})$ complex would act as an azaphilic Lewis acid helping the aziridine oxidative addition to $\operatorname{Pd}(0)$ (Scheme 35). The resulting $\operatorname{Pd}(\mathrm{II})$ intermediate would then undergo a syn-aminometalation, followed by a reductive elimination from the palladacyclic intermediate. This mechanistic hypothesis seems to contradict most of the reports emphasizing the carbophilicity of $\mathrm{Au}(\mathrm{I})$ towards carbon-carbon multiple bonds. However, most of these reports deal with alkynes, and therefore, the competitive binding of gold to heteroatoms should be seriously considered, when alkenes are involved. 
Scheme 35. Postulated catalytic cycle for the gold/palladium promoted rearrangement of vinyl aziridines into pyrrolizidines. Modified with permission from ref 191. Copyright 2012 American Chemical Society.

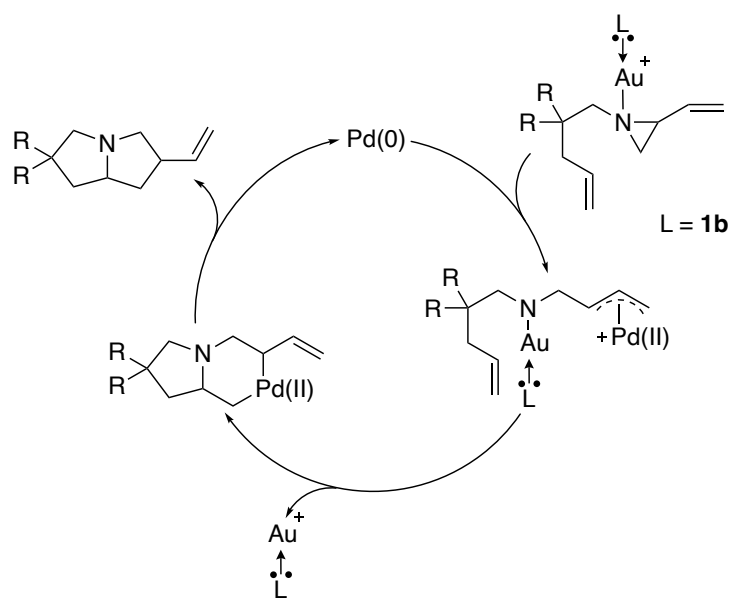

\subsection{3. (CAAC)-Gold(III) Complexes in Migratory Insertion of Carbenes into Au(III)-}

\section{Bonds.}

In 2018, Toste et al. ${ }^{193}$ reported the first examples of migratory insertion of carbenes generated from silyl- or carbonyl- diazoalkanes into $\mathrm{Au}$-carbon bonds. Indeed, abstraction of chloride from 72 with $\mathrm{AgNTf}_{2}$ or $\mathrm{NaBAr}^{\mathrm{F}}$ followed by addition of ethyl diazoacetate at room temperature, led to the formation of the fluorene derivative $\mathbf{7 3}$ as the major product (Scheme 36). This reaction appeared very sensitive to the experimental conditions used, especially the solvent and the amount of water, and its scope is rather limited. Interestingly for this Focus Review, a detailed study of the influence of the ligand has been done, and CAACs led to the highest yields, presumably through promotion of reductive elimination after migratory insertion in favor of other processes. It is noteworthy that although the migratory insertion of unsaturated carbon-based species into metal-carbon bonds is well-established for most transition metals, ${ }^{194}$ this is not the case for gold, ${ }^{195,196,197}$ with rare exceptions. ${ }^{198}$ Therefore, as concluded by the authors, "This study paves the way for homogeneous gold-catalyzed processes incorporating carbene migratory insertion steps." 
Scheme 36. The superiority of CAAC ligands for the migratory insertion of carbenes generated from diazoalkanes into $\mathrm{Au}$-carbon bonds.

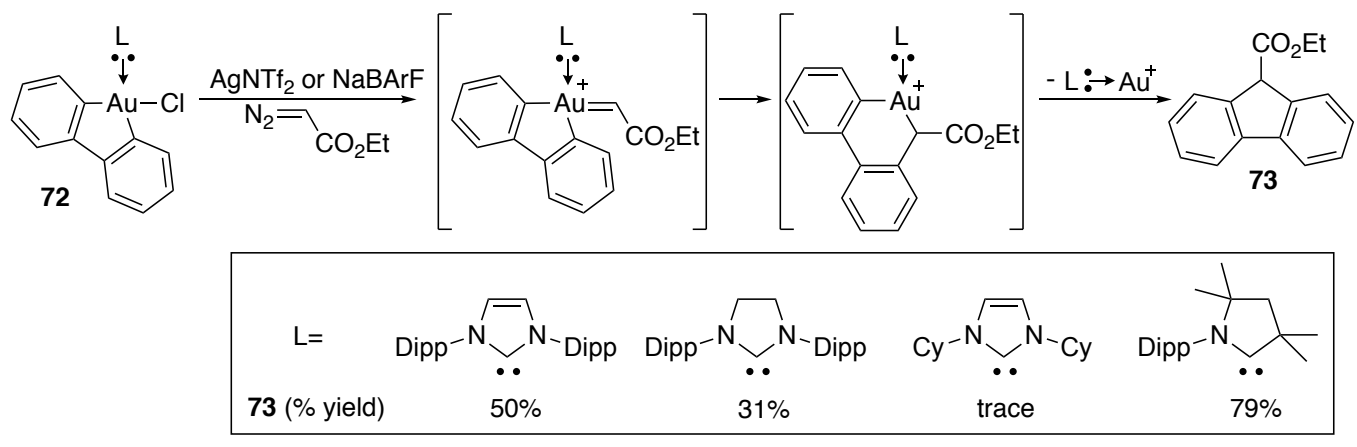

\subsection{Chiral CAAC Ligands in Enantioselective Catalysis}

Chiral NHCs were first used as ligands for transition metal-based catalysts in 1996. ${ }^{199,200}$ However, up until now, only imidazol-2-ylidenes 7, imidazolidin-2-ylidenes 8 and 1,2,4-triazol5-ylidenes (Enders carbene) ${ }^{201}$ have been used as ligands for enantioselective transformations. ${ }^{202}$ Since CAACs feature a quaternary carbon adjacent to the carbene carbon, and thus in closer proximity to the active site than NHCs, it is surprising that the first report of their use as ligands in enantioselective catalysis only appeared in $2019 .{ }^{203}$ This is even more astonishing since already in 2005, it has been shown that enantiopure CAACs, such as 1a, could be prepared without enantioor diastereo-selective separations from inexpensive starting materials such as (-)-menthol. ${ }^{1}$ The key step of the synthesis of enantiopure CAACs is based on the well-known propensity of bulky reactants to approach the cyclohexane moiety selectively from the equatorial direction, as shown for the menthylCAAC 1a (Scheme 37).

Scheme 37. Synthesis of the enantiopure menthyl-CAAC 1a with the key step

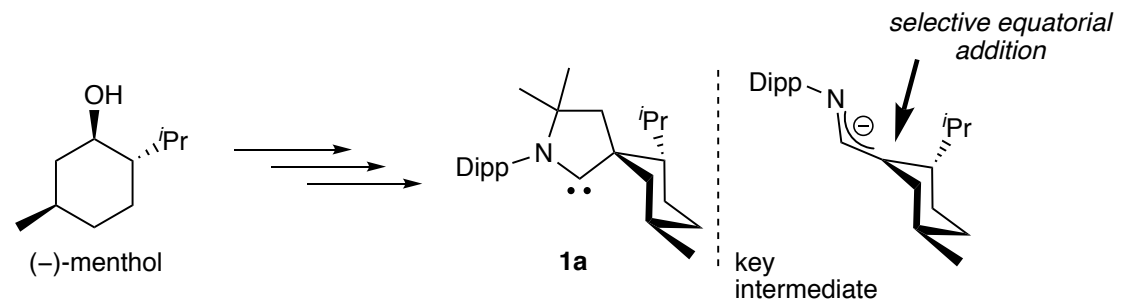

The menthyl-CAAC 1a was benchmarked in the copper-catalyzed asymmetric conjugate borylation reaction, a chemical transformation which allows for the preparation of very useful 
chiral organoboron building blocks. ${ }^{204,205}$ Although the menthyl CAAC copper complex 13a was very active in the addition of bis(pinacolato)diboron to various $\alpha, \beta$-unsaturated esters, an almost complete lack of asymmetric induction was observed (Scheme 38). In comparison, Hoveyda reported that the chiral NHC copper complex $\mathbf{7 4}$ gave $\beta$-boryl carbonyl compounds in up to $96 \%$ ee. ${ }^{206}$

\section{Scheme 38. Comparing menthylCAAC-CuCl 13a, NHC-CuCl 74 and cholesterolCAAC- $\mathrm{CuCl} 75$ in the asymmetric conjugate borylation reaction}
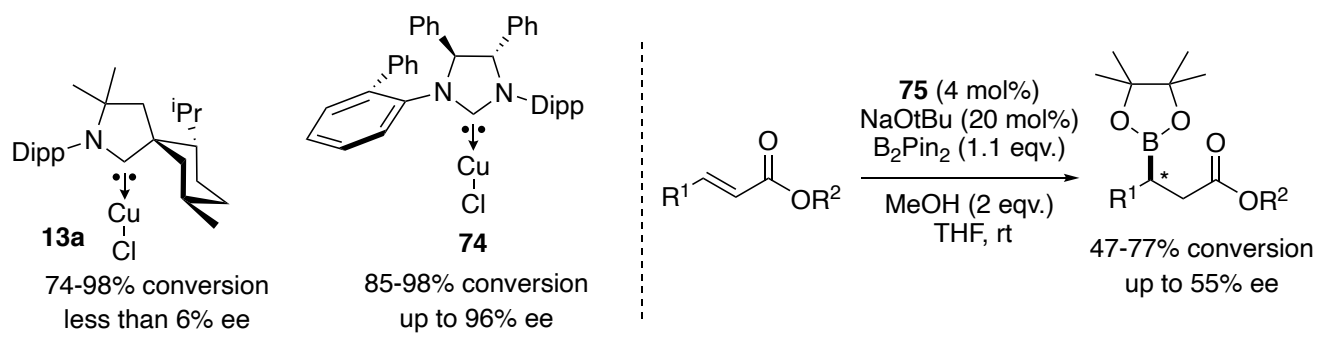

The absence of enantioselectivity observed with 13a is believed to be due to a conformational inversion of the menthyl ring, ${ }^{207}$ since the two conformers have antagonistic stereo-inducing effects (Figure 3).

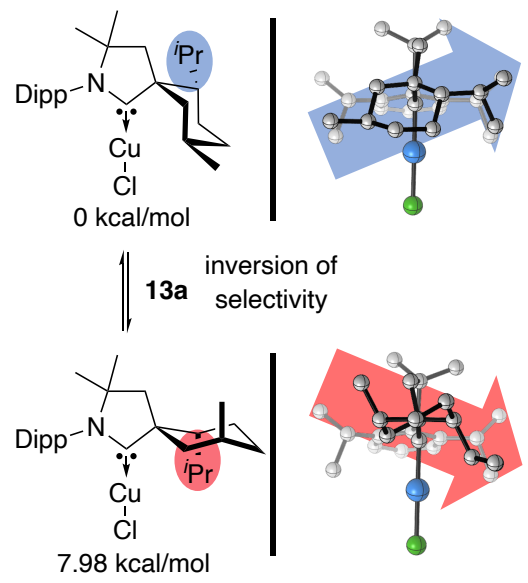

Figure 3. Proposed justification for the lack of asymmetric induction with catalyst 13a. Adapted with permission from ref 207. Copyright 2019 American Chemical Society.

To circumvent this issue, a more rigid chiral CAAC was prepared, using once again a precursor derived from the chiral pool, namely the 5a-cholestan-3-one. The X-ray data of the 
corresponding copper complex $\mathbf{7 5}$ show a distinctive orientation of the cholestanyl backbone, which gives rise to the topographic steric map showed in Figure 4. As can be seen, the corresponding quadrant diagram suggests facial stereoselectivity in catalyst-substrate adducts. As the menthylCAAC-CuCl $13 \mathrm{a}$, the cholesterolCAAC-CuCl 75 readily promotes the asymmetric conjugate borylation in moderate to good isolated yields (47 to $77 \%$ ), but with enantiomeric excesses reaching 55\% (Scheme 38).

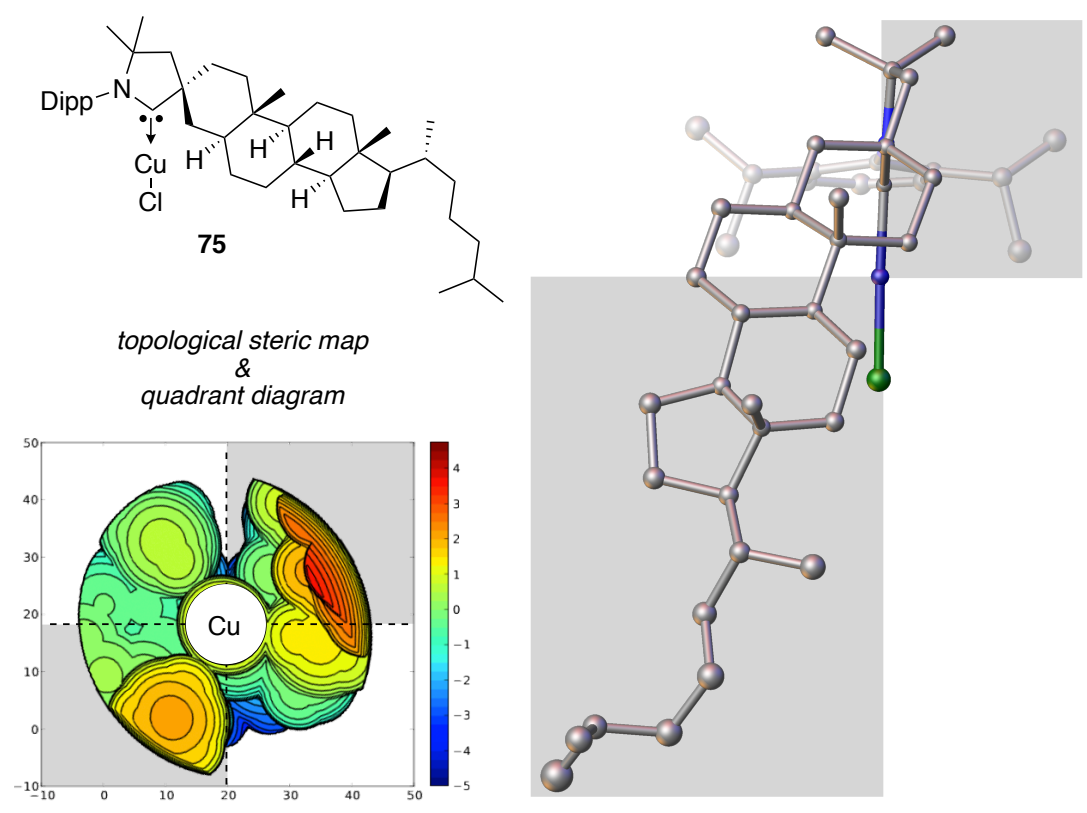

Figure 4. X-ray crystal structure of $\mathbf{7 5}$ and an overlaid topological steric map with a quadrant diagram. Adapted with permission from ref 207. Copyright 2019 American Chemical Society.

These results suggest that the use of chiral CAACs should not be overlooked in metalcatalyzed asymmetric transformations. These carbenes are readily available from precursors belonging to the chiral pool, not restricted to chiral amines (as for NHCs), but extends to chiral aldehydes, a much larger feedstock.

\section{BIOLOGICAL APPLICATIONS OF CYCLIC (ALKYL)(AMINO)CARBENE COINAGE METAL COMPLEXES}

The biological properties of coinage metal NHC complexes ( $\mathrm{NHC}=$ imidazol-2-ylidenes 7 and imidazolidin-2-ylidenes 8) have been widely investigated, and are the subject of numerous reviews. ${ }^{18,208,209,210,211}$ NHC-gold complexes show antimicrobial activity in several bacterial 
strains, they are antioxidant and antiparasitic agents that could be relevant in diseases such as leishmaniasis where there is no optimal drug treatment, and they have antitumor activity. NHCAg complexes have been shown to be effective against a wide range of both Gram-positive and Gram-negative bacterial strains, and they feature comparable or better antitumor activity than standard chemotherapeutics such as cisplatin and 5-fluorouracil.

The success of NHC-coinage metal complexes in medicinal applications has been rationalized by their great stability in biological media, which is due to their robustness towards ligand dissociation. Since cyclic (alkyl)- and (aryl)-(amino)carbene-coinage metal bonds are even stronger than those of NHCs, it seems reasonable to believe that these complexes could find medicinal applications. However, this field is still in its infancy.

In 2012, Huynh et al. ${ }^{212},{ }^{213}$ studied the cytotoxic activities of gold(I) and gold(III) complexes 76-79, bearing cyclic (amino)carbenes derived from pyrazoles, towards the NCI-H1666 non-small cell lung cancer cell line (Scheme 39). The neutral monocarbene complexes 76 and 78 displayed 2 orders of magnitude lower activity as compared to the cationic bis(carbenes) 77 and 79. This is in line with what has been previously referred to as delocalized lipophilic cations, which readily pass through the lipid membrane of mitochondria and eventually lead to mitochondriainduced apoptosis. Importantly, the cationic bis(carbene) complexes $\mathbf{7 7}$ and $\mathbf{7 9}$ showed better activities than cisplatin.

Similarly, in 2017, Bochmann et al. ${ }^{214}$ prepared a series mono- and bis-CAAC complexes of copper, silver and gold (Scheme 39). They were tested against a panel of human cancer cell lines including leukemia (HL 60), breast adenocarcinoma cells (MCF-7) and human lung adenocarcinoma epithelial cell lines (A549), which are known to have varying degrees of cisplatin resistance. These complexes appeared to be highly cytotoxic, with IC50 values in the submicromolar to $~ 100$ nanomolar range, even against cisplatin-insensitive MCF-7 and A549 cells. As in the case of complexes 76-79, cationic bis-carbene complexes of $\mathrm{Au}, \mathrm{Ag}$ and $\mathrm{Cu} \mathbf{1 1 f - 1 3 f}$ 
proved particularly effective with the mixed-carbene gold complex $\mathbf{8 0}$ being the most potent of the series (Scheme 39). Interestingly, the authors concluded that although the mechanism of cell growth control by these complexes remains to be established, the inhibition of thioredoxin reductase, which is a common pathway for gold NHC compounds could be ruled out as a primary pathway.

Scheme 39. Cationic bis(carbene) gold 77 and 79 displayed 2 orders of magnitude higher cytotoxicity than the neutral monocarbene complexes 76 and 78 , and are more potent than cisplatin towards the NCI-H1666 non-small cell lung cancer cell line. Cationic bis(carbenes) 11f-13f proved particularly effective against cisplatin-insensitive MCF-7 and A549 cells, the mixed-carbene gold complex 80 being the most potent of the series
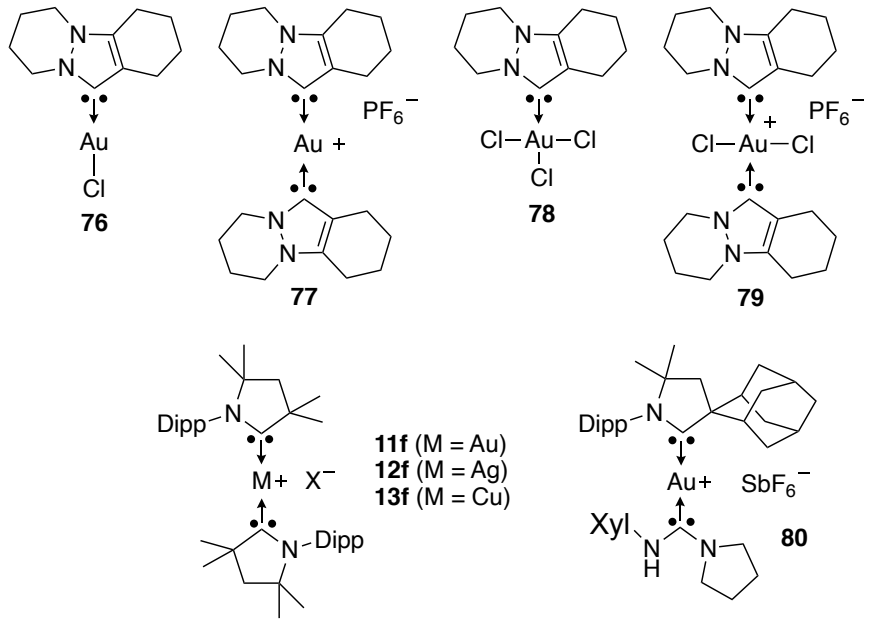

79

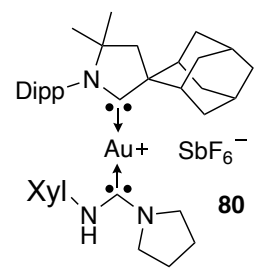

The CAAC-gold complexes, prepared via a cyclization-rearrangement cascade ${ }^{30}$ (Scheme 2), feature CAACs based on indole alkaloid scaffolds, which are by themselves often biologically active, including against cancer cells. It was found that complexes $\mathbf{8 1}$ displayed cytotoxicity towards the human ovarian cancer cell line A2780 and colorectal adenocarcinoma cell line HT29 at low micromolar or submicromolar concentration. Some of these complexes such as 81a appeared to have strong but nonselective anticancer activity against all cancer cell lines, while others displayed interesting selectivity (Scheme 40). For example, $\mathbf{8 1 b}$ is cytotoxic to HeLa cells and was the only complex active against the breast cancer cell line MCF7 in micromolar concentration. 
Scheme 40. Gold complexes based on indole alkaloid scaffolds. 81a displays strong but nonselective anticancer activity, while $81 \mathrm{~b}$ is cytotoxic to HeLa cells and the breast cancer cell line MCF7
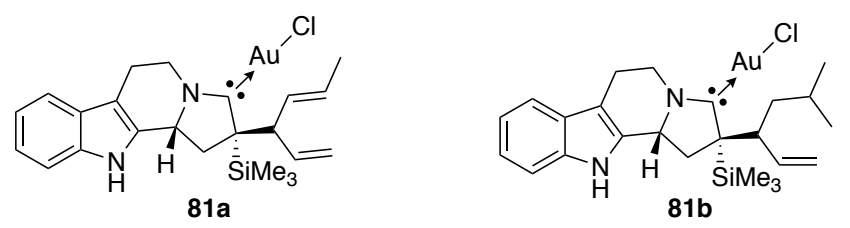

Overall, these preliminary investigations show that CAAC coinage metal complexes hold promise for medicinal applications.

\section{OPTOELECTRONIC APPLICATIONS OF CYCLIC (ALKYL)(AMINO)CARBENE COINAGE METAL COMPLEXES}

Since the pioneering discovery of electroluminescence by French chemist and physicist André Bernanose, ${ }^{215,216}$ and the preparation of an electroluminescent device using organic materials as the emitting element by Ching Tang and Steven Van Slyke at Eastman Kodak, ${ }^{217}$ Organic LightEmitting Diodes (OLEDs) have become vital components of many current technologies. In part due to their efficiency and greater contrast-ratio (black OLED emits no light), OLEDs are traditionally found in television and smartphone displays. However, with the advent of foldable and rollable OLED displays, or even 3D printing of transparent OLED displays, ${ }^{218}$ it is forecast that the global demand in light emitting OLED materials will double by 2023. Traditionally, these devices rely on expensive heavy transition metals such iridium, platinum, and ruthenium, as well as rare metal-based phosphors which intrinsically pose serious economical and sustainable challenges in a global economy. ${ }^{219}$ In recent years, focus has been put toward the development of $\mathrm{d}^{10}$-coinage metal alternatives which, aside from their low cost and low toxicity, are inherently more advantageous thanks to their fully filled $d$-orbitals which prevent internal quenching of excited states by low-lying $\mathrm{d}^{*}-\mathrm{d}$ transitions. ${ }^{220}$ In particular, three- and four-coordinate $\mathrm{Cu}(\mathrm{I})$ complexes bearing phosphine and $N$-heterocyclic ligands with good $\pi$-acceptor properties 
exhibiting low-lying metal-to-ligand charge-transfer (MLCT) and thermally activated delayed fluorescence (TADF) have been intensely investigated as emitting dopants in OLEDs. ${ }^{221,222}$ Recently, two-coordinate copper complexes with linear geometry $[(\mathrm{L}) \mathrm{CuX}]$, where $\mathrm{L}$ is a carbene and $\mathrm{X}$ an anionic ligand, have emerged as a new class of strongly photoemissive materials. ${ }^{223} \mathrm{In}$ 2016, Bochmann et al. observed that the adamantylCAAC-CuCl complex 13b displayed unexpected photoactivity $\left(\varnothing_{\mathrm{PL}}=96 \%\right.$ in the solid state) in marked contrast with the gold analogue 9b which was found to be comparatively inefficient (Scheme 41). ${ }^{224}$ As highlighted across several reports, the quantum yield in (CAAC) $\mathrm{CuCl}$ complexes is directly linked to the steric environment provided by the ligand in the order $\mathbf{1 3} \mathbf{b}^{225}>\mathbf{1 3} \mathbf{e}^{225,226}>\mathbf{1 3 f},{ }^{226,227}$ and is a consequence of the increased rigidity of the system. Moreover, these reports underline for the first time the unique properties of CAACs (i.e. stronger $\sigma$-donation destabilizing the $\mathrm{M}(\mathrm{d})$ orbitals and $\pi$ - acceptance stabilizing the LUMO) with respect to NHC ligands which are much less efficient. ${ }^{222}$

Scheme 41. The quantum yield in (CAAC)CuCl complexes is linked to the sterics $(\Phi$ : Quantum yield; $\mathrm{k}_{\mathrm{r}}$ : radiative rate constant)
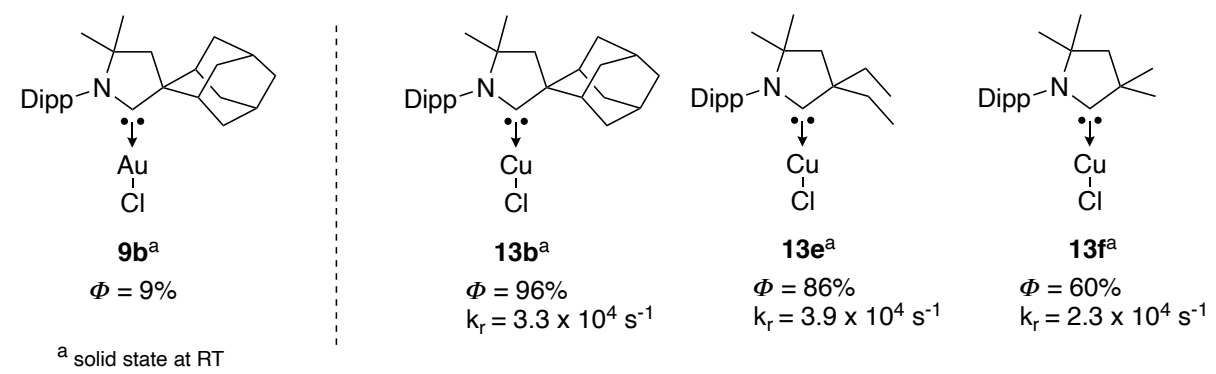

Examining the influence of the anionic ligand, Romanov et al. prepared the phenolato- 82, the thiopheno- $\mathbf{8 3}$ and the amido- $\mathbf{8 5}$ which displayed moderate photoactivity (Scheme 42);226 note that the later was reported by Steffen et al. to afford dimer $\mathbf{8 4}$ with the smaller CAAC 1f. ${ }^{227}$ However, a diverse array of anionic ligands have since been investigated with coordination geometries varying from hemilabile to linear-monodentate, including the formamidinato $\mathbf{8 6},{ }^{228}$ phenanthroline $\mathbf{8 7},{ }^{227}$ the trispyrazolylborate $\mathbf{8 8 - 8 9}^{225}$ derivatives, bis-CAAC $\mathbf{9 0}^{227}$ and 
zwitterionic mix-carbene $\mathbf{9 1},{ }^{229}$ all resulting in distinct changes in photophysical behavior. It is worth mentioning that the introduction of flexible electron-rich $\mathrm{N}$-donors such as the formamidinato 86 extends the photophysical properties toward the development of power-efficient white organic light-emitting diode (WOLEDs). ${ }^{228}$ With lighting accounting for $15 \%$ of global electricity consumption and $5 \%$ of worldwide greenhouse gas emissions, the production of WOLEDs based on abundant copper sources could have a substantial environmental and economical impact.

\section{Scheme 42. Influence of the anionic ligand on the quantum yields}
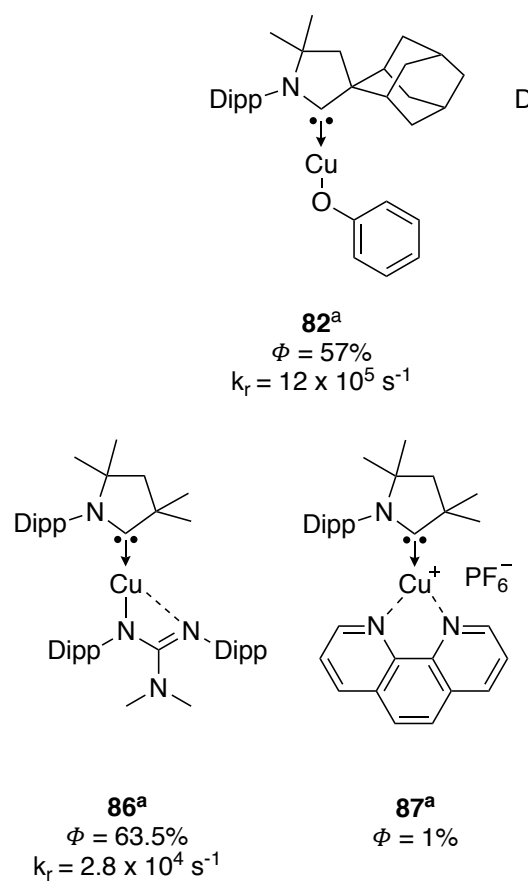
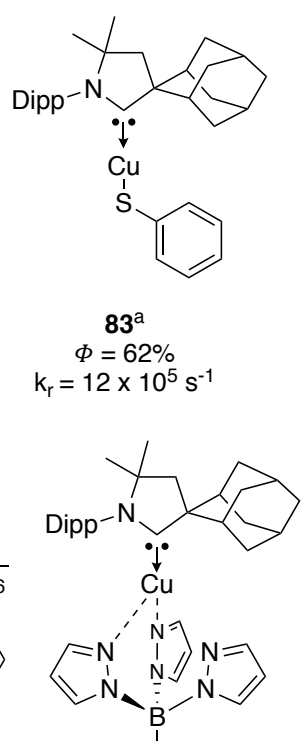

H

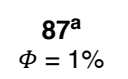

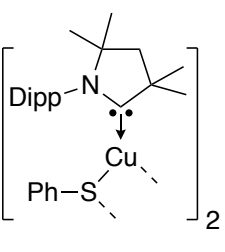
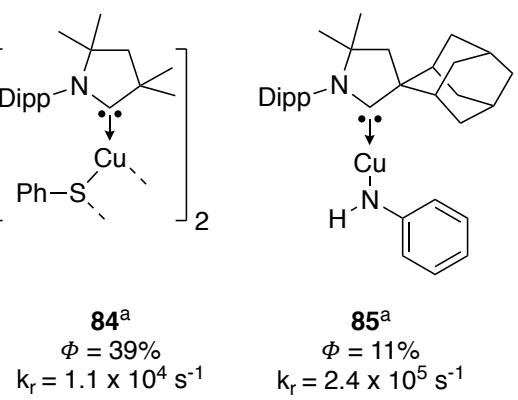

a solution
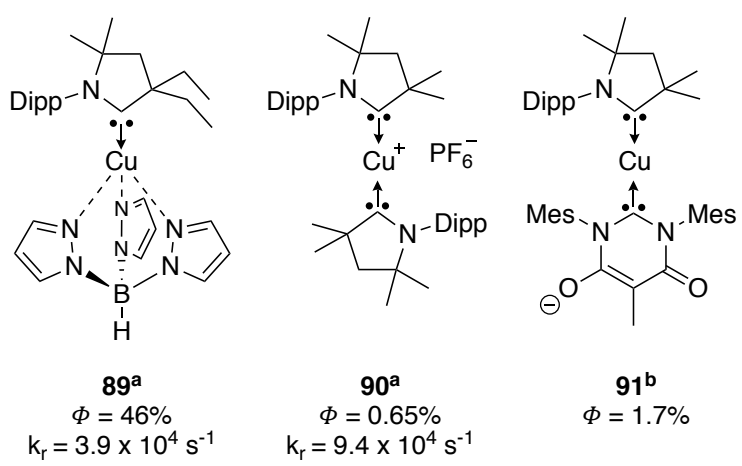

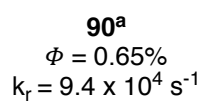

$91^{\mathrm{b}}$
$\Phi=1.7 \%$

Notwithstanding these promising reports, it is most likely the introduction of a second redox-active ligand, a carbazole moiety, that has so far yielded the most significant advancement in the field of coinage metal-based phosphors (Scheme 43). In 2017 and 2019, Di et al. and Thompson et al. respectively reported that both adamantyl- $\mathbf{1} \mathbf{b}^{230}$ and menthyl- $\mathbf{1}^{231}$ CAAC afford very emissive materials when bound to copper with an anionic carbazole moiety. Emission is also tailored to the rigidity of the ligand as in complexes $\mathbf{9 2 - 9 5}$. Initially believed to originate from rotationally 
assisted spin-state inversion, ${ }^{230}$ the luminescence properties of linear carbene-metal-amide (CMA) complexes were later shown to stem from thermally activated delayed fluorescence (TADF). This occurs through singlet ligand to ligand charge transfer (LLCT) between the electron rich carbazole (HOMO) and the electron-accepting carbene (LUMO). This is favored by a coplanar ligand conformation and coupling through the metal $d$ orbitals. ${ }^{231,232,233,234,235}$

\section{Scheme 43. Carbene metal amides emitters}
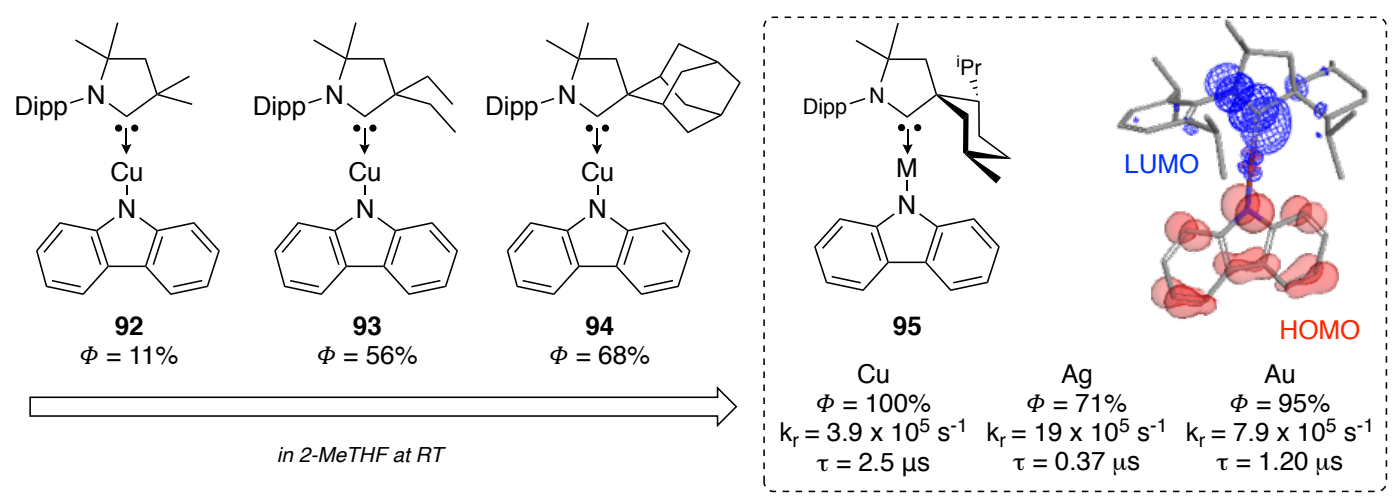

Thanks to these CMA emitters, OLEDs devices with external quantum efficiencies (EQEs) up to $25 \%$ have been reported with $\mathrm{Cu},{ }^{230,231}$ and $\mathrm{Au}^{236,237,238}$ but also with $\mathrm{Ag}^{25,239}$ As noted by Thompson et al. in a systematic study, ${ }^{240}$ despite blatant structural similarities, group 11 metals CMA emitters display marked photophysical differences. However, the metal ions in CMA are best described as redox "innocent" and only serve as a monatomic electronic conduit that modulates communication between the two redox active ligands. Capitalizing on these properties, emissions across the visible spectrum are readily achieved by simple modification of the carbazole moiety. ${ }^{231}$ In fact, by combining (1b)gold with sulfone 96, dibenzazepine 97, phenothiazine 98, phenoxazine 99 or phenazine 100, as conformationally flexible 7-membered carbazole surrogates, Romanov et al. could tune the luminescence from blue to deep red (Scheme 43). ${ }^{241}$ Note that with these non-rigid anionic ligands, copper analogues were found to be less emissive as illustrated by $96\left[\emptyset_{\mathrm{PL}}=89.6 \%(\mathrm{Au})\right.$ vs. $49.5 \%(\mathrm{Cu})$ - in toluene $]$. This observation was proposed to parallel the 
lower oscillator strength coefficients for the $S_{1} \rightarrow S_{0}$ transition as well as smaller contribution of the copper orbitals into the LUMO with respect to the gold analogues.

\section{Scheme 44. Tuning the luminescence from blue to deep red}

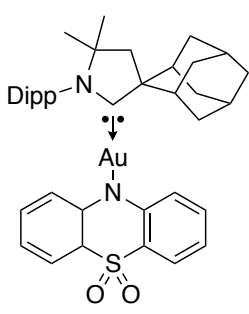

96

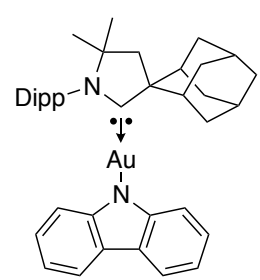

94

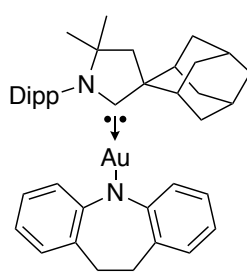

97

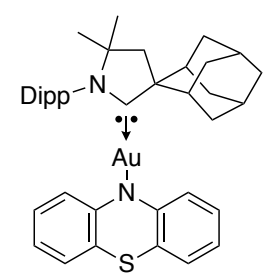

98

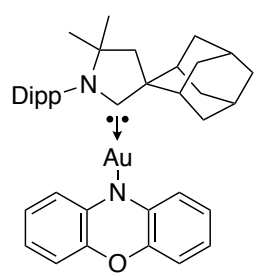

99

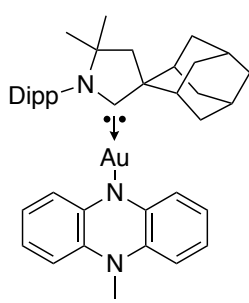

100

A similar effect was also observed in carbazole dendrimers $\mathbf{1 0 1},{ }^{242}$ which thanks to their excellent thermal stability and solubility allowed for the fabrication of solution-processed OLEDs (EQEs = $10 \%$; practical brightness of $1000 \mathrm{~cd} / \mathrm{m}^{2}$; maximum luminance of $29000 \mathrm{~cd} / \mathrm{m}^{2}$ ). As suggested by the authors, the physical properties displayed by these dendridic complexes could be suitable for the engineering of flexible OLEDs through inkjet or roll-to-roll printing. ${ }^{243}$

\section{Scheme 45. Dendridic phosphor emitters}

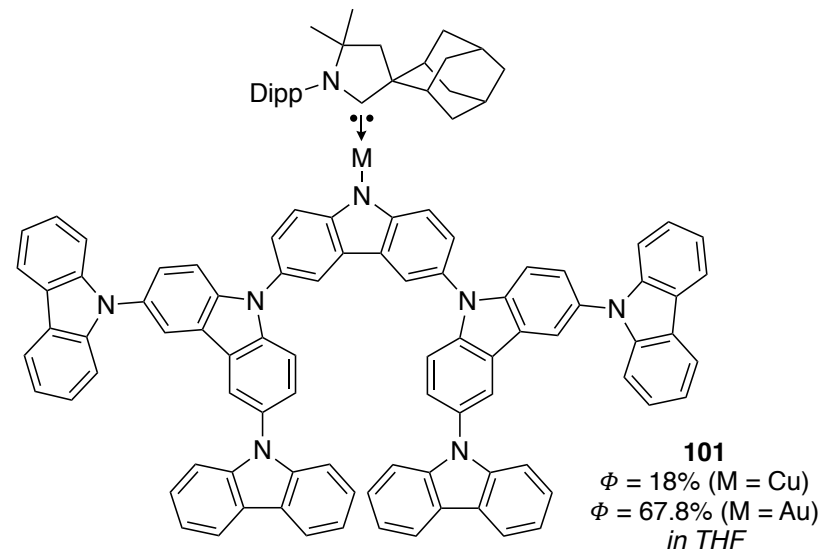

Recently, Ung et al. opened new avenues in the field of polarized OLEDS in demonstrating that the chiral framework of the menthylCAAC 1a allows for yellow circularly polarized luminescence 
(CPL) in copper complexes 102 (Scheme 46). ${ }^{244}$ Note that until this report, transition metal complexes exhibiting CPL were mainly limited to helical or axially chiral species. ${ }^{245,246}$

\section{Scheme 46. Chiral CAAC-Cu complexes for circularly polarized luminescence}

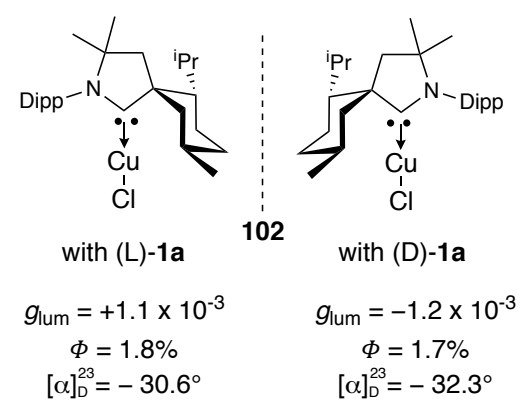

We can expect that the broad range of CAACs, ${ }^{6}$ and especially the emergence of original chiral CAACs motifs, ${ }^{203}$ should allow for further discoveries in the field of CMA emitters and efficient chiral CMA CPL emitters.

\section{CONCLUSIONS AND OUTLOOK}

Classical NHC (imidazol-2-ylidenes and imidazolidin-2 ylidenes) gold complexes have been described as early as $1973,{ }^{247}$ and their silver and copper complexes in $1993 .{ }^{248}$ In marked contrast, the first members of CAAC and CAArC coinage metal complexes have only been reported in $2008^{24}$ and $2015,{ }^{12}$ respectively. Nevertheless, despite their much more recent discovery, they have already found numerous applications, which are mainly the result of their peculiar steric and electronic properties. These carbenes, initially used in the isolation of low valent metals, have shined in the stabilization of transient catalytic intermediates, such as bis(copper)acetylides, the active catalytic species of the CuAAC Click reaction. The isolation of these species has led to a better understanding of reaction mechanisms, but more importantly to the discovery of new catalytic reactions, such as the copper catalyzed dehydroborylation of alkynes. The stability of CAAC-coinage metal complexes allowed for carrying out reactions under very drastic conditions, and thus to perform very difficult chemical transformations such as the hydroamination of alkynes 
and allenes with ammonia and parent hydrazine. In addition to their uses in catalysis, recent results show that their applications in medicinal and materials science holds an even greater potential. Notably, the extent of the recent breakthroughs made in the preparation of efficient coinage metal OLEDs could have a tangible technological impact on our society.

Altogether, we believe that the results summarized in this review article will lead to even more innovations with the newer members of the CAAC ligand family, namely, the bicyclic CAACs (BiCAACs), the 6-membered CAACs (CAAC-6), the aryl versions (CAArCs), the chiral ChiCAACs, and the bidentate CAACs (BICAACs).

\section{AUTHOR INFORMATION}

\section{ORCID}

Rodolphe Jazzar: 0000-0002-4156-7826

Michele Soleilhavoup: 0000-0001-5339-921X

Guy Bertrand: 0000-0003-2623-2363

\section{Notes}

The authors declare no competing interest.

\section{Biographies}

Rodolphe Jazzar was an undergraduate at the University of Poitiers and Liverpool, before obtaining his $\mathrm{PhD}$ in 2003 under the supervision of Prof. M. Whittlesey from the University of Bath. Following postdoctoral positions with Prof. E. P. Kündig (University of Geneva) and Prof. G. Bertrand (UC Riverside), he joined the CNRS in 2008 as a research fellow working in the field of $\mathrm{C}\left(\mathrm{sp}^{3}\right)$-H activation in collaboration with Prof. O. Baudoin (UCB Lyon). In 2014, he moved to the UCSD/CNRS Laboratory at the University of California, San Diego. Capitalizing on a 
mechanistic approach, his research interests are aimed toward the development of new catalytic methodologies, especially the enantioselective versions, using CAACs and other carbene ligands.

Michèle Soleilhavoup studied chemistry at the University Paul Sabatier in Toulouse and received her PhD in 1993 under the supervision of Guy Bertrand. From 1993 to 1995, she worked for BASF AG at Ludwigshafen. In 1995, she moved to the University Paris VI as a "Chargée de Recherche CNRS”, and from 2000 to 2001, she worked in the Remi Chauvin's group at the Laboratoire de Chimie de Coordination in Toulouse. In 2002, she joined the UCR/ CNRS Joint Research Laboratory at the University of California, Riverside and in 2012 the UCSD/CNRS Laboratory at the University of California, San Diego. Her current research interests are focused on the chemistry of carbenes and their application as tunable ligands for transition metal catalysts.

Guy Bertrand was an undergraduate in Montpellier, and obtained his PhD from the University of Toulouse. From 1988 to 1998 he was a "Director of Research" at the Laboratoire de Chimie de Coordination du CNRS, and from 1998 to 2005 the Director of the Laboratoire d'Hétérochimie Fondamentale et Appliquée at the University Paul Sabatier (Toulouse). From 2001 to 2012 he has been at the University of California at Riverside, and since 2012 he is Distinguished Professor and Director of the UCSD/CNRS Joint Research Laboratory at the University of California, San Diego. His research spans a wide range of topics at the border between organic and inorganic chemistry. He is a member of the French Academy of Sciences.

\section{ACKNOWLEDGMENTS}

Our work on CAAC-coinage metal complexes was supported by the US National Science Foundation (CHE-1661518) and the U.S. Department of Energy, Office of Science, Basic Energy 
Sciences, Catalysis Science Program, under Award \# DE-SC0009376. We are grateful to our dedicated coworkers who are co-authors of the papers cited in this review. 


\section{REFERENCES}

( 1 ) Lavallo, V.; Canac, Y.; Prasang, C.; Donnadieu, B.; Bertrand, G. Stable Cyclic (Alkyl)(Amino)Carbenes as Rigid or Flexible, Bulky, Electron-Rich Ligands for Transition-Metal Catalysts: A Quaternary Carbon Atom Makes the Difference. Angew. Chem. Int. Ed. 2005, 44, $5705-5709$.

( 2 ) Lavallo, V.; Canac, Y.; DeHope, A.; Donnadieu, B.; Bertrand, G. A Rigid Cyclic (Alkyl)(Amino) Carbene Ligand Leads to Isolation of Low-Coordinate Transition-Metal Complexes. Angew. Chem. Int. Ed. 2005, 44, 7236-7239.

(3) Melaimi, M.; Soleilhavoup, M.; Bertrand, G. Stable Cyclic Carbenes and Related Species beyond Diaminocarbenes. Angew. Chem. Int. Ed. 2010, 49, 8810-8849.

(4) Soleilhavoup, M.; Bertrand, G. Cyclic (Alkyl)(Amino)Carbenes (CAACs): Stable Carbenes on the Rise. Acc. Chem. Res. 2015, 48, 256-266.

(5) Roy, S.; Mondal, K. C.; Roesky, H. W. Cyclic Alkyl(amino) Carbene Stabilized Complexes with Low Coordinate Metals of Enduring Nature. Acc. Chem. Res. 2016, 49, 357-369.

(6) Melaimi, M.; Jazzar, R.; Soleilhavoup, M.; Bertrand, G. Cyclic (Alkyl)(amino)carbenes (CAACs): Recent Developments. Angew. Chem. Int. Ed. 2017, 56, 10046-10068.

( 7 ) Paul, U. S. D.; Radius, U. What Wanzlick Did Not Dare To Dream: Cyclic (Alkyl)(amino)carbenes (cAACs) as New Key Players in Transition-Metal Chemistry. Eur. J. Inorg. Chem. 2017, 3362-3375.

( 8 ) Kundu, S.; Sinhababu, S.; Chandrasekhar, V.; Roesky, H. W. Stable Cyclic (Alkyl)(Amino)Carbene (Caac) Radicals with Main Group Substituents. Chem. Sci. 2019, 10, $4727-4741$. 
(9) Weinstein, C. M.; Junor, G. P.; Tolentino, D. R.; Jazzar, R.; Melaimi, M.; Bertrand, G., Highly Ambiphilic Room Temperature Stable Six-Membered Cyclic (Alkyl)(amino)carbenes. J. Am. Chem. Soc. 2018, 140, 9255-9260.

(10) Tomas-Mendivil, E.; Hansmann, M. M.; Weinstein, C. M.; Jazzar, R.; Melaimi, M.; Bertrand, G., Bicyclic (Alkyl)(amino)carbenes (BICAACs): Stable Carbenes more Ambiphilic than CAACs. J. Am. Chem. Soc. 2017, 139, 7753-7756.

(11) Hashmi, A. S. K.; Riedel, D.; Rudolph, M.; Rominger, F.; Oeser, T. Regioselective Formation of Saturated Abnormal NHC-Gold(I) Complexes by [3+2] Cycloaddition of Azomethine Ylides and Isonitrile Gold(I) Complexes. Chem. Eur. J. 2012, 18, 3827-3830.

( 12 ) Rao, B.; Tang, H.; Zeng, X.; Liu, L.; Melaimi, M.; Bertrand, G., Cyclic (Amino)(aryl)carbenes (CAArCs) as Strong sigma-Donating and pi-Accepting Ligands for Transition Metals. Angew. Chem. Int. Ed. 2015, 54, 14915-14919.

(13) Jothibasu, R.; Huynh, H. V., Versatile Coordination Chemistry of Indazole-Derived Carbenes. Chem. Commun. 2010, 46, 2986-2988.

(14) Danopoulos, A. A.; Simler, T.; Braunstein, P. N-Heterocyclic Carbene Complexes of Copper, Nickel, and Cobalt. Chem. Rev. 2019, 119, 3730-3961.

(15) Trose, M.; Nahra, F.; Cazin, C. S. J. Dinuclear N-Heterocyclic Carbene Copper(I) Complexes. Coord. Chem. Rev. 2018, 355, 380-403.

(16) Lazreg, F.; Nahra, F.; Cazin, C. S. J. Copper-NHC Complexes in Catalysis. Coord. Chem. Rev. 2015, 293, 48-79.

(17) Nolan, S. P. The Development and Catalytic Uses of N-Heterocyclic Carbene Gold Complexes. Acc. Chem. Res. 2012, 44, 91-100.

(18) Mora, M.; Concepcion-Gimeno, M. C.; Visbal, R. Recent Advances in Gold-NHC Complexes with Biological Properties. Chem. Soc. Rev. 2019, 48, 447-462. 
(19) Marinelli, M.; Santini, C.; Pellei, M. Recent Advances in Medicinal Applications of CoinageMetal (Cu and Ag) N-Heterocyclic Carbene Complexes. Curr. Top. Med. Chem. 2016, 16, 29953017.

(20) Arduengo, A. J., III; Harlow, R. L.; Kline, M. A Stable Crystalline Carbene. J. Am. Chem. Soc. 1991, 113, 361-363.

(21) Arduengo, A. J. III; Goerlich, J. R.; Marshall, W. J. A Stable Diaminocarbene. J. Am. Chem. Soc. 1995, 117, 11027-11028.

(22) See also: Gaggioli, C. A.; Bistoni, G.; Ciancaleoni, G.; Tarantelli, F.; Belpassi, L.; Belanzoni, P., Modulating the Bonding Properties of N-Heterocyclic Carbenes (NHCs): A Systematic ChargeDisplacement Analysis. Chem. Eur. J. 2017, 23, 7558-7569.

(23) Hudnall, T. W.; Bielawski, C. W. An $N, N^{\prime}$-Diamidocarbene: Studies in C-H Insertion, Reversible Carbonylation, and Transition-Metal Coordination Chemistry. J. Am. Chem. Soc. 2009, $131,16039-16041$.

( 24 ) Frey, G. D.; Dewhurst, R. D.; Kousar, S.; Donnadieu, B.; Bertrand, G., Cyclic (Alkyl)(amino)carbene Gold(I) Complexes: A Synthetic and Structural Investigation. J. Organomet. Chem. 2008, 693, 1674-1682.

(25) Romanov, A. S.; Bochmann, M., Synthesis, Structures and Photoluminescence Properties of Silver Complexes of Cyclic (Alkyl)(amino)carbenes. J. Organomet. Chem. 2017, 847, 114-120.

(26) Hu, X.; Soleilhavoup, M.; Melaimi, M.; Chu, J.; Bertrand, G., Air-Stable (CAAC)CuCl and (CAAC)CuBH4 Complexes as Catalysts for the Hydrolytic Dehydrogenation of BH3NH3. Angew. Chem. Int. Ed. 2015, 54, 6008-6011.

(27) Bidal, Y. D.; Lesieur, M.; Melaimi, M.; Nahra, F.; Cordes, D. B.; Arachchige, K. S. A.; Slawin, A. M. Z.; Bertrand, G.; Cazin, C. S. J., Copper(I) Complexes Bearing Carbenes Beyond Classical N-Heterocyclic Carbenes: Synthesis and Catalytic Activity in "Click Chemistry". Adv.

Synth. \& Catal. 2015, 357, 3155-3161. 
(28) Wang, H. M. J.; Lin, I. J. B. Facile Synthesis of Silver(I)-Carbene Complexes. Useful Carbene Transfer Agents. Organometallics 1998, 17, 972-975.

(29) Bidal, Y. D.; Santoro, O.; Melaimi, M.; Cordes, D. B.; Slawin, A. M.; Bertrand, G.; Cazin, C. S., Generalization of the Copper to Late-Transition-Metal Transmetallation to Carbenes beyond N-Heterocyclic Carbenes. Chem. Eur. J. 2016, 22, 9404-9409.

(30) Kolundzic, F.; Murali, A.; Perez-Galan, P.; Bauer, J. O.; Strohmann, C.; Kumar, K.; Waldmann, H., A Cyclization-Rearrangement Cascade for the Synthesis of Structurally Complex Chiral Gold(I)-Aminocarbene Complexes. Angew. Chem. Int. Ed. 2014, 53, 8122-8126.

( 31 ) Romanov, A. S.; Bochmann, M. Gold(I) and Gold(III) Complexes of Cyclic (Alkyl)(amino)carbenes. Organometallics, 2015, 34, 2439-2454.

(32) (a) Gaillard, S.; Slawin, A. M. Z.; Nolan, S. P. A N-Heterocyclic Carbene Gold Hydroxide Complex: A Golden Synthon. Chem. Commun. 2010, 46, 2742-2744.

(33) Tsui, E. Y.; Muller, P.; Sadighi, J. P. Reactions of a Stable Monomeric Gold(I) Hydride Complex. Angew. Chem. Int. Ed. 2008, 47, 8937-8940.

(34) Hashmi, A. S. K. Fire and Ice: A Gold(III) Monohydride. Angew. Chem. Int. Ed. 2012, 51, 12935-12936.

(35) Jordan, A. J.; Lalic, G.; Sadighi, J. P. Coinage Metal Hydrides: Synthesis, Characterization, and Reactivity. Chem. Rev. 2016, 116, 8318-8372.

(36) Mahoney, W. S.; Brestensky, D. M.; Stryker, J. M. Selective Hydride-Mediated Conjugate Reduction of .Alpha.,.Beta.-Unsaturated Carbonyl Compounds Using $\left[\left(\mathrm{Ph}_{3} \mathrm{P}\right) \mathrm{CuH}\right]_{6 .}$.J. Am. Chem. Soc. 1988, 110, 291-293.

(37) Romero, E. A.; Olsen, P. M.; Jazzar, R.; Soleilhavoup, M.; Gembicky, M.; Bertrand, G. Spectroscopic Evidence for a Monomeric Copper(I) Hydride, and Crystallographic Characterization of a Monomeric Silver(I) Hydride. Angew. Chem. Int. Ed. 2017, 56, 4024-4027. 
(38) Hussong, M. W.; Hoffmeister, W. T.; Rominger, F.; Straub, B. F. Copper and Silver Carbene

Complexes without Heteroatom-Stabilization: Structure, Spectroscopy, and Relativistic Effects. Angew. Chem. Int. Ed. 2015, 54, 10331-10335.

(39) Mankad, N. P.; Laitar, D. S.; Sadighi, J. P. Synthesis, Structure, and Alkyne Reactivity of a Dimeric (Carbene)copper(I) Hydride. Organometallics 2004, 23, 3369-3371.

(40) Welle, A.; Diez-Gonzalez, S.; Tinant, B.; Nolan, S. P.; Riant, O. A Three-Component Tandem Reductive Aldol Reaction Catalyzed by N-Heterocyclic Carbene-Copper Complexes. Org. Lett. 2006, 8, 6059-6062.

(41) Jordan, A. J.; Wyss, C. M.; Bacsa, J.; Sadighi, J. P. Synthesis and Reactivity of New Copper(I) Hydride Dimers. Organometallics 2016, 35, 613-616.

(42) Frey, G. D.; Donnadieu, B.; Soleilhavoup, M.; Bertrand, G., Synthesis of A RoomTemperature-Stable Dimeric Copper(I) Hydride. Chem. Asian. J. 2011, 6, 402-405.

(43) Ung, G.; Bertrand, G., Beta- and Alpha-Hydride Abstraction in Gold(I) Alkyl Complexes. Angew. Chem. Int. Ed. 2013, 52, 11388-11391.

(44) Harris, R. J.; Widenhoefer, R. A. Synthesis, Structure, and Reactivity of a Gold Carbenoid Complex That Lacks Heteroatom Stabilization. Angew. Chem. Int. Ed. 2014, 53, 9369-9371.

(45) Harris, R.; Widenhoefer, R. Gold Carbenes, Gold-Stabilized Carbocations, and Cationic Intermediates Relevant to Gold-Catalysed Enyne Cycloaddition. Chem. Soc. Rev. 2016, 45, 45334551

(46) Hussong, M. W.; Rominger, F.; Kramer, P.; Straub, B. F. Isolation of a Non-HeteroatomStabilized Gold-Carbene Complex. Angew. Chem. Int. Ed. 2014, 53, 9372-9375.

(47) Sarria Toro, J. M.; García-Morales, C.; Raducan, M.; Smirnova, E. S.; Echavarren, A. M. Gold(I) Carbenoids: On-Demand Access to Gold(I) Carbenes in Solution. Angew. Chem. Int. Ed. 2017, 129, 1859-1863. 
(48) Werle, C.; Goddard, R.; Fürstner, A., The First Crystal Structure of a Reactive Dirhodium Carbene Complex and a Versatile Method for the Preparation of Gold Carbenes by Rhodium-toGold Transmetalation. Angew. Chem. Int. Ed. 2015, 54, 15452-15456.

(49) Wang, Y.; Muratore, M. E.; Echavarren, A. M. Gold Carbene or Carbenoid: Is There a Difference? Chem. Eur. J. 2015, 21, 7332-7339.

(50) Joost, M.; Estevez, L.; Mallet-Ladeira, S.; Miqueu, K.; Amgoune, A.; Bourissou, D. Enhanced pi-Backdonation from Gold(I): Isolation of Original Carbonyl and Carbene Complexes. Angew. Chem. Int. Ed. 2014, 53, 14512-14516.-2021.

( 51 ) Jin, L.; Tolentino, D. R.; Melaimi, M.; Bertrand, G. Isolation of Bis(copper) Key Intermediates in Cu-Catalyzed Azide-Alkyne "Click Reaction". Sci. Adv. 2015, 1, e1500304.

(52) Worrell, B. T., Malik, J. A., Fokin, V. V. Direct Evidence of a Dinuclear Copper Intermediate in $\mathrm{Cu}(\mathrm{I})-$ Catalyzed Azide-Alkyne Cycloadditions. Science 2013, 340, 457-460.

(53) Kolb, H. C.; Finn, M. G.; Sharpless, K. B. Click Chemistry: Diverse Chemical Function from a Few Good Reactions. Angew. Chem. Int. Ed. 2001, 40, 2004-2021.

(54) Hein, J. E.; Fokin, V. V. Copper-Catalyzed Azide-Alkyne Cycloaddition (Cuaac) and Beyond: New Reactivity of Copper(I) Acetylides. Chem. Soc. Rev. 2010, 39, 1302-1315.

(55) Meldal, M.; Tornoe, C. W. Cu-Catalyzed Azide-Alkyne Cycloaddition. Chem. Rev. 2008, $108,2952-3015$.

(56) Nolte, C.; Mayer, P.; Straub, B. F. Isolation of a Copper(I) Triazolide: A “Click” Intermediate. Angew. Chem. Int. Ed. Engl. 2007, 46, 2101-2103.

(57) Lavallo, V.; Frey, G. D.; Kousar, S.; Donnadieu, B.; Bertrand, G., Allene Formation by Gold Catalyzed Cross-Coupling of Masked Carbenes and Vinylidenes. Proc. Natl. Acad. Sci. 2007, 104, 13569-13573.

(58) Herrero-Gomez, E.; Nieto-Oberhuber, C.; Lopez, S.; Benet-Buchholz, J.; Echavarren, A. M. Cationic $\eta 1 / \eta 2-G o l d(I)$ Complexes of Simple Arenes. Angew. Chem. Int. Ed. 2006, 45, 5455-5459. 
(59) Goicoechea, J. M.; Grützmacher, H. The Chemistry of the 2-Phosphaethynolate Anion. Angew. Chem. Int. Ed. 2018, 57, 16968-16994.

(60) Liu, L.; Ruiz, D. A.; Dahcheh, F.; Bertrand, G.; Suter, R.; Tondreau, A. M.; Grützmacher, H., Isolation of Au-, Co- $\eta^{1} \mathrm{PCO}$ and $\mathrm{Cu}-\eta^{2} \mathrm{PCO}$ Complexes, Conversion of an Ir- $\eta^{1} \mathrm{PCO}$ Complex into a Dimetalladiphosphene, and an Interaction-Free PCO Anion. Chem. Sci. 2016, 7, 2335-2341

(61) Back, O.; Henry-Ellinger, M.; Martin, C. D.; Martin, D.; Bertrand, G., ${ }^{31}$ P NMR Chemical Shifts of Carbene-Phosphinidene Adducts as an Indicator of the $\pi$-Accepting Properties of Carbenes. Angew. Chem. Int. Ed. 2013, 52, 2939-2943.

(62) Liske, A.; Verlinden, K.; Buhl, H.; Schaper, K.; Ganter, C., Determining the $\pi$-Acceptor Properties of N-Heterocyclic Carbenes by Measuring the ${ }^{77}$ Se NMR Chemical Shifts of Their Selenium Adducts. Organometallics 2013, 32, 5269-5272.

(63) Martin, C. D.; Soleilhavoup, M.; Bertrand, G. Carbene-Stabilized Main Group Radicals and Radical Ions. Chem. Sci. 2013, 4, 3020-3030.

( 64 ) Kundu, S.; Sinhababu, S.; Chandrasekhar, V.; Roesky, H. W. Stable Cyclic (Alkyl)(amino)carbene (Caac) Radicals with Main Group Substituents. Chem. Sci. 2019, 10, 47274741 .

(65) Weinberger, D. S.; Melaimi, M.; Moore, C. E.; Rheingold, A. L.; Frenking, G.; Jerabek, P.; Bertrand, G., Isolation of Neutral Mono- and Dinuclear Gold Complexes of Cyclic (Alkyl)(amino)carbenes. Angew. Chem. Int. Ed. 2013, 52, 8964-8967.

(66) Weinberger, D. S.; Amin Sk, N.; Mondal, K. C.; Melaimi, M.; Bertrand, G.; Stuckl, A. C.; Roesky, H. W.; Dittrich, B.; Demeshko, S.; Schwederski, B.; Kaim, W.; Jerabek, P.; Frenking, G., Isolation of Neutral Mononuclear Copper Complexes Stabilized by Two Cyclic (Alkyl)(amino)carbenes. J. Am. Chem. Soc. 2014, 136, 6235-6238. 
(67) Jerabek, P.; Roesky, H. W.; Bertrand, G.; Frenking, G. Coinage Metals Binding as Main Group Elements: Structure and Bonding of the Carbene Complexes [TM(cAAC)(2)) and $[\mathrm{TM}(\mathrm{cAAC})(2)](+)(\mathrm{TM}=\mathrm{Cu}, \mathrm{Ag}, \mathrm{Au}) J$. Am. Chem. Soc. 2014, 136, 17123-17135.

(68) Landis, C. R.; Hughes, R. P.; Weinhold, F. Bonding Analysis of TM(cAAC) $2(\mathrm{TM}=\mathrm{Cu}$, $\mathrm{Ag}$, and $\mathrm{Au}$ ) and the Importance of Reference State. Organometallics 2015, 34, 3442-3449.

(69) Schwerdtfeger, P.; Boyd, P. D. W. Role of Phosphine Ligands in Gold Cluster Chemistry. Relativistic SCF Calculations on $\mathrm{Au}_{2}$ And $\mathrm{Au}_{2}\left(\mathrm{PH}_{3}\right)_{2}$. Inorg. Chem. 1992, 31, 327-329.

(70) Raubenheimer, H. G. ; Schmidbaur, H. Gold Chemistry Guided by the Isolobality Concept. Organometallics 2012, 31, 2507-2522.

(71) Briant, C. E.; Hall, K. P.; Mingos, D. M. P. Synthesis and Structural Characterisation of $\left[\mathrm{Au}_{6}\left(\mathrm{Pph}_{3}\right)_{6}\right]-\left(\mathrm{NO}_{3}\right)_{2} \cdot 3 \mathrm{CH}_{2} \mathrm{Cl}_{2} ;$ An Edge-Shared Bitetrahedral Gold Cluster. J. Organomet. Chem. 1983, 254, C18-C20

(72) Zeller, E.; Beruda, H.; Schmidbaur, H. Tetrahedral Gold Cluster $\left[\mathrm{Au}_{4}\right]^{2+}$ : Crystal Structure of $\left\{\left[(\text { tert-Bu })_{3} \mathrm{PAu}\right]_{4}\right\}^{2+}\left(\mathrm{BF}_{4}^{-}\right)_{2}$. $2 \mathrm{CHCl}_{3}$. Inorg. Chem. 1993, 32, 3203-3204.

(73) Tsui, E. Y.; Muller, P.; Sadighi, J. P. Reactions of a Stable Monomeric Gold(I) Hydride Complex. Angew. Chem. Int. Ed. 2008, 47, 8937-8940.

(74) Jin, L.; Melaimi, M.; Kostenko, A.; Karni, M.; Apeloig, Y.; Moore, C. E.; Rheingold, A. L.; Bertrand, G., Isolation of Cationic and Neutral (Allenylidene)(carbene) and Bis(allenylidene)gold Complexes. Chem. Sci. 2016, 7, 150-154.

(75) Roh, S. W.; Choi, K.; Lee, C. Transition Metal Vinylidene- and Allenylidene-Mediated Catalysis in Organic Synthesis. Chem. Rev. 2019, 119, 4293-4356.

(76) Hansmann, M. M.; Rominger, F.; Hashmi, A. S. K. Gold-Allenylidenes - An Experimental and Theoretical Study. Chem. Sci. 2013, 4, 1552-1559. 
(77) Xiao, X. S.; Kwong, W. L.; Guan, X.; Yang, C.; Lu, W.; Che, C. M. Platinum(II) and Gold(III) Allenylidene Complexes: Phosphorescence, Self-Assembled Nanostructures and Cytotoxicity. Chem. - Eur. J. 2013, 19, 9457-9462.

(78) Asay, M.; Donnadieu, B.; Schoeller, W. W.; Bertrand, G. Synthesis of Allenylidene Lithium and Silver Complexes, and Subsequent Transmetalation Reactions. Angew. Chem. Int. Ed. 2009, 48, 4796-4799.

(79) Kessler, F.; Weibert, B.; Fischer, H. Bis(allenylidene) Complexes of Palladium and Platinum. Organometallics 2010, 29, 5154-5161.

(80) Rigaut, S.; Costuas, K.; Touchard, D.; Saillard, J. Y.; Golhen, S.; Dixneuf, P. H. Bisallenylidene Metal Complex and Unique Related Radical with Delocalization of One Electron over Both Trans Carbon-Rich Chains. J. Am. Chem. Soc. 2004, 126, 4072-4073.

(81) Jin, R. C.; Zeng, C. J. Zhou, M.; Chen, X. Y. Atomically Precise Colloidal Metal Nanoclusters and Nanoparticles: Fundamentals and Opportunities. Chem. Rev. 2016, 116, 10346-10413.

(82) Du, Y.; Sheng, H.; Astruc, D.; Zhu, M. Atomically Precise Noble Metal Nanoclusters as Efficient Catalysts: A Bridge between Structure and Properties. Chem. Rev. 2010, 120, 526-622.

(83) Zhao, P.; Li, N.; Astruc, D. State of The Art in Gold Nanoparticle Synthesis. Coord. Chem. Rev. 2013, 257, 638-665.

(84) Hakkinen, H. The Gold-Sulfur Interface at the Nanoscale. Nat. Chem. 2012, 4, 443-455.

(85) Higaki, T.; Li, Y. W.; Zhao, S.; Li, Q.; Li, S. T.; Du, X. S.; Yang, S.; Chai, J. S.; Jin, R. C. Atomically Tailored Gold Nanoclusters for Catalytic Application. Angew. Chem. Int. Ed. 2019, $58,8291-8302$.

(86) Jin, L.; Weinberger, D. S.; Melaimi, M.; Moore, C. E.; Rheingold, A. L.; Bertrand, G., Trinuclear Gold Clusters Supported by Cyclic (alkyl)(amino)carbene Ligands: Mimics for Gold Heterogeneous Catalysts. Angew. Chem. Int. Ed. 2014, 53, 9059-9063. 
(87) Robilotto, T. J.; Bacsa, J.; Gray, T. G.; Sadighi, J. P. Synthesis of a Trigold Monocation: An Isolobal Analogue of $\left[\mathrm{H}_{3}\right]+$. Angew. Chem. Int. Ed. 2012, 51, 12077-12080.

(88) Nesmeyanov, A. N.; Perevalova, E. G.; Struchkov, Y. T.; Antipin, M. Y.; Grandberg, K. I.; Dyadhenko, V. P. Tris(triphenylphosphinegold)oxonium Salts. J. Organomet. Chem. 1980, 201, 343-349.

(89) Ube, H.; Zhang, Q.; Shionoya, M. A Carbon-Centered Hexagold(I) Cluster Supported by NHeterocyclic Carbene Ligands. Organometallics 2018, 37, 2007-2009.

(90) Ramamoorthy, V.; Wu, Z.; Yi, Y.; Sharp, P. R. Preparation and Decomposition of Gold(I) Hydrazido Complexes: Gold Cluster Formation. J. Am. Chem. Soc. 1992, 114, 1526-1527.

(91) Schiegerl, L. J.; Melaimi, M.; Tolentino, D. R.; Klein, W.; Bertrand, G.; Fassler, T. F., Silylated Ge9 Clusters as New Ligands for Cyclic (Alkyl)amino and Mesoionic Carbene Copper Complexes. Inorg. Chem. 2019, 58, 3256-3264.

(92) Geitner, F. S.; Fässler, T. F. Introducing Tetrel Zintl Ions to N-Heterocyclic Carbenes Synthesis of Coinage Metal NHC Complexes of $\left[\mathrm{Ge}_{9}\left\{\mathrm{Si}\left(\mathrm{SiMe}_{3}\right)_{3}\right\}_{3}\right]^{-}$. Eur. J. Inorg. Chem. 2016, 2688-2691.

(93) Polgar, A. M.; Zhang, A.; Mack, F.; Weigend, F.; Lebedkin, S.; Stillman, M. J.; Corrigan, J. F., Tuning the Metal/Chalcogen Composition in Copper(I)-Chalcogenide Clusters with Cyclic (Alkyl)(amino)carbene Ligands. Inorg. Chem. 2019, 58, 3338-3348.

(94) Chu, J.; Munz, D.; Jazzar, R.; Melaimi, M.; Bertrand, G., Synthesis of Hemilabile Cyclic (Alkyl)(amino)carbenes (CAACs) and Applications in Organometallic Chemistry. J. Am. Chem. Soc. 2016, 138, 7884-7887.

(95) Hashmi, A. S. K.; Lothschütz, C.; Döpp, R.; Ackermann, M.; De Buck Becker, J.; Rudolph, M.; Scholz, C.; Rominger, F. On Homogeneous Gold/Palladium Catalytic Systems. Adv. Synth. Catal. 2012, 354, 133-147. 
(96) Livendahl, M.; Goehry, C.; Maseras, F.; Echavarren, A. M. Rationale for the Sluggish Oxidative Addition of Aryl Halides to Au(I). Chem. Commun. 2014, 50, 1533-1536.

(97) Joost, M.; Amgoune, A.; Bourissou, D. Reactivity of Gold Complexes towards Elementary Organometallic Reactions. Angew. Chem. Int. Ed. 2015, 54, 15022-15045.

(98) Joost, M.; Estévez, L.; Miqueu, K.; Amgoune, A.; Bourissou D. Oxidative Addition of Carbon-Carbon Bonds to Gold. Angew. Chem. Int. Ed. 2015, 54, 5236-5240.

(99) Wu, C.-Y.; Horibe, T.; Jacobsen, C. B.; Toste, F. D. Stable Gold(III) Catalysts by Oxidative Addition of a Carbon-Carbon Bond. Nature 2015, 517, 449-454.

(100) Teles, J. H. Oxidative Addition to Gold(I): A New Avenue in Homogeneous Catalysis with Au. Angew. Chem. Int. Ed. 2015, 54, 5556-5558.

(101) Peris, E. Smart N-Heterocyclic Carbene Ligands in Catalysis. Chem. Rev. 2018, 118, 998810031.

(102) Falivene, L.; Credendino, R.; Poater, A.; Petta, A.; Serra, L.;Oliva, R.; Scarano, V.; Cavallo, L. SambVca 2. A Web Tool for Analyzing Catalytic Pockets with Topographic Steric Maps. Organometallics 2016, 35, 2286-2293.

(103) Durand, D. J.; Fey, N. Computational Ligand Descriptors for Catalysts Design. Chem. Rev. 2019, $119,6561-6594$

(104) Huynh, H. V. Electronic Properties of N-Heterocyclic Carbenes and Their Experimental Determination. Chem. Rev. 2018, 118, 9457-9492.

( 105 ) Manzano, R.; Rominger, F.; Hashmi, A. S. K. Saturated Abnormal NHC-Gold(I) Complexes: Synthesis and Catalytic Activity. Organometallics 2013, 32, 2199-22203.

(106) Lorkowski, J.; Krahfuss, M.; Kubicki, M.; Radius, U.; Pietraszuk, C., Intramolecular RingExpansion Reaction (RER) and Intermolecular Coordination of In Situ Generated Cyclic (Amino)(aryl)carbenes (cAArCs). Chem. Eur. J. 2019, 25, 11365-11374 
(107) Zhou, Y.; Liu, Q.; Lv, W.; Pang, Q.; Ben, R.; Qian, Y.; Zhao, J. Indazolin-s-ylidene-NHeterocyclic Carbene Complexes of Rhodium, Palladium, and Gold: Synthesis, Characterization, and Catalytic Hydration of Alkynes. Organometallics 2013, 32, 3753-3759.

(108) Sivaram, H.; Jothibasu, R.; Huynh, H. V., Gold Complexes of an Alicyclic Indazole-Derived N-Heterocyclic Carbene: Syntheses, Characterizations, and Ligand Disproportionation. Organometallics 2012, 31, 1195-1203.

(109) Guo, S.; Lim, M. H.; Huynh, H. V., Copper(I) Heteroleptic Bis(NHC) and Mixed NHC/Phosphine Complexes: Syntheses and Catalytic Activities in the One-Pot Sequential CuAAC Reaction of Aromatic Amines. Organometallics 2013, 32, 7225-7233.

(110) Gaillard, S.; Cazin, C. S. J.; Nolan, S. P. N-Heterocyclic Carbene Gold(I) and Copper(I) Complexes in C-H Bond Activation. Acc. Chem. Res. 2012, 45, 778-787.

(111) Deck, E.; Reiter, K.; Klopper, W.; Breher, F., A Dinuclear Gold(I) Bis(Carbene) Complex Based on a Ditopic Cyclic (Aryl)(Amino)Carbene Framework. Z. Anorg. Allg. Chem. 2016, 642, 1320-1328.

(112) Waters, J. B.; Goicoechea, J. M. Coordination chemistry of ditopic carbanionic Nheterocyclic carbenes. Coord. Chem. Rev. 2015, 293, 80-94.

(113) Neilson, B. M.; Tennyson, A. G.; Bielawski, C. W. Advances in Bis(N-Heterocyclic Carbene) Chemistry: New Classes of Structurally Dynamic Materials. J. Phys. Org. Chem. 2012, $25,531-543$.

(114) For a thematic issue on coinage metals in catalysis, see: Lipshutz, B. H.; Yamamoto, Y. Introduction: Coinage Metals in Organic Synthesis. Chem. Rev. 2008, 108, 2793-2795.

(115) Hashmi, A. S. K. Gold-Catalyzed Organic Reactions. Chem. Rev. 2007, 107, 3180-3211.

(116) Zi, W.; Toste, F. D. Recent Advances in Enantioselective Gold Catalysis. Chem. Soc. Rev. 2016, 45, 4567-4589. 
(117) Pflaesterer, D.; Hashmi, A. S. K. Gold Catalysis in Total Synthesis - Recent Achievements. Chem. Soc. Rev. 2016, 45, 1331-1367.

(118) Monnier, F.; Taillefer, M. Catalytic C-C, C-N, and C-O Ullmann-Type Coupling Reactions. Angew. Chem. Int. Ed. 2009, 48, 6954-6971.

(119) Lin, J. C. Y.; Huang, R. T. W.; Lee, C. S.; Bhattacharyya, A.; Huang, W. S.; Lin, I. J. B. Coinage Metal-N-Heterocyclic Carbene Complexes. Chem. Rev. 2009, 109, 3561-3598.

(120) Wei, C.; Li, C. A Highly Efficient Three-Component Coupling of Aldehyde, Alkyne, and Amines via $\mathrm{C}-\mathrm{H}$ Activation Catalyzed by Gold in Water. J. Am. Chem. Soc. 2003, 125, 95849585.

(121) Zeng, X.; Frey, G. D.; Kousar, S.; Bertrand, G., A Cationic Gold(I) Complex as a General Catalyst for The Intermolecular Hydroamination of Alkynes: Application to the One-Pot Synthesis of Allenes from Two Alkynes and a Sacrificial Amine. Chem. Eur. J. 2009, 15, 3056-3060.

(122) Huang, L. B.; Arndt, M.; Goosen, K.; Heydt, H.; Goosen, L. J. Late Transition MetalCatalyzed Hydroamination and Hydroamidation. Chem. Rev. 2015, 115, 2596-2697.

(123) Muller, T. E.; Hultzsch, K. C.; Yus, M.; Foubelo, F.; Tada, M. Hydroamination: Direct Addition of Amines to Alkenes and Alkynes. Chem. Rev. 2008, 108, 3795-3892.

(124) Widenhoefer, R. A.; Han, X. Gold-Catalyzed Hydroamination of C-C Multiple Bonds. Eur. J. Org. Chem. 2006, 4555-4563.

(125) Shi, S. L.; Buchwald, S. L. Copper-Catalysed Selective Hydroamination Reactions of Alkynes. Nat. Chem. 2015, 7, 38-44.

(126) Lavallo, V.; Frey, G. D.; Donnadieu, B.; Soleilhavoup, M.; Bertrand, G. Homogeneous Catalytic Hydroamination of Alkynes and Allenes with Ammonia. Angew. Chem. Int. Ed. 2008, $47,5224-5228$.

(127) Shen, Q.; Hartwig, J. F. Palladium Catalyzed Coupling of Ammonia and Lithium Amide with Aryl Halides. J. Am. Chem. Soc. 2006, 128, 10028-10029. 
(128) Surry, D. S.; Buchwald, S. L. Selective Palladium-Catalyzed Arylation of Ammonia: Synthesis of Anilines as Well as Symmetrical and Unsymmetrical Di- and Triarylamines. J. Am. Chem. Soc. 2007, 129, 10354-10355.

(129) Schranck, J.; Tlili, A. "Transition-Metal-Catalyzed Monoarylation of Ammonia" ACS Catal. 2018, $8,405-418$.

(130) Klinkenberg, J. L.; Hartwig, J. F. Catalytic Organometallic Reactions of Ammonia. Angew. Chem. Int. Ed. 2011, 50, 86-95.

(131) van der Vlugt, J. I. Advances in Selective Activation and Application of Ammonia in Homogeneous Catalysis" Chem. Soc. Rev. 2010, 39, 2302-2322.

(132) Kovacs, G.; Lledos, A.; Ujaque, G. Hydroamination of Alkynes with Ammonia: Unforeseen Role of the Gold(I) Catalyst. Angew. Chem. Int. Ed. 2011, 50, 11147-11151.

(133) Kinjo, R.; Donnadieu, B.; Bertrand, G., Gold-Catalyzed Hydroamination of Alkynes and Allenes with Parent Hydrazine. Angew. Chem. Int. Ed. 2011, 50, 5560-5563.

(134) Lundgren, R. J.; Stradiotto, M. Palladium-Catalyzed Cross-Coupling of Aryl Chlorides and Tosylates with Hydrazine. Angew. Chem. Int. Ed. 2010, 49, 8686-8690.

(135) Yang, X.-F.; Wang, A.-Q.; Wang, Y.-L.; Zhang, T.; Li, J. Unusual Selectivity of Gold Catalysts for Hydrogenation of 1,3-Butadiene toward cis-2-Butene: A Joint Experimental and Theoretical Investigation. J. Phys. Chem. C 2010, 114, 3131-3139.

(136) Shan, H.; Yang, Y.; James, A. J.; Sharp, P. R. Dinitrogen Bridged Gold Clusters. Science 1997, 275, 1460-1462.

( 137 ) Manzano, R.; Wurm, T.; Rominger, F.; Hashmi, A. S. K. Room-Temperature Hydrohydrazination of Terminal Alkynes Catalyzed by Saturated Abnormal N-Heterocyclic Carbene-Gold(I) Complexes. Chem. Eur. J. 2014, 20, 6844-6848. 
(138) Martin, D.; Lassauque, N.; Donnadieu, B.; Bertrand, G. Cyclic Diaminocarbene with a Pyramidalized Nitrogen Atom: A Stable N-Heterocyclic Carbene with Enhanced Electrophilicity, Angew. Chem. Int. Ed. 2012, 51, 6172-6175.

(139) López-Gómez, M. J.; Martin, D.; Bertrand, G. Anti-Bredt N-Heterocyclic Carbene: an Efficient Ligand for the Gold(I)-Catalyzed Hydroamination of Terminal Alkynes with Parent Hydrazine. Chem. Commun. 2013, 49, 4483-4485.

(140) Couce-Rios, A.; Kovacs, G.; Ujaque, G.; Lledos, A. Hydroamination of C-C Multiple Bonds with Hydrazine Catalyzed by N-Heterocyclic Carbene-Gold(I) Complexes: Substrate and Ligand Effects. ACS Catal. 2015, 5, 815-829.

(141) Johnson, J. S.; Bergman, R. G. Imidotitanium Complexes as Hydroamination Catalysts: Substantially Enhanced Reactivity from an Unexpected Cyclopentadienide/Amide Ligand Exchange. J. Am. Chem. Soc. 2001, 123, 2923-2924.

(142) Zeng, X.; Frey, G. D.; Kinjo, R.; Donnadieu, B.; Bertrand, G. Synthesis of a Simplified Version of Stable Bulky and Rigid Cyclic (Alkyl)(amino)carbenes, and Catalytic Activity of the Ensuing Gold(I) Complex in the Three-Component Preparation of 1,2-Dihydroquinoline Derivatives. J. Am. Chem. Soc. 2009, 131, 8690-8696.

( 143 ) Zeng, X.; Soleilhavoup, M.; Bertrand, G., Gold-Catalyzed Intermolecular Markovnikov Hydroamination of Allenes with Secondary Amines. Org. Lett. 2009, 11, 3166-3169.

(144) Yi, C. S.; Yun, S. Y.; Guzei, I. A. Catalytic Synthesis of Tricyclic Quinoline Derivatives from the Regioselective Hydroamination and $\mathrm{C}-\mathrm{H}$ Bond Activation Reaction of Benzocyclic Amines and Alkynes. J. Am. Chem. Soc. 2005, 127, 5782-5783.

( 145 ) Liu, X.-Y.; Ding, P.; Huang, J.-S.; Che, C.-M. Synthesis of Substituted 1,2Dihydroquinolines and Quinolines from Aromatic Amines and Alkynes by Gold(I)-Catalyzed Tandem Hydroamination-Hydroarylation under Microwave-Assisted Conditions. Org. Lett. 2007, $9,2645-2648$. 
(146) Zeng, X.; Kinjo, R.; Donnadieu, B.; Bertrand, G., Serendipitous Discovery of the Catalytic Hydroammoniumation and Methylamination of Alkynes. Angew. Chem. Int. Ed. 2010, 49, 942945.

(147) Shimada, T.; Nakamura, I.; Yamamoto, Y. Intramolecular C-N Bond Addition of Amides to Alkynes Using Platinum Catalyst. J. Am. Chem. Soc. 2004, 126, 10546-10547.

( 148 ) Cacchi, S.; Fabrizi, G.; Pace, P. Palladium-Catalyzed Cyclization of oAlkynyltrifluoroacetanilides with Allyl Esters. A Regioselective Synthesis of 3-Allylindoles. J. Org. Chem. 1998, 63, 1001-1011.

(149) Jin, L.; Romero, E. A.; Melaimi, M.; Bertrand, G., The Janus Face of the X Ligand in the Copper-Catalyzed Azide-Alkyne Cycloaddition. J. Am. Chem. Soc. 2015, 137, 15696-15698.

(150) Khistyaev, K.; Golan, A.; Bravaya, K. B.; Orms, N.; Krylov, A. I.; Ahmed, M. Proton Transfer in Nucleobases is Mediated by Water. J. Phys. Chem. A 2013, 117, 6789-6797.

(151) See also an interesting review article on the role of the counter anion in gold catalysis: Schieß1, J.; Schulmeister, J.; Doppiu, A.; Wörner, E.; Rudolph, M.; Karch, R.; Hashmi, A. S. K., An Industrial Perspective on Counter Anions in Gold Catalysis: Underestimated with Respect to “Ligand Effects". Adv. Synth. Catal. 2018, 360, 2493-2502.

(152) Romero, E. A.; Jazzar, R.; Bertrand, G., (CAAC)CuX-Catalyzed Hydroboration of Terminal Alkynes with Pinacolborane Directed by the X-Ligand. J. Organomet. Chem. 2017, 829, 11-13.

(153) Romero, E. A.; Jazzar, R.; Bertrand, G., Copper-Catalyzed Dehydrogenative Borylation of Terminal Alkynes with Pinacolborane. Chem. Sci. 2017, 8, 165-168.

(154) Chen, H.; Schlecht, S.; Semple, T. C.; Hartwig, J. F. Thermal, Catalytic, Regiospecific Functionalization of Alkanes. Science 2000, 287, 1995-1997.

(155) Cho, J. Y.; Tse, M. K.; Holmes, D.; Maleczka, R. E.; Smith, M. R. Remarkably Selective Iridium Catalysts for the Elaboration of Aromatic C-H Bonds. Science 2002, 295, 305-308. 
(156) Mkhalid, I. A.; Barnard, J. H.; Marder, T. B.; Murphy, J. M.; Hartwig, J. F. C-H Activation for the Construction of C-B Bonds. Chem. Rev. 2010, 110, 890-931.

(157) Lee, C. I.; Zhou, J.; Ozerov, O. V. Catalytic Dehydrogenative Borylation of Terminal Alkynes by a SiNN Pincer Complex of Iridium. J. Am. Chem. Soc. 2013, 135, 3560-3566.

(158) Pell, C. J.; Ozerov, O. V. Catalytic Dehydrogenative Borylation of Terminal Alkynes by POCOP-Supported Palladium Complexes. Inorg. Chem. Front. 2015, 2, 720-724.

( 159 ) Zhou, J.; Lee, C. I.; Ozerov, O. V. Computational Study of the Mechanism of Dehydrogenative Borylation of Terminal Alkynes by SiNN Iridium Complexes. ACS Catal. 2018, $8,536-545$.

(160) Tsuchimoto, T.; Utsugi, H.; Sugiura, T.; Horio, S. Alkynylboranes: A Practical Approach by Zinc-Catalyzed Dehydrogenative Coupling of Terminal Alkynes with 1,8Naphthalenediaminatoborane. Adv. Synth. Catal. 2015, 357, 77-82.

(161) Rossin, A.; Peruzzini, M. Ammonia-Borane and Amine-Borane Dehydrogenation Mediated by Complex Metal Hydrides. Chem. Rev. 2016, 116, 8848-8872.

(162) Marder, T. B. Will We Soon Be Fueling our Automobiles with Ammonia-Borane. Angew.Chem. Int. Ed. 2007, 46, 8116-8118.

(163) Hertz, R. K.; Goetze, R.; Shore, S. G. Removal of Ligands from Bis(triphenylphosphine) copper(I)Boranes: Preparation of $\mathrm{CuB}_{3} \mathrm{H}_{8}$ and $\mathrm{Cu}_{2} \mathrm{~B}_{10} \mathrm{H}_{10}$ and Evidence for the Existence of $\mathrm{P}\left(\mathrm{C}_{6} \mathrm{H}_{5}\right)_{3} \mathrm{CuB}_{3} \mathrm{H}_{8}$ and $\mathrm{P}\left(\mathrm{C}_{6} \mathrm{H}_{5}\right)_{3} \mathrm{CuBH}_{4}$ in Solution. Inorg. Chem. 1979, 18, 2813-2816.

(164) Kalidindi, S. B.; Indirani, M.; Jagirdar, B. R. First Row Transition Metal Ion-Assisted Ammonia-Borane Hydrolysis for Hydrogen Generation. Inorg. Chem. 2008, 47, 7424-7429.

(165) Inoue, Y., Izumida, H.; Hashimoto, H. Catalytic Fixation of Carbon Dioxide to Formic Acid by Transition Metal Complexes Under Mild Conditions. Chem. Lett. 1976, 5, 863-864.

(166) Dong, K., Razzaq, R., Hu, Y.; Ding, K. Homogeneous Reduction of Carbon Dioxide with Hydrogen. Top. Curr. Chem. 2017, 375:23, 1-26. 
(167) Tanaka, R., Yamashita, M.; Nozaki, K. Catalytic Hydrogenation of Carbon Dioxide Using Ir(III)-Pincer Complexes. J. Am. Chem. Soc. 2009, 131, 14168-14169.

(168) Liu, Q., Wu, L., Jackstell, R.; Beller, M. Using Carbon Dioxide as a Building Block in Organic Synthesis. Nat. Comm. 2015, 6, 5933.

(169) Wang, S., Du, G.; Xi, C. Copper-Catalyzed Carboxylation Reactions Using Carbon Dioxide. Org. Biomol. Chem. 2016, 14, 3666-3676.

(170) Zall, C. M., Linehan, J. C.; Appel, A. M. Triphosphine-Ligated Copper Hydrides for $\mathrm{CO}_{2}$ Hydrogenation: Structure, Reactivity, and Thermodynamic Studies. J. Am. Chem. Soc. 2016, 138, 9968-9977.

(171) Stephan, D. W. The Broadening Reach of Frustrated Lewis Pair Chemistry. Science 2016, 354 , aaf7229.

(172) Stephan, D. W.; Erker, G. Frustrated Lewis Pairs: Metal-Free Hydrogen Activation and More. Angew. Chem. Int. Ed. 2010, 49, 46-76.

(173) Welch, G. C., Juan, R. R. S., Masuda, J. D.; Stephan, D. W. Reversible Metal-Free Activation. Science 2006, 314, 1124-1126.

( 174 ) Lam, J.; Szkop, K. M.; Mosaferi, E.; Stephan, D. W. FLP Catalysis: Main Group Hydrogenations of Organic Unsaturated Substrates. Chem. Soc. Rev. 2019, 48, 3592-3612.

(175) Courtemanche, M. A.; Pulis, A. P.; Rochette, E.; Legare, M. A.; Stephan, D. W.; Fontaine, F. G. Intramolecular B/N Frustrated Lewis Pairs and the Hydrogenation of Carbon Dioxide. Chem. Commun. 2015, 51, 9797-9800.

(176) Romero, E. A.; Zhao, T.; Nakano, R.; Hu, X.; Wu, Y.; Jazzar, R.; Bertrand, G., Tandem Copper Hydride-Lewis Pair Catalysed Reduction of Carbon Dioxide into Formate with Dihydrogen. Nat. Catal. 2018, 1, 743-747.

(177) See also: Kayaki, Y.; Watari, R. Harmonious Hydrogenation Catalysts. Nat. Catal. 2018, 1, 739-740. 
(178) Jiang, C., Blacque, O., Fox, T.; Berke, H. Heterolytic Cleavage of $\mathrm{H}_{2}$ by Frustrated B/N Lewis Pairs. Organometallics 2011, 30, 2117-2124.

(179) Oliver-Meseguer, J.; Cabrero-Antonino, J. R.; Dominguez, I.; Leyva-Perez, A.; Corma, A. Small Gold Clusters Formed in Solution Give Reaction Turnover Numbers of $10^{7}$ at Room Temperature. Science 2012, 338, 1452-1455.

(180) Liu, L.; Corma, A. Metal Catalysts for Heterogeneous Catalysis: From Single Atoms to Nanoclusters and Nanoparticles. Chem. Rev. 2018, 118, 4981-5079.

(181) See also: Hashmi, A. S. K. Sub-Nanosized Gold Catalysts. Science 2012, 338, 1434-1434.

(182) Díaz, D. J.; Darko, A. K.; McElwee-White, L. Transition Metal-Catalyzed Oxidative Carbonylation of Amines to Ureas. Eur. J. Org. Chem. 2009, 4453-4465.

(183) For a review, see: Hopkinson, M. N.; Gee, A. D.; Gouverneur, V. Au ${ }^{\mathrm{I}} / \mathrm{Au}^{\mathrm{III}}$ Catalysis: An Alternative Approach for C-C Oxidative Coupling. Chem. Eur. J. 2011, 17, 8248-8262.

( 184 ) Rodriguez, J.; Zeineddine, A.; Carrizo, E. D. S.; Miqueu, K.; Saffon-Merceron, N.; Amgoune, A.; Bourissou, D. Catalytic Au(I)/Au(III) Arylation with the Hemilabile Medalphos Ligand: Unusual Selectivity for Electron-Rich Iodoarenes and Efficient Application to Indoles. Chem. Sci. 2019, 10, 7183-7192.

(185) Wolf, W. J.; Winston, M. S.; Toste, F. D. Exceptionally Fast Carbon-Carbon Bond Reductive Elimination from Gold(III). Nat. Chem. 2014, 6, 159-164.

( 186 ) Andreatta, J. R.; McKeown, B. A.; Gunnoe, T. B. Transition Metal Catalyzed Hydroarylation of Olefins Using Unactivated Substrates: Recent Developments and Challenges. J. Organomet. Chem. 2011, 696, 305-315.

( 187 ) De Mendoza, P.; Echavarren, A. M. Synthesis of Arenes and Heteroarenes by Hydroarylation Reactions Catalyzed by Electrophilic Metal Complexes. Pure Appl. Chem. 2010, $82,801-820$. 
(188) Hu, X.; Martin, D.; Melaimi, M.; Bertrand, G. Gold-Catalyzed Hydroarylation of Alkenes with Dialkylanilines. J. Am. Chem. Soc. 2014, 136, 13594-13597.

(189) Reichart, B.; Guedes de la Cruz, G.; Zangger, K.; Kappe, C. O.; Glasnov, T. Copper/NafionCatalyzed Hydroarylation Process Involving Ketenimine Intermediates: A Novel and Synthetic Approach to 4-Sulfonamidoquinoline-2-ones and Derivatives Thereof. Adv. Synth. Catal. 2016, 358, 50-55.

(190) Hirner, J. J.; Shi, Y.; Blum, S. A. Organogold Reactivity with Palladium, Nickel, and Rhodium: Transmetalation, Cross-Coupling, and Dual Catalysis. Acc. Chem. Res. 2011, 44, 603613.

(191) See also: Zhao, X. M.; Rudolph, M.; Hashmi, A. S. K. Dual Gold Catalysis - An Update. Chem. Commun. 2019, 55, 12127-12135.

(192) Hirner, J. J.; Roth, K. E.; Shi, Y.; Blum, S. A., Mechanistic Studies of Azaphilic versus Carbophilic Activation by Gold(I) in the Gold/Palladium Dual-Catalyzed Rearrangement of Alkenyl Vinyl Aziridines. Organometallics 2012, 31, 6843-6850.

(193) Zhukhovitskiy, A. V.; Kobylianskii, I. J.; Wu, C.-Y.; Toste, F. D., Migratory Insertion of Carbenes into Au(III)-C Bonds. J. Am. Chem. Soc. 2018, 140, 466-474.

(194) Hartwig, J. F. Organotransition Metal Chemistry: From Bonding to Catalysis; University Science Books, 2010.

( 195 ) Rekhroukh, F.; Brousses, R.; Amgoune, A.; Bourissou, D. Cationic Gold(III) Alkyl Complexes: Generation, Trapping, and Insertion of Norbornene. Angew. Chem. Int. Ed. 2015, 54, 1266-1269.

(196) Rekhroukh, F.; Blons, C.; Estévez, L.; Mallet-Ladeira, S.; Miqueu, K.; Amgoune, A.; Bourissou, D. Gold(III)-Arene Complexes by Insertion of Olefins into Gold-Aryl Bonds. Chem. Sci. 2017, 8, 4539-4545. 
(197) Levin, M.; Chen, T. Q.; Neubig, M. E.; Hong, C. M.; Theulier, C. A.; Kobylianskii, I. J.; Janabi, M.; O’Neil, J. P.; Toste, F. D. A Catalytic Fluoride-Rebound Mechanism for C( $\left.\mathrm{Sp}^{3}\right)-\mathrm{CF}_{3}$ Bond Formation. Science 2017, 356, 1272-1276.

(198) Rekhroukh, F.; Estevez, L.; Mallet-Ladeira, S.; Miqueu, K.; Amgoune, A.; Bourissou, D. $\beta$ Hydride Elimination at Low-Coordinate Gold(III) Centers. J. Am. Chem. Soc. 2016, 138, 1192011929.

(199) Enders, D.; Gielen, H.; Raabe, G.; Runsink. J.; Teles, J. H. Synthesis and Stereochemistry of the First Chiral (Imidazolinylidene)- and (Triazolinylidene)palladium(ii) Complexes. Chem. Ber. 1996, 129, 1483-1488.

(200) Herrmann, W. A.; Goossen, L. J.; Köcher, C.; Artus, G. R. J. Chiral Heterocylic Carbenes in Asymmetric Homogeneous Catalysis. Angew. Chem. Int. Ed. 1996, 35, 2805-2807.

(201) Enders, D.; Breuer, K.; Raabe, G.; Runsink, J.; Teles, J. H.; Melder, J. P.; Ebel, K.; Brode, S. Preparation, Structure, and Reactivity of 1,3,4-Triphenyl-4,5-dihydro-1H-1,2,4-triazol-5ylidene, a New Stable Carbene. Angew. Chem. Int. Ed. 1995, 34, 1021-1023.

(202) Janssen-Mueller, D.; Schlepphortst, C.; Glorius, F. Privileged Chiral N-Heterocyclic Carbene Ligands for Asymmetric Transition-Metal Catalysis . Chem. Soc. Rev. 2017, 46, 48454854.

(203) Pichon, D.; Soleilhavoup, M.; Morvan, J.; Junor, G. P.; Vives, T.; Crévisy, C.; Lavallo, V.; Campagne, J. M.; Mauduit, M.; Jazzar, R.; Bertrand. G. The Debut of Chiral Cyclic (Alkyl)(amino)carbenes (CAACs) in Enantioselective Catalysis. Chem. Sci. 2019, 10, 7807-7811. (204) Neeve, E. C.; Geier, S. J.; Mkhalid, I. A.; Westcott, S. A.; Marder, T. D. Diboron(4) Compounds: From Structural Curiosity to Synthetic Workhorse. Chem. Rev. 2016, 116, 9091-9161 (205) Zheng, K.; Liu, X.; Feng, X, Recent Advances in Metal-Catalyzed Asymmetric 1,4Conjugate Addition (ACA) of Nonorganometallic Nucleophiles. Chem. Rev. 2018, 118, 75867656. 
(206) O'Brien, J. M.; Lee, K. S.; Hoveyda, A. H. Enantioselective Synthesis of Boron-Substituted Quaternary Carbons by $\mathrm{NHC}-\mathrm{Cu}-\mathrm{Catalyzed} \mathrm{Boronate} \mathrm{Conjugate} \mathrm{Additions} \mathrm{to} \mathrm{Unsaturated}$ Carboxylic Esters, Ketones, or Thioesters. J. Am. Chem. Soc. 2010, 132, 10630-10633.

(207) Tolentino, D.; Neale, S.; Isaac, C.; Macgregor, S.; Whittlesey, M.; Jazzar, R.; Bertrand, G. Reductive Elimination at Carbon under Steric Control. J. Am. Chem. Soc. 2019, 141, 9823-9826. (208) Johnson, N. A.; Southerland, M. R.; Youngs, W. J. Recent Developments in the Medicinal Applications of Silver-NHC Complexes and Imidazolium Salts. Molecules 2017, 22, 1263.

(209) Liu, W. K.; Gust, R. Update on Metal N-Heterocyclic Carbene Complexes as Potential AntiTumor Metallodrugs. Coord. Chem. Rev. 2016, 329, 191-293.

(210) Hussaini, S. Y.; Haque, R. A.; Razali, M. R. Recent Progress in Silver(I)-, Gold(I)/(III)- and Palladium(II)-N-Heterocyclic Carbene Complexes: A Review Towards Biological Perspectives. J. Organomet. Chem. 2019, 882, 96-111.

(211) Porchia, M.; Pellei, M.; Marinelli, M.; Tisato, F.; Del Bello, F.; Santini, C. New Insights in Au-NHCs Complexes as Anticancer Agents. Eur. J. Med. Chem. 2018, 146, 709-746.

(212) Sivaram, H.; Tan, J.; Huynh, H. V. Syntheses, Characterizations, and a Preliminary Comparative Cytotoxicity Study of Gold(I) and Gold(III) Complexes Bearing Benzimidazole- and Pyrazole-Derived N-Heterocyclic Carbenes. Organometallics 2012, 31, 5875-5883.

(213) Sivaram, H.; Tan, J.; Huynh, H. V., Cationic Gold(I) Heteroleptic Complexes Bearing a Pyrazole-Derived N-Heterocyclic Carbene: Syntheses, Characterizations, and Cytotoxic Activities. Dalton Trans. 2013, 42, 12421-12428.

(214) Bertrand, B.; Romanov, A. S.; Brooks, M.; Davis, J.; Schmidt, C.; Ott, I.; O'Connell, M.; Bochmann, M. Synthesis, Structure and Cytotoxicity of Cyclic (Alkyl)(amino)carbene and Acyclic Carbene Complexes of Group 11 Metals. Dalton Trans. 2017, 46, 15875-15887.

(215) Bernanose, A.; Comte, M.; Vouaux, P. A New Method of Light Emission by Certain Organic Compounds. J. Chim. Phys. 1953, 50, 64-68. 
(216) Bernanose, A.; Vouaux, P. Organic Electroluminescence Type of Emission. J. Chim. Phys. 1953, 50, 261-263.

(217) Tang, C. W.; Vanslyke, S. A. Organic Electroluminescent Diodes. Applied Physics Letters., 1987, 51, 913-915.

(218) An, H. S.; Park, Y.G.; Kim, K.; Nam, S., Y.; Song, M. H.; Park, J.-U. High-Resolution 3D Printing of Freeform, Transparent Displays in Ambient Air. Adv. Sci. 2019, 6, 1901603.

(219) Li, T.-Y.; Wu, J.; Wu, Z.-G.; Zheng, Y.-X.; Zuo, J.-L.; Pan, Y. Rational Design of Phosphorescent Iridium(III) Complexes for Emission Color Tunability and their Applications in OLEDs. Coord. Chem. Rev., 2018, 374, 55-92.

(220) Bizzarri, C.; Spuling, E.; Knoll, D. M.; Volz, D. Bräse, S. Sustainable Metal Complexes for Organic Light-Emitting Diodes (OLEDs). Coord. Chem. Rev., 2018, 373, 49-82.

(221) Leitl, M. J.; Zink, D. M.; Schinabeck, A.; Baumann, T.; Volz, D.; Yersin, H. Copper(I) Complexes for Thermally Activated Delayed Fluorescence: From Photophysical to Device Properties. Top. Curr. Chem. 2016, 374:25, 1-34.

(222) Visbal, R.; Gimeno, M. C. N-Heterocyclic Carbene Metal Complexes: Photoluminescence and Applications. Chem. Soc. Rev. 2014, 43, 3551-3574.

(223) Shi, S.; Jung, M. C.; Coburn, C.; Tadle, A.; Sylvinson M. R., D.; Djurovich, P. I.; Forrest, S. R.; Thompson, M. E. Highly Efficient Photo- and Electroluminescence from Two-Coordinate $\mathrm{Cu}(\mathrm{I})$ Complexes Featuring Nonconventional N-Heterocyclic Carbenes. J. Am. Chem. Soc. 2019, $141,3576-3588$.

(224) Romanov, A. S.; Di, D.; Yang, L.; Fernandez-Cestau, J.; Becker, C. R.; James, C. E.; Zhu, B.; Linnolahti, M.; Credgington, D.; Bochmann, M. Highly Photoluminescent Copper Carbene Complexes Based on Prompt rather than Delayed Fluorescence. Chem. Comm. 2016, 52, 63796382. 
(225) Hamze, R.; Jazzar, R.; Soleilhavoup, M.; Djurovich, P. I.; Bertrand, G.; Thompson, M. E., Phosphorescent 2-, 3- and 4-Coordinate Cyclic (Alkyl)(amino)carbene (CAAC) Cu(I) Complexes. Chem. Comm. 2017, 53, 9008-9011.

(226) Romanov, A. S.; Becker, C. R.; James, C. E.; Di, D.; Credgington, D.; Linnolahti, M.; Bochmann, M., Copper and Gold Cyclic (Alkyl)(amino)carbene Complexes with SubMicrosecond Photoemissions: Structure and Substituent Effects on Redox and Luminescent Properties. Chem. Eur. J. 2017, 23, 4625-4637.

(227) Gernert, M.; Muller, U.; Haehnel, M.; Pflaum, J.; Steffen, A., A Cyclic Alkyl(amino)carbene as Two-Atom pi-Chromophore Leading to the First Phosphorescent Linear $\mathrm{Cu}(\mathrm{I})$ Complexes. Chem. Eur. J. 2017, 23, 2206-2216.

(228) Romanov, A. S.; Chotard, F.; Rashid, J.; Bochmann, M. Synthesis of Copper(I) Cyclic (Alkyl)(Amino)Carbene Complexes with Potentially Bidentate $\mathrm{N}^{\wedge} \mathrm{N}, \mathrm{N}^{\wedge} \mathrm{S}$ and $\mathrm{S}^{\wedge} \mathrm{S}$ Ligands for Efficient White Photoluminescence. Dalton Trans. 2019, 48, 15445-15454.

(229) Chotard, F.; Romanov, A. S. ; Hughes, D. L.; Linnolahti, M.; Bochmann, M. Zwitterionic Mixed-Carbene Coinage Metal Complexes: Synthesis, Structures and Photophysical Studies. Eur. J. Inorg. Chem. 2019, 4234-4240.

(230) Di, D.; Romanov, A. S.; Yang, L.; Richter, J. M.; Rivett, J. P. H.; Jones, S.; Thomas, T. H.; Abdi Jalebi, M.; Friend, R. H.; Linnolahti, M.; Bochmann, M.; Credgington, D. High-Performance Light-Emitting Diodes Based on Carbene-Metal-Amides. Science, 2017, 356, 159-163.

(231) Hamze, R.; Peltier, J. L.; Sylvinson, D.; Jung, M.; Cardenas, J.; Haiges, R.; Soleilhavoup, M.; Jazzar, R.; Djurovich, P. I.; Bertrand, G.; Thompson, M. E., Eliminating Nonradiative Decay in $\mathrm{Cu}(\mathrm{I})$ Emitters: >99\% Quantum Efficiency and Microsecond Lifetime. Science 2019, 363, 601606.

(232) Föller, J.; Marian, C. M., Rotationally Assisted Spin-State Inversion in Carbene-MetalAmides Is an Artifact. J. Phys. Chem. Lett. 2017, 8, 5643-5647. 
(233) Taffet, E. J.; Olivier, Y.; Lam, F.; Beljonne, D.; Scholes, G. D., Carbene-Metal-Amide Bond

Deformation, Rather Than Ligand Rotation, Drives Delayed Fluorescence. J. Phys. Chem. Lett. 2018, 9, 1620-1626.

(234) Thompson, S.; Eng, J.; Penfold, T. J. The Intersystem Crossing of a Cyclic (Alkyl)(amino) Carbene Gold(I) Complex. J. Chem. Phys. 2018, 149, 014304.

(235) Hall, C. R.; Romanov, A. S.; Bochmann, M.; Meech, S. R., Ultrafast Structure and Dynamics in the Thermally Activated Delayed Fluorescence of a Carbene-Metal-Amide. J. Phys. Chem. Lett. 2018, 9, 5873-5876.

(236) Conaghan, P. J.; Menke, S. M.; Romanov, A. S.; Pearson, A. J.; Evans, E. W.; Bochmann, M.; Greenham, N. C.; Credgington, D. Efficient Vacuum-Processed Light-Emitting Diodes Based on Carbene-Metal-Amides. Adv. Mater. 2018, 30, 1802285.

(237) Yang, L.; Kim, V.; Lian, Y.; Zhao, B.; Di, D. High-Efficiency Dual-Dopant Polymer LightEmitting Diodes with Ultrafast Inter-fluorophore Energy Transfer. Joule 2019, 3, 2381-2389.

(238) Feng, J.; Yang, L.; Romanov, A. S.; Ratanapreechachai, J.; Jones, S. T. E.; Reponen, A.-P. M.; Linnolahti, M.; Hele, T. J. H.; Köhler, A.; Bässler, H.; Bochmann, M.; Credgington, D. Environmental Control of Triplet Emission in Donor-Bridge-Acceptor Organometallics. Adv. Funct. Mater. 2020 https://doi.org/10.1002/adfm.201908715

(239) Romanov, A. S.; Jones, S. T. E. ; Yang, L. ; Conaghan, P. J.; Di, D.; Linnolahti, M.; Credgington, D.; Bochmann, M. Mononuclear Silver Complexes for Efficient Solution and Vacuum-processed OLEDs. Adv. Optical Mater. 2018, 6, 1801347.

(240) Hamze, R.; Shi, S.; Kapper, S. C.; Muthiah Ravinson, D. S.; Estergreen, L.; Jung, M.-C.; Tadle, A. C.; Haiges, R.; Djurovich, P. I.; Peltier, J. L.; Jazzar, R.; Bertrand, G.; Bradforth, S. E.; Thompson, M. E., "Quick-Silver" from a Systematic Study of Highly Luminescent, TwoCoordinate, d10 Coinage Metal Complexes. J. Am. Chem. Soc. 2019, 141, 8616-8626.

(241) Romanov, A. S.; Jones, S.T.E.; Gu, Q.; Conaghan, P. J.; Drummond, B. H.; Feng, J.; Chotard, F.; Buizza, L.; Foley, M.; Linnolahti, M.; Credgington, D.; Bochmann, M. Carbene Metal 
Amide Photoemitters: Tailoring Conformationally Flexible Amides for Full Color Range Emissions Including White-Emitting OLED. Chem. Sci. 2020, 11, 435-446.

(242) Romanov, A. S.; Yang, L.; Jones, S. T. E.; Di, D.; Morley, O. J.; Drummond, B.; Reponen, A. P. M.; Linnolahti, M.; Credgington, D.; Bochmann, M. Dendritic Carbene Metal Carbazole Complexes as Photo-Emitters for Fully Solution-Processed OLEDs. Chem. Mater. 2019, 31, 36133623.

(243) Hast, J.; Tuomikoski, M. R.; Suhonen, K.-L. Väisänen, M. Välimäki, T. Maaninen, P. Apilo, A. Alastalo, A. Maanineny, Roll-to-Roll Manufacturing of Printed OLEDs. SID Int. Symp. Dig. Tech. Pap. 2013, 44, 192-195.

(244) Deng. A.; Mukthar. N. F. M.; Schley, N. D.; Ung, G. Yellow Circularly Polarized Luminescence from C1-Symmetrical Copper(I) Complexes. Angew. Chem. Int. Ed. 2020, 132, 1244-1247.

( 245 ) Dhbaibi, K.; Favereau, L.; Crassous, J. Enantioenriched Helicenes and Helicenoids Containing Main-Group Elements (B, Si, N, P). Chem. Rev. 2019, 119, 8846 - 8953.

(246) Ou-Yang J.-K.; Crassous J. Chiral Multifunctional Molecules Based on Organometallic Helicenes: Recent Advances. Coord. Chem. Rev. 2018, 376, 533-547.

(247) Cetinkaya, B.; Dixneuf, P.; Lappert, M. F. General Synthesis Of Transition-Metal Carbene Complexes $-\mathrm{Cr}(0), \operatorname{Fe}(0), \operatorname{Ir}(1), \operatorname{Ni}(2), \operatorname{Pd}(2), \operatorname{Pt}(2)$, and $\mathrm{Au}(1)$ Mono-Carbene and Oligo-Carbene Species from Electron-Rich Olefins. J. Chem. Soc. Chem. Commun. 1973, 206-206.

(248) Arduengo, A. J.; Dias, H. V. R.; Calabrese, J. C.; Davidson, F. Homoleptic Carbene-Silver(I) and Carbene-Copper(I) Complexes. Organometallics 1993, 12, 3405-3409. 


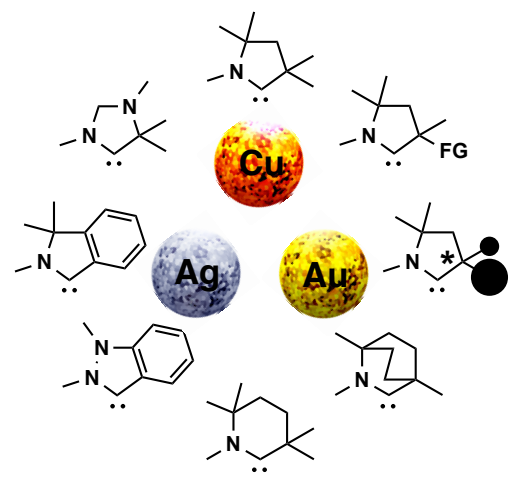

